MILANA LIMA DOS SANTOS

\title{
AVALIAÇÃO DO DESEMPENHO DE LINHAS DE TRANSMISSÃO DE ENERGIA ELÉTRICA DE MEIA ONDA
}

Dissertação apresentada à Escola Politécnica da Universidade de São Paulo para obtenção do título de Mestre em Engenharia Elétrica

São Paulo

2010 
MILANA LIMA DOS SANTOS

\section{AVALIAÇÃO DO DESEMPENHO DE LINHAS DE TRANSMISSÃO DE ENERGIA ELÉTRICA DE MEIA ONDA}

Dissertação apresentada à Escola Politécnica da Universidade de São Paulo para obtenção do título de Mestre em Engenharia Elétrica

Área de concentração: Sistemas de Potência Orientador: Prof. Dr. José Antonio Jardini

São Paulo

2010 
Este exemplar foi revisado e alterado em relação à versão original, sob responsabilidade única do autor e com a anuência de seu orientador.

São Paulo, 10 de setembro de 2010.

Assinatura do autor

Assinatura do orientador

FICHA CATALOGRÁFICA

Santos, Milana Lima dos

Avaliação do desempenho de linhas de transmissão de energia elétrica de meia onda / M.L. dos Santos. -- ed.rev. -- São Paulo, 2010.

$77 \mathrm{p}$.

Dissertação (Mestrado) - Escola Politécnica da Universidade de São Paulo. Departamento de Engenharia de Energia e Automação Elétricas.

1. Transmissão de energia elétrica por corrente alternada 2. Linhas aéreas de transmissão de energia elétrica 3. Sistemas elétricos I. Universidade de São Paulo. Escola Politécnica.

Departamento de Engenharia de Energia e Automação Elétricas II. t. 
Dedico este trabalho a meus pais, que sempre me incentivam e me apóiam, de todas as formas, na busca por aprimoramento. 


\section{AGRADECIMENTOS}

Ao meu orientador, Prof. Dr. José Antonio Jardini, pela paciência, visão prática, incentivo e confiança depositada.

Ao pesquisador Mário Masuda pela extraordinária colaboração, sem a qual este trabalho não seria realizado.

Aos demais amigos do Grupo de Automação da Geração, Transmissão e Distribuição de Energia - GAGTD, pela disposição em ajudar e por tão agradável convivência.

Ao Conselho Nacional de Desenvolvimento Científico e Tecnológico - CNPq e à Comissão de Bolsas do PPGEE, pela concessão de bolsa de mestrado.

À Eletrobras Eletronorte, por autorizar licença não-remunerada, para que eu pudesse me dedicar adequadamente a este trabalho. Aos amigos e colegas desta Empresa, pelo incentivo.

Aos professores e colegas da pós-graduação, pelo embasamento teórico e intercâmbio de experiências. Aos funcionários da Escola Politécnica da USP, pelo apoio prestado.

Aos que me encorajaram para o desafio de iniciar a carreira acadêmica, após onze anos de exercício profissional: meus pais Ana Amália e Amaro Cícero, meu irmão Helano, o amigo Waslon Lopes, o amigo Clóvis Paulino e os professores da graduação Prof. Dr. Benemar Alencar de Souza, Prof. Dr. Washington Luiz Araújo Neves e Prof. Dr. Cursino Brandão Jacobina.

Aos amigos, pela compreensão e apoio.

Aos familiares, pelos sinceros votos de sucesso. 


\section{RESUMO}

A transmissão de grandes blocos de energia elétrica por longas distâncias é uma tecnologia cujo domínio é de bastante interesse para o Brasil, devido às suas características de grande dimensão territorial, com uma distância considerável entre geração e centros de carga, e com um grande potencial energético ainda não explorado. A solução mais utilizada na transmissão em corrente alternada convencional, que é a compensação, ao longo da linha, da reatância série e paralela, se torna dispendiosa quando aplicada em distâncias muito longas. Sabe-se que a transmissão em corrente continua é uma solução viável para este tipo de transmissão. Outra opção, que é objeto deste trabalho, é a transmissão em linhas de "pouco mais de meio comprimento de onda", cujo principal atrativo é o fato de as distâncias entre as gerações na Amazônia e os centros de carga no Sudeste brasileiro serem bastante próximas do meio comprimento de onda das tensões e correntes alternadas em $60 \mathrm{~Hz}$. Neste trabalho, serão descritas etapas de definição de condutor economicamente mais adequado e projeto da geometria da torre. Com base nesses dados, serão avaliados algumas propriedades das linhas de meia onda, durante operação normal, curtos-circuitos e energização. Serão também analisadas as perdas resistivas.

Palavras-chave: Transmissão de energia elétrica por corrente alternada, linhas aéreas de transmissão de energia elétrica, sistemas elétricos de potência. 


\begin{abstract}
Bulk power transmission over long distances is a technology of much interest to Brazil, due mainly to the large territory owned with considerable distances between generation and the load centers; to which, it can be added the large amount of energetic potential still unexplored.

When conventional AC power transmission is used, usually it is necessary to provide series and shunt compensation, solution that becomes expensive when applied to very long distances. It is known, though, that DC power transmission is still a viable solution to this type of transmission. In this work, differently of the above alternatives, it will be addressed another type of transmission, the so-called half-wavelength transmission lines (HWLL). One interesting requirement of this technology is the fact that these lines should be about $2500 \mathrm{~km}$ long, which is approximately the same distance between the generation area (Amazon region) and the load centers located in the Southeast region of the country.

In this work, it will be suggested some steps to define the most suitable conductor cross section resulting from the compromise between line components acquisition and installation costs as well as power loss costs. Subsequently, a suitable geometry for the tower that could be used will be selected.

Some of the properties of HWLL will be assessed for normal operation, short circuits and line energization. Finally, Joule losses will also be examined.

Keywords: AC power transmission lines, overhead power transmission lines, power systems.
\end{abstract}




\section{SUMÁRIO}

1.1 Introdução 1

1.2 Motivação 2

$1.3 \quad$ Metodologia 2

$\begin{array}{lll}1.4 & \text { Estrutura do trabalho } & 4\end{array}$

2 REVISÃO BIBLIOGRÁFICA 5

$3 \quad$ PRINCIPAIS PROPRIEDADES DA LINHA DE MEIA ONDA 7

$4 \quad$ PROJETO DA LINHA $\quad 8$

4.1 Definição da impedância característica $\quad 8$

4.2 Definição da seção transversal do condutor (cálculo do condutor econômico) 10

$\begin{array}{lll}\text { 4.2.1 } & \text { Custos de construção } & 10\end{array}$

$\begin{array}{lll}\text { 4.2.2 } & \text { Custos de perdas } & 11\end{array}$

$\begin{array}{lll}\text { 4.2.3 Minimização do custo anual } & 12\end{array}$

$\begin{array}{lll}\text { 4.2.4 } & \text { Resultados do condutor econômico } & 13\end{array}$

$\begin{array}{lll}4.3 & \text { Definição da disposição física dos subcondutores } & 14\end{array}$

$\begin{array}{lll}\text { 4.3.1 } & \text { Linhas de Potência Natural Elevada (LPNE) } & 14\end{array}$

$\begin{array}{lll}\text { 4.3.2 } & \text { Geometria A proposta } & 14\end{array}$

$\begin{array}{lll}\text { 4.3.3 } & \text { Premissas para a geometria A } & 15\end{array}$

$\begin{array}{lll}\text { 4.3.3.1 Isoladores e ferragens } & 15\end{array}$

$\begin{array}{lll}\text { 4.3.3.2 } & \text { Flecha e altura mínima do condutor } & 16\end{array}$

$\begin{array}{lll}\text { 4.3.3.3 Cabos para-raios } & 16\end{array}$

$\begin{array}{lll}\text { 4.3.3.4 Geometria do feixe } & 16\end{array}$

$\begin{array}{lll}\text { 4.3.3.5 } & \text { Alternativas a serem simuladas para a geometria A } & 17\end{array}$

$\begin{array}{lll}\text { 4.3.4 } & \text { Resultados para a geometria A } & 17\end{array}$

$\begin{array}{lll}\text { 4.3.5 } & \text { Geometria B considerada } & 19\end{array}$

$\begin{array}{lll}\text { 4.3.6 Premissas para a geometria B } & 19\end{array}$

$\begin{array}{lll}\text { 4.3.6.1 Isoladores e ferragens } & 19\end{array}$ 
$\begin{array}{lll}\text { 4.3.6.2 } & \text { Flecha e altura mínima do condutor } & 19\end{array}$

$\begin{array}{lll}\text { 4.3.6.3 Cabos para-raios } & 20\end{array}$

$\begin{array}{lll}\text { 4.3.6.4 Geometria do feixe } & 20\end{array}$

4.3.6.5 Alternativas a serem simuladas para a geometria B 20

$\begin{array}{lll}\text { 4.3.7 } & \text { Resultados para a geometria B } & 20\end{array}$

$\begin{array}{lll}\text { 4.3.8 } & \text { Seleção da geometria dos projetos I, II e III } 22\end{array}$

$5 \quad$ AVALIAÇÃO TÉCNICA DO SISTEMA 24

$\begin{array}{lll}5.1 & \text { Operação em regime } & 24\end{array}$

$\begin{array}{llr}\text { 5.1.1 } & \text { Premissas } & 24\end{array}$

5.1.2 Operação em regime - Projeto I 25

5.1.3 Operação em regime - Projeto II 26

$\begin{array}{lll}\text { 5.1.4 Operação em regime - Projeto III } & 27\end{array}$

5.1.5 Operação em regime com fator de potência não-unitário 28

$\begin{array}{lll}\text { 5.1.6 } & \text { Avaliação de perdas } & 29\end{array}$

5.1.6.1 Estratégia para redução de perdas 29

$\begin{array}{lll}\text { 5.1.6.1.1 } & \text { Metodologia de estimativa de perdas } & 31\end{array}$

5.1.7 Utilização de reator no meio da linha 32

$\begin{array}{lll}5.2 & \text { Curto-circuito } & 33\end{array}$

$\begin{array}{lll}5.3 & \text { Energizações } & 39\end{array}$

$6 \quad$ CONCLUSÕES 42

ANEXO A - EXPRESSÕES MATEMÁTICAS PARA LINHAS DE MEIA ONDA 44

A.1 Tensões e correntes para $\mathrm{Zr}=\mathrm{Zc} \quad 46$

A.2 Tensões e correntes no início da linha para uma linha de meia onda

A.3 Tensões e correntes no meio da linha para uma linha de meia onda 48

A.4 Tensões e correntes ao longo de uma linha de meia onda para fatores de potência quaisquer $\quad 49$

ANEXO B - DETALHES DO CÁLCULO DE PARÂMETROS DAS LINHAS 52

B.1 Geometria A 52

B.1.1 Dados de entrada para o ATP 52

B.1.2 Resultados seqüência positiva 53 
B.1.3 Resultados seqüência zero

$\begin{array}{lll}\text { B.1.4 Gráficos } & 54\end{array}$

B.2 Geometria B 58

B.2.1 Dados de entrada para o ATP

B.2.2 Resultados sequência positiva

$\begin{array}{lll}\text { B.2.3 Resultados seqüência zero } & 60\end{array}$

$\begin{array}{lll}\text { B.2.4 Gráficos } & 60\end{array}$

REFERÊNCIAS BIBLIOGRÁFICAS $\quad 64$ 


\section{LISTA DE FIGURAS}

FIGURA 1 - GEOMETRIA A PROPOSTA

FIGURA 2 - DETALHE DA GEOMETRIA DO FEIXE DE 6 SUBCONDUTORES

FIGURA 3 - VALORES DO MÓDULO DA IMPEDÂNCIA CARACTERÍSTICA $\left(Z_{c}\right)$, SEQÜÊNCIA POSITIVA, GEOMETRIA A.

FIGURA 4 - VALORES DE POTÊNCIA CARACTERÍSTICA, SEQÜÊNCIA POSITIVA, GEOMETRIA A.

FIGURA 5 - METADE DOS VALORES CALCULADOS PARA OS COMPRIMENTOS DE ONDA, SEQÜÊNCIA POSITIVA, GEOMETRIA A.

FIGURA 6 - GEOMETRIA B PROPOSTA

FIGURA 7 - VALORES DO MÓDULO DA IMPEDÂNCIA CARACTERÍSTICA $\left(Z_{c}\right)$, SEQÜÊNCIA

POSITIVA, GEOMETRIA B.

FIGURA 8 - VALORES DE POTÊNCIA CARACTERÍSTICA, SEQÜÊNCIA POSITIVA, GEOMETRIA B.

FIGURA 9 - METADE DOS VALORES CALCULADOS PARA OS COMPRIMENTOS DE ONDA, SEQÜÊNCIA POSITIVA, GEOMETRIA B.

FIGURA 10 - CIRCUITO UTILIZADO PARA SIMULAÇÃO EM REGIME.

FIGURA 11 - TENSÕES AO LONGO DA LINHAS, PROJETO I.

FIGURA 12 - CORRENTES AO LONGO DA LINHA, PROJETO I.

FIGURA 13 - TENSÕES AO LONGO DA LINHA, 2 E 1 LINHA EM OPERAÇÃO,

RESPECTIVAMENTE, PROJETO II.

FIGURA 14 - CORRENTES AO LONGO DA LINHA, 2 E 1 LINHA EM OPERAÇÃO,

RESPECTIVAMENTE, PROJETO II.

FIGURA 15 - TENSÕES AO LONGO DA LINHA, 2 E 1 LINHA EM OPERAÇÃO,

RESPECTIVAMENTE, PROJETO III.

FIGURA 16 - CORRENTES AO LONGO DA LINHA, 2 E 1 LINHA EM OPERAÇÃO,

RESPECTIVAMENTE, PROJETO III.

FIGURA 17 - TENSÕES E CORRENTES AO LONGO DA LINHA, PARA FATOR DE POTÊNCIA 1 E 0,92, 1 LINHA EM OPERAÇÃO, PROJETO II

FIGURA 18 - PERFIS DE TENSÃO E CORRENTE, PARA POTÊNCIA TRANSMITIDA DE 0,6 PU, PARA DIVERSOS VALORES DE TENSÃO OPERATIVA

FIGURA 19 - PERFIS DE TENSÃO E CORRENTE, PARA POTÊNCIA TRANSMITIDA DE 0,75 PU, PARA DIVERSOS VALORES DE TENSÃO OPERATIVA

FIGURA 20 - PERFIS DE TENSÃO E CORRENTE, PARA POTÊNCIA TRANSMITIDA DE 1 PU,

PARA DIVERSOS VALORES DE TENSÃO OPERATIVA

FIGURA 21 - CIRCUITO UTILIZADO PARA SIMULAÇÃO DA UTILIZAÇÃO DE REATOR NO MEIO DA LINHA

FIGURA 22 - PERFIS DE TENSÃO, PARA O PROJETO II, TRANSMITINDO 6000 MW COM EM UM ÚNICO CIRCUITO: COM A UTILIZAÇÃO DE REATOR DE 1000 MVAR E DE 1500 MVAR EM PARALELO NO MEIO DA LINHA, EM COMPARAÇÃO COM NENHUM REATOR NO MEIO DA $\operatorname{LINHA}(\mathrm{Q}=0)$

FIGURA 23 - CIRCUITO UTILIZADO PARA SIMULAÇÕES DE CURTOS-CIRCUITOS, 2 LINHAS EM OPERAÇÃO 
FIGURA 24 - CIRCUITO UTILIZADO PARA SIMULAÇÕES DE CURTOS-CIRCUITOS, 1 LINHA EM OPERAÇÃO

FIGURA 25 - CURTO EM F1 - CORRENTES NO INÍCIO DA LINHA EM CURTO, NO INÍCIO DA

LINHA SÃ, NO FINAL DA LINHA EM CURTO E NO FINAL DA LINHA SÃ, RESPECTIVAMENTE. 35

FIGURA 26 - CURTO EM F2 - CORRENTES NO INÍCIO DA LINHA EM CURTO, NO INÍCIO DA

LINHA SÃ, NO FINAL DA LINHA EM CURTO E NO FINAL DA LINHA SÃ, RESPECTIVAMENTE. 36

FIGURA 27 - CURTO EM F3 - CORRENTES NO INÍCIO DA LINHA EM CURTO, NO INÍCIO DA

LINHA SÃ, NO FINAL DA LINHA EM CURTO E NO FINAL DA LINHA SÃ, RESPECTIVAMENTE. 37

FIGURA 28 - CURTO EM F4 - TENSÕES EM UM PONTO LOCALIZADO A 1771 KM DO INÍCIO DA

LINHA EM CURTO.

FIGURA 29 - CURTO EM F4 - TENSÕES EM UM PONTO LOCALIZADO A 1146 KM DO INÍCIO DA LINHA SÃ.

FIGURA 30 - CURTO EM F5 - TENSÕES EM UM PONTO LOCALIZADO A 781 KM DO INÍCIO DA LINHA EM CURTO.

FIGURA 31 - CIRCUITO UTILIZADO PARA SIMULAÇÃO DE ENERGIZAÇÃO 39

FIGURA 32 - TENSÕES MÉDIAS DURANTE ENERGIZAÇÃO 40

FIGURA B1 - VALORES DO MÓDULO DA IMPEDÂNCIA CARACTERÍSTICA $\left(Z_{c}\right)$, SEQÜÊNCIA

ZERO, GEOMETRIA A.

FIGURA B2 - METADE DOS VALORES CALCULADOS PARA OS COMPRIMENTOS DE ONDA, SEQÜÊNCIA ZERO, GEOMETRIA A.

FIGURA B3 - VALORES DE REATÂNCIA INDUTIVA POR KM, SEQÜÊNCIA POSITIVA,

GEOMETRIA A.

FIGURA B4 - VALORES DE REATÂNCIA INDUTIVA POR KM, SEQÜÊNCIA ZERO, GEOMETRIA A.

FIGURA B5 - VALORES DE CAPACITÂNCIA POR KM, SEQÜÊNCIA POSITIVA, GEOMETRIA A. 57 FIGURA B6 - VALORES DE CAPACITÂNCIA POR KM, SEQÜÊNCIA ZERO, GEOMETRIA A. 57 FIGURA B7 - VALORES DO MÓDULO DA IMPEDÂNCIA CARACTERÍSTICA $\left(Z_{c}\right)$, SEQÜÊNCIA ZERO, GEOMETRIA B.

FIGURA B8 - METADE DOS VALORES CALCULADOS PARA OS COMPRIMENTOS DE ONDA, SEQÜÊNCIA ZERO, GEOMETRIA B.

FIGURA B9 - VALORES DE REATÂNCIA INDUTIVA POR KM, SEQÜÊNCIA POSITIVA,

GEOMETRIA B.

FIGURA B10 - VALORES DE REATÂNCIA INDUTIVA POR KM, SEQÜÊNCIA ZERO, GEOMETRIA B.

FIGURA B11 - VALORES DE CAPACITÂNCIA POR KM, SEQÜÊNCIA POSITIVA, GEOMETRIA B. 63 FIGURA B12 - VALORES DE CAPACITÂNCIA POR KM, SEQÜÊNCIA ZERO, GEOMETRIA B. 63 


\section{LISTA DE TABELAS}

TABELA 1 - CURVA DE CARGA PARA A LINHA 10

TABELA 2 - CUSTO DE LINHAS $750 \mathrm{KV}$ [9] 10

TABELA 3 - DIMENSÕES DE ISOLAMENTO E FERRAGENS PARA A LINHA PROPOSTA 16

TABELA 4 - ALTERNATIVAS SELECIONADAS PARA PROJETOS I, II E III

TABELA 5 - PERDAS NA LINHA, PROJETO I. 26

TABELA 6 - PERDAS TOTAIS NAS DUAS LINHAS, PROJETO II. 27

TABELA 7 - PERDAS TOTAIS NAS DUAS LINHAS, PROJETO III 28

TABELA 8 - VALORES DE CARGA, TENSÃO E PERDAS, PROJETO II, 2 LINHAS EM OPERAÇÃO,

ALTERNATIVA (A), TENSÃO NO INÍCIO DA LINHA = 1,05 PU 30

TABELA 9 - VALORES DE CARGA, TENSÃO E PERDAS, PROJETO II, 2 LINHAS EM OPERAÇÃO, ALTERNATIVA (B)

TABELA 10 - VALORES DE PICO DE CORRENTES NOS INÍCIOS DAS LINHAS PARA CURTOS FASE A-TERRA EM F1, F2 E F3.

TABELA 11 - ESTATÍSTICAS DAS TENSÕES MÁXIMAS DURANTE ENERGIZAÇÃO 41

TABELA 12 - DADOS DE ENTRADA DAS DIVERSAS ALTERNATIVAS, GEOMETRIA A

TABELA 13 - RESULTADOS DE PARÂMETROS DA LINHA, SEQÜÊNCIA POSITIVA, GEOMETRIA A

TABELA 14 - MEIO COMPRIMENTO DE ONDA E POTÊNCIA CARACTERÍSTICA PARA 1000 KV, SEQÜÊNCIA POSITIVA, GEOMETRIA A

TABELA 15 - RESULTADOS DE PARÂMETROS DA LINHA, SEQÜÊNCIA ZERO, GEOMETRIA A 54

TABELA 16 - MEIO COMPRIMENTO DE ONDA, SEQÜÊNCIA ZERO, GEOMETRIA A

TABELA 17 - DADOS DE ENTRADA DAS DIVERSAS ALTERNATIVAS, GEOMETRIA B 58

TABELA 18 - RESULTADOS DE PARÂMETROS DA LINHA, SEQÜÊNCIA POSITIVA, GEOMETRIA $B$

TABELA 19 - MEIO COMPRIMENTO DE ONDA E POTÊNCIA CARACTERÍSTICA PARA 1000 KV, SEQÜÊNCIA POSITIVA, GEOMETRIA B

TABELA 20 - RESULTADOS DE PARÂMETROS DA LINHA, SEQÜÊNCIA ZERO, GEOMETRIA B 60

TABELA 21 - MEIO COMPRIMENTO DE ONDA, SEQÜÊNCIA ZERO, GEOMETRIA B 


\section{PRELIMINARES}

\subsection{Introdução}

A transmissão de energia elétrica pode ser realizada em corrente alternada (CA) ou em corrente contínua (CC).

Linhas longas de transmissão em CA, com freqüência operativa de 50 ou $60 \mathrm{~Hz}$, apresentam valores consideráveis de reatância indutiva e admitância capacitiva. Para evitar a ocorrência de instabilidades após perturbações e elevações de tensão durante energizações, é necessário prover a linha de compensação série, que reduz a reatância indutiva total, e de compensação paralelo, que reduz a admitância capacitiva total da linha.

As linhas de transmissão em CC, por não apresentarem reatância ou admitância, não precisam de nenhuma compensação indutiva ou capacitiva. Por outro lado, esta modalidade de transmissão exige unidades de retificação $(\mathrm{CA} / \mathrm{CC})$ e conversão (CC/CA).

A linha de meia onda é um tipo de linha de transmissão em CA que, por apresentar um comprimento específico (cerca de $2500 \mathrm{~km}$ para uma freqüência de $60 \mathrm{~Hz}$ ), dispensa a compensação série ou paralelo. Ela é aplicável para transmissão pontoa-ponto por longas distâncias (por exemplo, acima de 2000 km). Equipamentos terminais podem utilizados para alongar ou encurtar eletricamente a linha, de forma a se obter um sistema com característica de meia onda.

Neste trabalho é, pois, apresentado o resultado de estudos iniciais sobre o comportamento de linhas de meia onda, a partir de um cenário adequado à sua aplicação. Espera-se que este texto possa servir, também, como uma introdução ao tema, para os interessados no assunto.

Este trabalho se baseia em revisão bibliográfica e em simulações computacionais. Como ainda não existe nenhuma linha de meia onda em operação no mundo, não é possível obter dados reais a respeito de seu funcionamento. 


\subsection{Motivação}

A necessidade de aproveitamento do potencial hidrelétrico da Amazônia fez nascer discussões técnicas a respeito dos desafios que devem ser enfrentados, para que este aproveitamento seja eficiente, confiável e com o menor impacto ambiental possível.

Entre os desafios, se destaca a transmissão de energia elétrica do ponto de geração até os centros de carga, por distâncias que podem superar $2000 \mathrm{~km}$, percorrendo regiões sem subestações intermediárias de alta tensão.

Uma possível alternativa é a transmissão em corrente continua, que não é abordada neste trabalho.

A alternativa mais utilizada na transmissão em CA convencional é a compensação da reatância série e da admitância em paralelo ao longo da linha. Quanto mais longa a linha, maiores serão a reatância e a admitância, e serão necessários mais equipamentos de compensação ou com maior capacidade em MVAr. Isso, além de contribuir com o aumento no custo total do empreendimento, aumenta o seu impacto ambiental, pois estes equipamentos de compensação serão instalados em subestações que, se não existem, terão de ser construídas.

Desta forma, buscam-se alternativas que permitam a transmissão "ponto-a-ponto", ou com a menor quantidade possível de equipamentos intermediários.

No final de 2008, a Agência Nacional de Energia Elétrica (ANEEL) publicou uma chamada de projeto estratégico [10] intitulada "Alternativas não convencionais para transmissão de energia elétrica em longas distâncias", através da qual convoca empresas e instituições de pesquisa a apresentar propostas de trabalho sobre este tema. $O$ fato de esse projeto ser considerado estratégico pela Agência confirma a necessidade de estudar diversas alternativas técnicas específicas para linhas extralongas (comprimentos maiores que $2000 \mathrm{~km}$ ), e não simplesmente utilizar as opções hoje definidas para linhas longas de, por exemplo, 700 ou $1000 \mathrm{~km}$.

\subsection{Escopo e Metodologia}

$\mathrm{Na}$ definição de um sistema CA convencional para transmissão de energia, é necessária a realização de estudos para o dimensionamento de linhas, subestações e compensações reativas. Inicia-se com a avaliação das condições de transmissão 
em regime permanente: i) com o sistema em condição normal e ii) com a contingência de um elemento (de acordo com o critério N-1 de planejamento). Nesta fase são definidos os equipamentos de compensação reativa.

Em seguida são realizados estudos de transitórios eletromecânicos para análise do desempenho dinâmico do sistema, que podem recomendar complementos à compensação reativa determinada anteriormente (compensação série ou paralela controlada).

Finalmente, são realizados estudos de transitórios eletromagnéticos para escolha da isolação do sistema (linhas e equipamentos).

O sistema então selecionado pode ser avaliado economicamente para a escolha final.

A linha de meia onda tem comportamento diferente da linha convencional, no que diz respeito a relações tensão/corrente em regime permanente e transitórios eletromagnéticos. Para seu correto dimensionamento, os estudos desse tipo de linha devem levar em conta esse fato.

Assim, neste trabalho, são descritos alguns aspectos da utilização da linha de meia onda como solução a uma necessidade de transportar um grande bloco de potência (no caso, $6000 \mathrm{MW}$ nominais), por uma distância bastante longa (no caso, $2500 \mathrm{~km}$ ). Buscou-se utilizar dados bastante próximos de uma realidade, e por isso são descritas as etapas de definição dos condutores e das geometrias da torre que fossem mais adequadas às premissas do projeto. Este trabalho busca também contribuir com a descrição de etapas importantes dos estudos de planejamento de linhas de meia onda. Para isto, foram utilizados dados de catálogos, dados de custos Eletrobrás e simulações no software Alternative Transients Program (ATP). Foram definidos três projetos de linha (dois projetos que consideram a construção de duas linhas, para maior confiabilidade, e um que considera a construção de uma única linha). Foram feitas avaliações de características importantes de cada um dos projetos, não havendo a intenção de selecionar um dentre os três.

Foram avaliados, através de simulações no ATP, o comportamento das linhas na operação em regime, verificando o comportamento de correntes, tensões e perdas.

Para as situações em que foram detectados grandes valores de perdas, foi proposta uma estratégia para minimização do problema. 
Como, para algumas situações, foram percebidas elevadas tensões no meio da linha, é descrita uma tentativa de solução do problema, através da utilização de um reator em paralelo no meio da linha.

Foram simuladas situações de transitórios de curtos-circuitos monofásicos em alguns pontos das linhas, com posterior análise das correntes e tensões resultantes. Por fim, foi realizada uma simulação de transitório de energização de uma linha de meia onda, e apresentação dos resultados de tensões médias ao longo da linha.

\subsection{Estrutura do trabalho}

Em seqüência a este capítulo 1, no capítulo 2 é feita uma breve revisão da literatura sobre linhas de meia onda, incluindo textos escritos entre os anos de 1965 a 2008. Devido ao fato de que este tipo de linha é mais adequado para sistemas elétricos de dimensão continental, a produção científica sobre o assunto não é numerosa.

O capítulo 3 apresenta as principais propriedades da linha de transmissão de meia onda. Com o objetivo de facilitar a leitura do texto, as deduções das expressões são apresentadas no anexo $A$.

No capítulo 4, é apresentada a definição de três projetos de linha de meia-onda, a serem utilizados nas simulações posteriores.

No capítulo 5, os projetos definidos no capítulo anterior são avaliados em termos de operação em regime, comportamento durante curtos-circuitos e energizações.

No capítulo 6, são apresentadas as conclusões deste trabalho.

Este trabalho apresenta dois anexos, onde são apresentadas informações que, apesar de terem sido importantes durante o desenvolvimento do trabalho, não são fundamentais para o seu entendimento. São elas: a dedução de expressões que comprovam o comportamento de linhas de meia onda (anexo A) e dados numéricos adicionais do cálculo de parâmetros de linhas (anexo B).

Ao final, são apresentadas as referências bibliográficas consultadas. 


\section{REVISÃO BIBLIOGRÁFICA}

Em meados do século $X X$, houve a publicação de alguns artigos a respeito da possibilidade de transmitir energia elétrica a grandes distâncias através de linhas de meia-onda. Segundo [1], o primeiro artigo sobre o assunto foi publicado na antiga União Soviética, em 1940, por A. A. Wolf e O. V. Shcherbachev, cujo título, traduzido para o inglês, é "On normal working conditions of compensated lines with half-wave characteristics". Em 1965, foi publicado um artigo [2] propondo a utilização de linhas de meia onda para transmissão, através da adição de reatâncias séries e capacitâncias paralelas (chamados de tuning equipments ou equipamentos de ajuste) a uma linha de 900 milhas $=1450 \mathrm{~km}$ de comprimento, de forma que 0

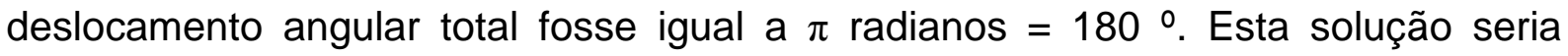
adequada para os sistemas de transmissão da América do Norte, nos quais as distâncias entre geração e centros de carga não alcançam os $2500 \mathrm{~km}$ (que corresponde a meio comprimento de onda para freqüência de $60 \mathrm{~Hz}$ ). Em 1968, outro artigo [1] tratava deste assunto, abordando linhas de meia onda naturais, ou seja, linhas cujo comprimentos reais fossem um pouco maior que a metade do comprimento de onda, sem o artifício de inserir impedâncias.

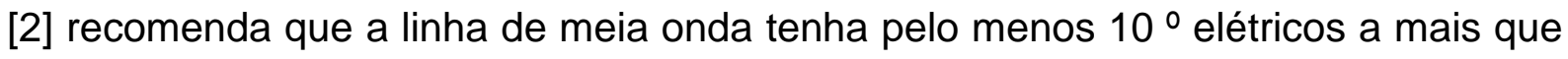
a metade do comprimento de onda, para facilitar o controle de reativos da geração e também para garantir as propriedades da linha quando da redução momentânea da freqüência do sistema. Neste trabalho, o comprimento das linhas simuladas não atende a essa exigência, pois os cenários mencionados não fazem parte deste escopo. As conclusões obtidas neste trabalho, para linhas de $2500 \mathrm{~km}$, são válidas para linhas um pouco maiores. Em trabalhos futuros, sugere-se que o comprimento da linha seja definido somente após estudos de estabilidade.

Em [3], os autores incluíram o efeito corona na modelagem e simulação de linhas de meia onda, e indicam que ele contribuiria para reduzir as elevadas tensões no meio da linha decorrentes de carregamento superior à potência característica e de curtoscircuitos, o que seria uma vantagem, mas também ocasionaria limitação da capacidade de transmissão e afetaria a estabilidade transitória.

Em [1],[2],[3], [4], a transmissão em meia onda é comparada com a transmissão em corrente contínua, que apresenta a desvantagem econômica da necessidade de 
utilização de estações conversoras, para as quais há poucos fabricantes no mundo quando comparadas a equipamentos utilizados na transmissão em corrente alternada. Em todos os trabalhos, a transmissão em meia onda surge como uma proposta a ser melhor estudada antes de ser considerada uma alternativa à transmissão em CC.

[1] e [3] discutem a necessidade de a linha ser constituída de dois circuitos, de preferência utilizando rotas distintas, de forma a garantir o fornecimento de energia ao sistema receptor em caso de falha em algum trecho da linha. Em ambos os trabalhos é verificada a possibilidade de seccionamento da linha, de forma que apenas um determinado trecho seja retirado de operação em caso de falha, já que uma linha muito longa tem um total de falhas bem maior que uma linha mais curta.

Segundo [1], esse seccionamento sujeita a linha a uma possibilidade de perda da estabilidade transitória para determinados tipos de falta, e recomenda que, em vez de subestações intermediárias, sejam construídos dois circuitos paralelos ponto-aponto. [3] verifica que, em caso de perda de algum trecho de um dos circuitos, haverá sobretensões em determinados pontos da linha, e propõe a instalação de equipamentos de compensação (reatores série e capacitores shunt) a serem utilizados somente nos trechos em que haja apenas um circuito operando. Os autores admitem que, nesse caso, a principal vantagem da linha de meia-onda, que é a não necessidade de equipamentos de compensação, seria reduzida, mas afirmam que os custos da compensação para uma linha meia onda são cerca de $20 \%$ dos custos de compensação de uma linha CA convencional.

Neste trabalho, não será considerada a hipótese de utilização de estações intermediárias, optando-se por uma linha ponto-a-ponto. 


\section{PRINCIPAIS PROPRIEDADES DA LINHA DE MEIA ONDA}

As linhas de meia onda apresentam propriedades bastante interessantes. Elas são apresentadas nesta seção de forma bastante resumida. As expressões matemáticas que traduzem essas propriedades constam do Anexo A. Exemplos dessas propriedades podem ser vistos na seção 5 .

Uma linha de meia onda, para uma freqüência de operação de $60 \mathrm{~Hz}$, tem cerca de $2500 \mathrm{~km}$. As tensões e correntes na linha têm uma velocidade de propagação próxima à velocidade da luz, $300.000 \mathrm{~km} / \mathrm{s}$, o que resulta num comprimento de onda de $5000 \mathrm{~km}$ para a freqüência de $60 \mathrm{~Hz}$.

As tensões nos dois terminais de linhas de meia onda apresentam módulos

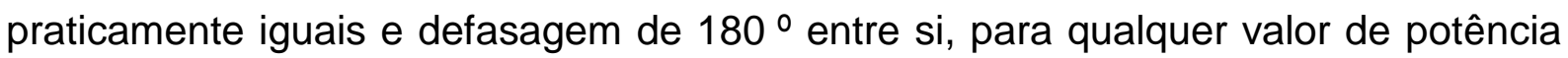
transportada, inclusive para nula (linha sem carga). O mesmo se observa para as correntes nos dois terminais da linha. Linhas de meia onda não apresentam, portanto, o efeito Ferranti.

Porém, essa propriedade só diz respeito aos terminais da linha. Valores de carga diferentes da potência transmitida resultam num perfil de carga com sensível elevação ou redução da tensão no meio da linha, para cargas maiores ou menores que a potência característica da linha, respectivamente. O perfil de tensões plano somente é observado para potência transmitida igual à potência característica.

Uma linha de meia onda produz, ao longo de seu comprimento, a energia reativa que consome. Desta forma, não necessita de compensação reativa.

As propriedades são mantidas quando o comprimento da linha é pouco maior que o meio comprimento de onda. Assim, não é necessário projetá-la para estar exatamente sintonizada à meia onda.

A linha de meia onda apresenta outra vantagem, que é o seu bom desempenho em termos de estabilidade, pois ela se comporta de forma bastante semelhante a uma linha curta. Porém, este aspecto não será avaliado neste trabalho. 


\section{PROJETO DA LINHA}

Nesta seção, são definidos os parâmetros de algumas linhas de meia onda, que servem como exemplo para as simulações mencionadas na seção seguinte.

Como será visto, um aspecto chave para avaliação do comportamento desta linha é o valor da sua potência característica (ou potência natural). Este aspecto será mantido considerando-se uma carga de 6000 MW a ser suprida por um ou dois circuitos.

\subsection{Definição da impedância característica}

Ao transmitir uma potência maior que a potência característica, uma linha de meia onda apresenta tensões elevadas nas proximidades do meio da linha. Por outro lado, ao transmitir uma potência muito inferior à potência característica, as perdas na linha aumentam. Então, considerando que o carregamento da linha não é constante, a escolha da impedância característica, que define a potência característica, depende da escolha entre os seguintes critérios:

i) admitem-se sobretensões na linha quando houver um maior carregamento (o que exigirá um projeto mais robusto do ponto de vista de isolamento), privilegiando a redução de perdas, ou

ii) evitam-se sobretensões na linha, aceitando-se que as perdas aumentem (ou seja, a eficiência da linha seja reduzida).

Além disso, é necessário levar em conta a confiabilidade da transmissão. Para atender ao critério $\mathrm{N}-1$ de planejamento, seria necessário projetar duas linhas, de forma que o fornecimento não seja interrompido em caso de indisponibilidade de uma das linhas. Por outro lado, [4] considera que, em caso de impossibilidade de se construir duas linhas, o religamento monopolar seria uma alternativa para manter o fornecimento em caso de curtos monofásicos.

Considerando-se as diversas possibilidades de decisão, serão buscados três projetos de linha, de forma que diferentes aspectos do comportamento da linha de meia onda possam ser avaliados:

I. Uma única linha, com potência característica igual à potência máxima (carga) a ser transmitida 
II. Duas linhas, cada uma com potência característica igual à potência máxima a ser transmitida

III. Duas linhas, cada uma com potência característica igual à metade da potência máxima a ser transmitida

Cada um dos projetos I, II e III deverá transmitir, no total, uma potência máxima de 6000 MW, em uma tensão de 1000 kV, percorrendo uma distância de $2500 \mathrm{~km}$.

Aplicando-se, então, esses valores, o projeto I deverá ter uma potência característica de aproximadamente $6000 \mathrm{MW}$, e uma potência máxima transmitida de $6000 \mathrm{MW}$ na única linha existente. Esse projeto se constitui numa alternativa que, apesar de não atender o critério $\mathrm{N}-1$ de planejamento, apresenta $\mathrm{o}$ melhor desempenho em termos de eficiência e sobretensões em regime permanente.

Cada linha do projeto II deverá ter uma potência característica de aproximadamente $6000 \mathrm{MW}$, com uma potência máxima transmitida de $3000 \mathrm{MW}$, quando houver duas linhas em operação; ou 6000 MW quando houver uma única linha em operação. Esse projeto atende ao critério N-1. Quando houver duas linhas em operação, este projeto deverá apresentar maiores perdas. Quando somente uma linha estiver em operação, não deverá haver sobretensões em regime permanente.

Cada linha do projeto III deverá ter uma potência característica de aproximadamente $3000 \mathrm{MW}$, com uma potência máxima transmitida de $3000 \mathrm{MW}$, quando houver duas linhas em operação; ou 6000 MW quando houver uma única linha em operação. Esse projeto atende ao critério $\mathrm{N}-1$. Quando somente uma linha estiver em operação, deverão ser observadas sobretensões em regime permanente ao se transmistir a potência máxima de 6000 MW.

Para os projetos I e II, busca-se uma impedância característica de:

$Z_{c}=\frac{V^{2}}{P \max }=\frac{(1000 \mathrm{kV})^{2}}{6000 \mathrm{MW}}=167 \Omega$

Para o projeto III, a impedância característica deve ser de:

$Z_{c}=\frac{V^{2}}{P \max / 2}=\frac{(1000 \mathrm{kV})^{2}}{3000 \mathrm{MW}}=333 \Omega$ 


\subsection{Definição da seção transversal do condutor (cálculo do condutor econômico)}

Considera-se que o carregamento total da(s) linha(s) varia de acordo com a Tabela 1:

Tabela 1 - Curva diária de carga para a linha

\begin{tabular}{|c|c|c|}
\hline Carga & Intervalo & Valor \\
\hline Leve & $12 \mathrm{~h}$ & $0,60 \times 6000 \mathrm{MW}=3600 \mathrm{MW}$ \\
\hline Média & $10 \mathrm{~h}$ & $0,75 \times 6000 \mathrm{MW}=4500 \mathrm{MW}$ \\
\hline Pesada & $2 \mathrm{~h}$ & $1,00 \times 6000 \mathrm{MW}$ \\
\hline
\end{tabular}

Nota: no caso de um sistema de usina hidráulica, o despacho pode não seguir a carga, e sim o fluxo de entrada de água. Se os despachos nos vários períodos do ano seguirem a mesma proporção da tabela acima, a análise a seguir permanece válida

Deve-se escolher a seção $S$ do condutor que proporcione o menor custo anual $C$, para o regime de carga estabelecido, onde

$C=C_{\text {cons }}+C_{\text {perdas }}$

$\mathrm{C}_{\text {cons }}=$ custo anual de construção da linha;

$\mathrm{C}_{\text {perdas }}=$ custo anual de perdas resistivas na linha.

\subsubsection{Custos de construção}

Para estimar os custos das linhas, usam-se dados históricos de custos de construção de linhas da Tabela 2 [9] e considera-se que o investimento total $C_{\text {cons,total }}$ varia de acordo com a seção total de alumínio (MCM), dada por $\mathrm{S}$, segundo a expressão

$$
C_{\text {cons,total }}=A+B S \text {, }
$$

onde A e B são constantes.

Tabela 2 - Custo de linhas $750 \mathrm{kV}[9]$
\begin{tabular}{|c|c|}
\hline MCM & Custo $\mathbf{( R \mathbf { \$ m } )}$ \\
\hline 4452 & $886.570,00$ \\
\hline 4770 & $915.700,00$ \\
\hline 5088 & $945.660,00$ \\
\hline 5406 & $976.450,00$ \\
\hline 5724 & $1.007 .240,00$ \\
\hline 6042 & $1.038 .850,00$ \\
\hline
\end{tabular}


Os valores de A e B são obtidos por ajuste de curva linear. A análise seria mais precisa se os valores fossem adaptados para 1000 kV. Porém, não há valores históricos disponíveis para essa tensão nominal.

Para o cálculo do valor anual correspondente ao investimento na linha, foram considerados juros de $11 \%$ a.a., 30 anos de amortização e custo de $2 \%$ a.a. de manutenção.

Desta forma, o custo anual de construção da linha pode ser estimado pela expressão:

$$
C_{\text {cons }}=K \cdot(A+B \cdot S)=a+b \cdot S,
$$

onde:

$K=\frac{j}{1-(1+j)^{-n}}+m$,

$j=$ taxa de juros a.a.,

$n=$ quantidade de anos para amortização,

$m=$ custo percentual de manutenção.

Como $K, A$ e $B$ já são conhecidos, e, consequentemente, $a$ e $b$, o valor de $C_{c o n s}$ depende apenas da seção $S$.

\subsubsection{Custos de perdas}

Estimam-se as perdas resistivas a cada quilômetro de linha pela expressão (1). Esse cálculo é simplificado, pois considera que a corrente é constante ao longo da linha, fato que não é exato, principalmente no caso de linha de meia onda. Contudo, ele é válido para fins de escolha inicial entre diferentes valores de seção transversal.

$$
\text { Perdas }=3 r I^{2}=r\left(\frac{P_{M W}}{V_{k V}}\right)^{2}
$$

$r$ é a resistência da linha em $\Omega / \mathrm{km}$.

Dado o preço da energia $C_{e}$, o custo anual das perdas (em $R \$ / M W h$ ) será: 


$$
\begin{aligned}
C_{\text {perdas }} & =C_{e}\left(\text { Perdas }_{\text {leve }} \cdot t_{\text {leve }}+\text { Perdas }_{\text {média }} \cdot t_{\text {média }}+\text { Perdas }_{\text {pesada }} \cdot t_{\text {pesada }}\right) * 365= \\
& =C_{e} \cdot r\left[t_{\text {leve }} \cdot i_{\text {leve }}{ }^{2}+t_{\text {média }} \cdot i_{\text {média }}{ }^{2}+t_{\text {pesada }} \cdot i_{\text {pesada }}{ }^{2}\right] * 365= \\
& =C_{e} \cdot r\left[t_{\text {leve }}\left(\frac{P_{M W, \text { leve }}}{V_{k v}}\right)^{2}+t_{\text {média }}\left(\frac{P_{M W, \text { média }}}{V_{k v}}\right)^{2}+t_{\text {pesada }}\left(\frac{P_{M W, \text { pesada a }}}{V_{k v}}\right)^{2}\right] * 365= \\
& =C_{e} \cdot r \cdot\left(\frac{P_{M W, \text { pesada }}}{V_{k v}}\right)^{2} \cdot\left[t_{\text {pesada }}+t_{\text {média }}\left(\frac{P_{M W, \text { média }}}{P_{M W, \text { pesada }}}\right)^{2}+t_{\text {carga média }}\left(\frac{P_{M W, \text { leve }}}{P_{M W, \text { pesada }}}\right)^{2}\right] * 365 .
\end{aligned}
$$

Agrupam-se os termos entre colchetes multiplicados pelo número de dias no ano. Tem-se

$$
h_{p}=\left[t_{\text {carga pesada }}+t_{\text {carga média }}\left(\frac{P_{M W, \text { carga média }}}{P_{M W, \text { carga pesada }}}\right)^{2}+t_{\text {carga média }}\left(\frac{P_{M W, \text { carga leve }}}{P_{M W, \text { carga pesada }}}\right)^{2}\right] * 365,
$$

onde $h_{p}$ é chamado de "horas equivalentes de perdas por ano". Então,

$$
C_{\text {perdas }}=C_{e} \cdot r \cdot\left(\frac{P_{M W, \text { carga pesada }}}{V_{k v}}\right)^{2} \cdot h_{p} .
$$

Estimando-se a resistência CC (para corrente contínua) de cabos de alumínio pela expressão $r=\frac{57,1}{S}$, com o valor de S em MCM,

$$
\begin{aligned}
& C_{\text {perdas }}=C_{e} \cdot \frac{57,1}{S} \cdot\left(\frac{P_{M W, \text { carga pesada }}}{V_{k v}}\right)^{2} \cdot h_{p}=\frac{c_{p}}{S}, \\
& \text { onde } c_{p}=C_{e} \cdot 57,1 \cdot\left(\frac{P_{M W, \text { carga pesada }}}{V_{k v}}\right)^{2} .
\end{aligned}
$$

\subsubsection{Minimização do custo anual}

O custo anual é dado por $C=C_{\text {cons }}+C_{\text {perdas }}=(a+b S)+\frac{c_{p}}{S}$.

O ponto de mínimo custo ocorre quando $S=\sqrt{\frac{c_{p}}{b}}$. 
Nota.: Ao se obter o valor $\mathrm{S}$, podem ser feitas estimativas do valor das perdas corona, que pode ser usado para realimentar o cálculo, influenciando a seleção da seção condutora. Isto não será feito neste trabalho para simplificar a análise.

\subsubsection{Resultados do condutor econômico}

Utilizando-se os dados da seção anterior, obtém-se, para a tensão de $750 \mathrm{kV}$, $A=R \$ 458820, B=R \$ 96 / M C M$ e $K=0,135 /$ ano.

Adotando-se o mesmo valor de B para $1000 \mathrm{kV}, \mathrm{b}=\mathrm{B} \cdot \mathrm{K}=\mathrm{R} \$ 12,96$ / $\mathrm{MCM} /$ ano.

Para o projeto I, os dados da Tabela 1 serão utilizados diretamente para 0 cálculo de perdas. A hora equivalente de perdas é $h_{p}=4360 \mathrm{~h} / \mathrm{ano}$ e o custo da energia utilizada é $\mathrm{C}_{e}=\mathrm{R} \$ 138 / \mathrm{MWh}$, resultando um coeficiente $c_{p}=R \$ 1.236 .792 .133,00 \times M C M /$ ano.

Então, para o projeto I, o condutor econômico tem a seção total:

$$
S=\sqrt{\frac{c_{p}}{b}}=9769 \text { MCM }
$$

Para os projetos II e III, os dados da Tabela 1 deverão ser divididos por dois para o cálculo de perdas (pois cada linha transmitirá a metade da potência total). A hora equivalente de perdas é a mesma do projeto $\mathrm{I}$, e o coeficiente $c_{p}=R \$ 309.198 .033 .133,00 \times M C M /$ ano (que é $1 / 4$ do $c_{p}$ do projeto I, já que a

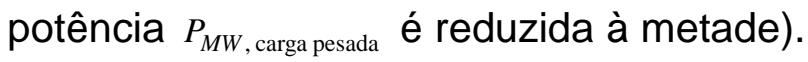

Então, para os projetos II e III, o condutor econômico tem a seção total:

$$
S=\sqrt{\frac{c_{p}}{b}}=4884 M C M
$$

Serão utilizados feixes de 6 subcondutores por fase. Dessa forma, para o projeto I, serão utilizados feixes 6xLapwing (6x1590 MCM) por fase e, para os projetos II e III, feixes 6xDrake (6x795 MCM) por fase.

Nota: seria preciso verificar se as configurações mencionadas atendem ao critério de gradiente máximo na superfície dos condutores. Isso não será feito neste trabalho, por ser dirigido a discutir uma metodologia. 


\subsection{Definição da disposição física dos subcondutores}

\subsubsection{Linhas de Potência Natural Elevada (LPNE)}

Os projetos I, II e III de linha de meia onda deverão apresentar valores de potência característica definidos na seção 4.1. Esses valores são relativamente elevados em comparação com os projetos convencionais de geometria de torres.

Uma das estratégias utilizadas para aumentar a potência característica da linha é a utilização de feixes com maior número de subcondutores e com maior espaçamento entre eles [5]. É possível ainda otimizar o arranjo da linha, através da redução da distância entre fases e da escolha de arranjos de feixes assimétricos, mas estes tópicos não serão aqui aprofundados. Portanto, as simulações de arranjos foram feitas com variação apenas no número e no espaçamento dos subcondutores.

O aumento no número de subcondutores contribui com a redução da impedância série devido ao fato de estarem ligados em paralelo. Já o aumento da distância entre os subcondutores reduz a indutância série própria do feixe, devido ao aumento do raio médio geométrico (RMG) do feixe.

Apesar de não ser utilizada nesta simulação, a redução da distância entre fases diminui a reatância série da linha (reduzindo consequentemente a impedância série $Z=R+j X=R+j \omega L$ ), bem como aumenta a capacitância em paralelo (pelo aumento da admitância em paralelo $Y=j \omega C$ ). Consequentemente, a impedância característica $\left(Z_{c}=\sqrt{Z / Y}\right)$ será menor.

A determinação dos parâmetros das linhas de transmissão foi realizada através do módulo Line/Cable Constants (LCC) do software ATP. Foi utilizado o modelo Pi, para que fossem retornados os valores de resistência, reatância e susceptância por quilômetro.

\subsubsection{Geometria A proposta}

A geometria A proposta para cada linha é a da Figura 1. 


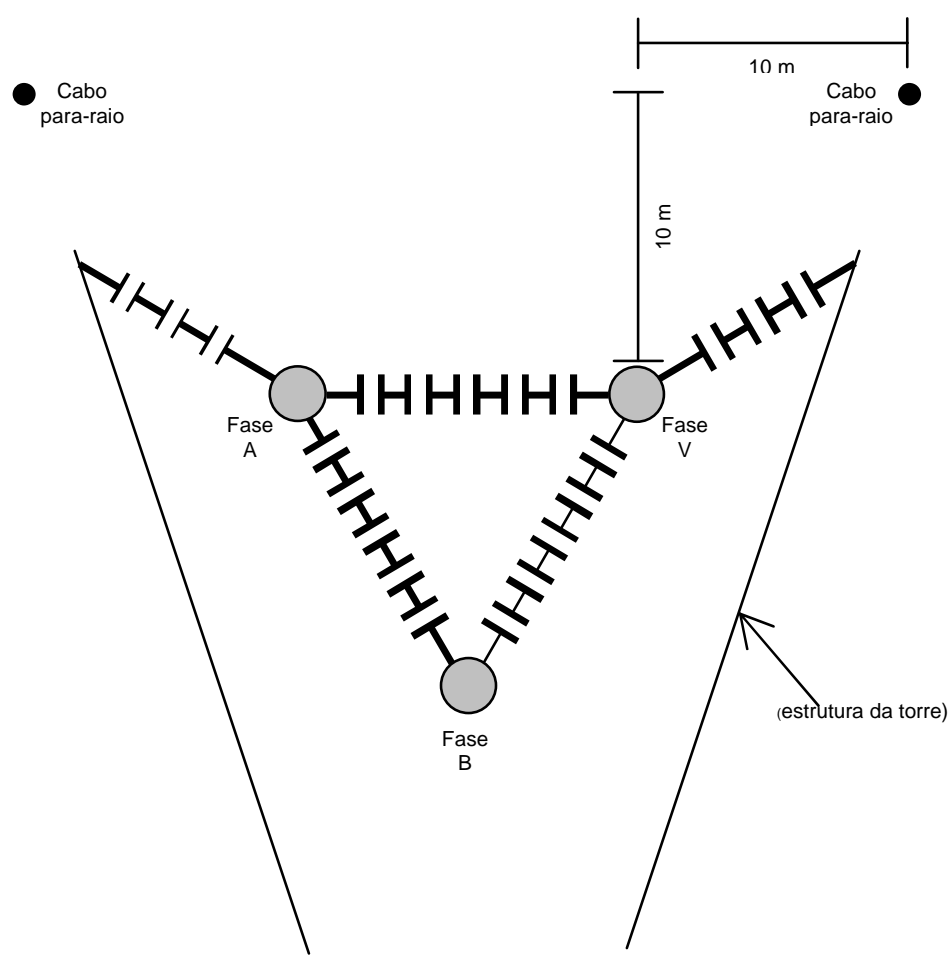

Figura 1 - Geometria A proposta

\subsubsection{Premissas para a geometria A}

\subsubsection{Isoladores e ferragens}

Adotou-se para a região da linha um nível de poluição leve, e consequentemente, uma distância de fuga (creepage) para as cadeias de isoladores de $16 \mathrm{~mm} / \mathrm{kVef}$ fase-fase. Foi considerado um isolador padrão IEC para $240 \mathrm{kN}$ que possui uma distância de fuga de $380 \mathrm{~mm}$ e um passo de $170 \mathrm{~mm}$.

O número de isoladores necessários para o isolamento fase-terra é $\mathrm{n}=$ Tensão da linha $(\mathrm{kV}) \times 16 \mathrm{~mm} / \mathrm{kV} / 380 \mathrm{~mm}$.

Para as cadeias entre os feixes das fases, será adotada um isolamento igual a $\sqrt{3}$ vezes 0 isolamento entre fase-terra. Dessa forma, as quantidades de isoladores, e os comprimentos da cadeia e das ferragens estão apresentados na Tabela 3. 
Tabela 3 - Dimensões de isolamento e ferragens para a linha proposta

\begin{tabular}{|l|c|}
\hline № Isoladores fase-terra & 47 \\
\hline № isoladores fase-fase & 82 \\
\hline Comprimento do isolamento fase terra $(\mathrm{m})$ & 8,0 \\
\hline Comprimento das ferragens & 1,5 \\
\hline
\end{tabular}

\subsubsection{Flecha e altura mínima do condutor}

Considerou-se a altura mínima condutor-solo, no meio do vão, igual a 18 metros, e a flecha do condutor igual a 20 metros (valores típicos estimados para linhas de 1000 $k \mathrm{~V})$.

\subsubsection{Cabos para-raios}

Adotou-se o cabo de aço 3/8" EHS como cabo pára-raios. Esses cabos estão localizados a uma altura de 10 metros acima das fases mais altas e a uma distância horizontal de 10 metros da fase mais próxima.

\subsubsection{Geometria do feixe}

Os subcondutores do feixe são dispostos em forma de hexágono, conforme Figura 2.

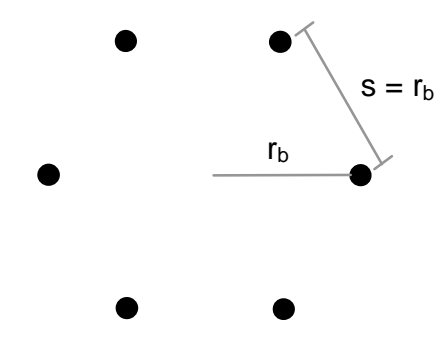

Figura 2 - Detalhe da geometria do feixe de 6 subcondutores 


\subsubsection{Alternativas a serem simuladas para a geometria A}

Serão consideradas, para os projetos I (cabo 6xLapwing), II e III (cabo 6xDrake), três opções de diâmetro do feixe: 1, 2 ou 3 metros.

\subsubsection{Resultados para a geometria A}

Os resultados estão apresentados na Figura 3 à Figura 5. Os valores numéricos, bem como os gráficos dos demais parâmetros, estão no Anexo B. A potência característica é calculada considerando-se uma tensão de 1000 kV.

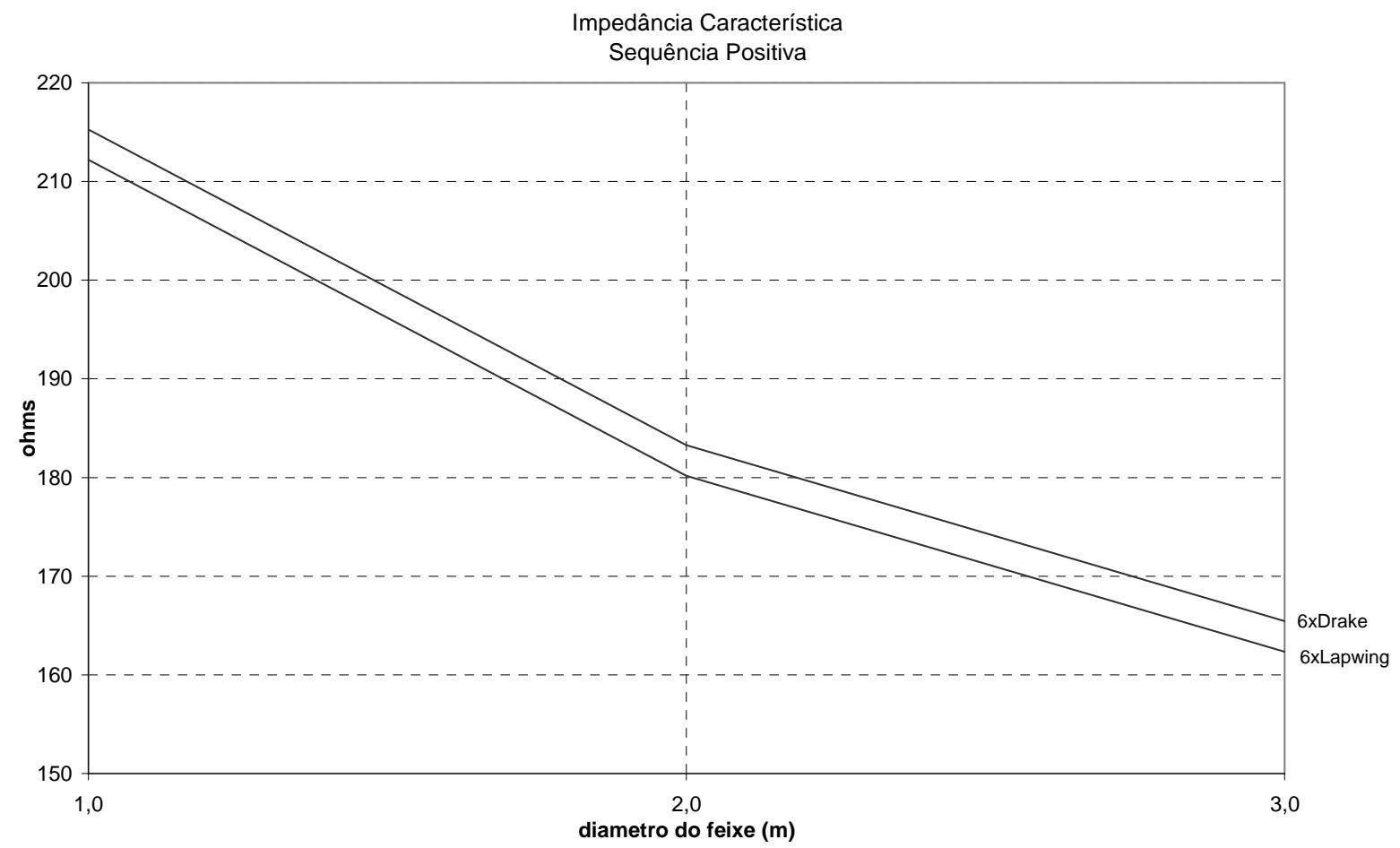

Figura 3 - Valores do módulo da impedância característica $\left(Z_{c}\right)$, seqüência positiva, geometria A. 


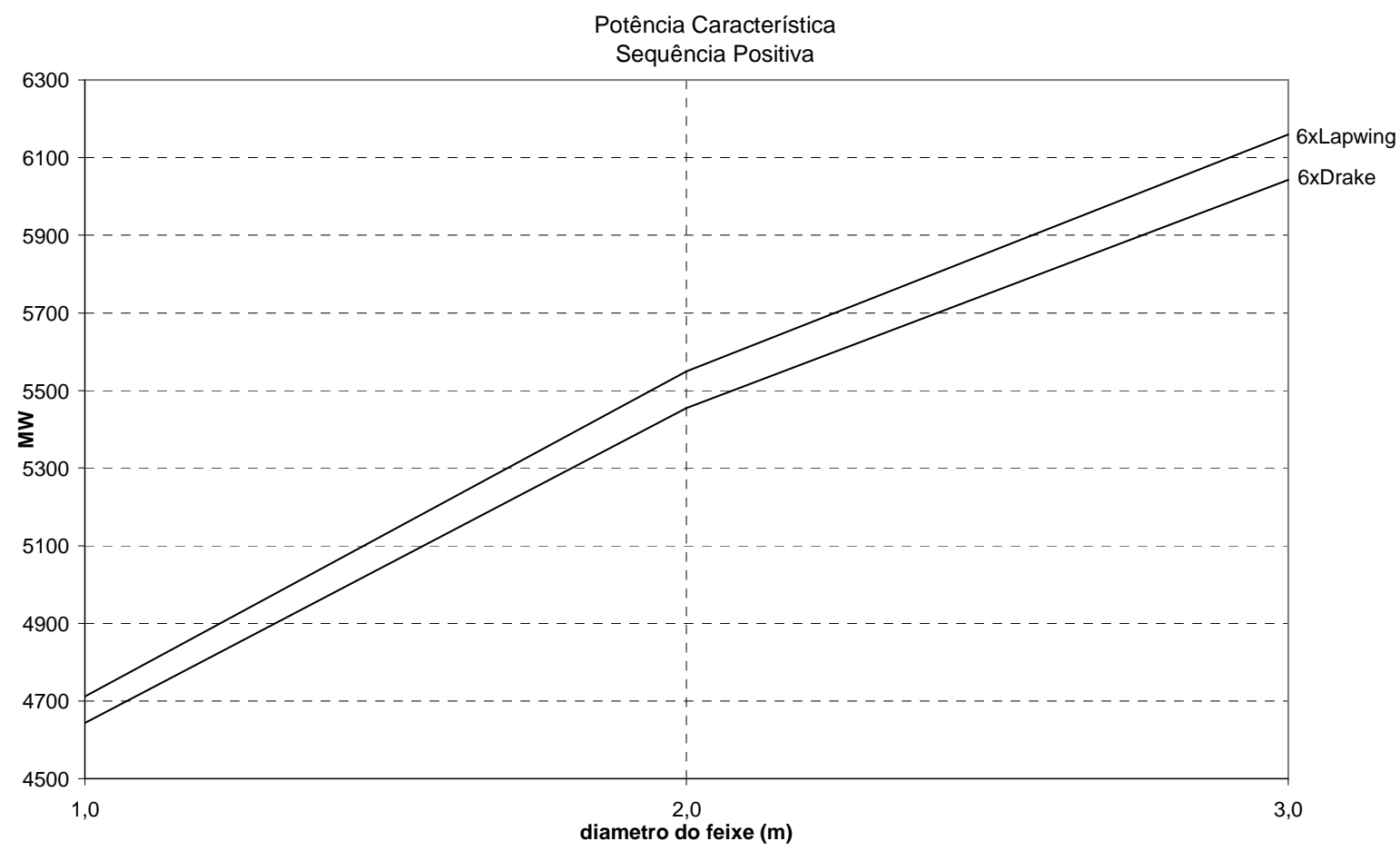

Figura 4 - Valores de potência característica, seqüência positiva, geometria A.

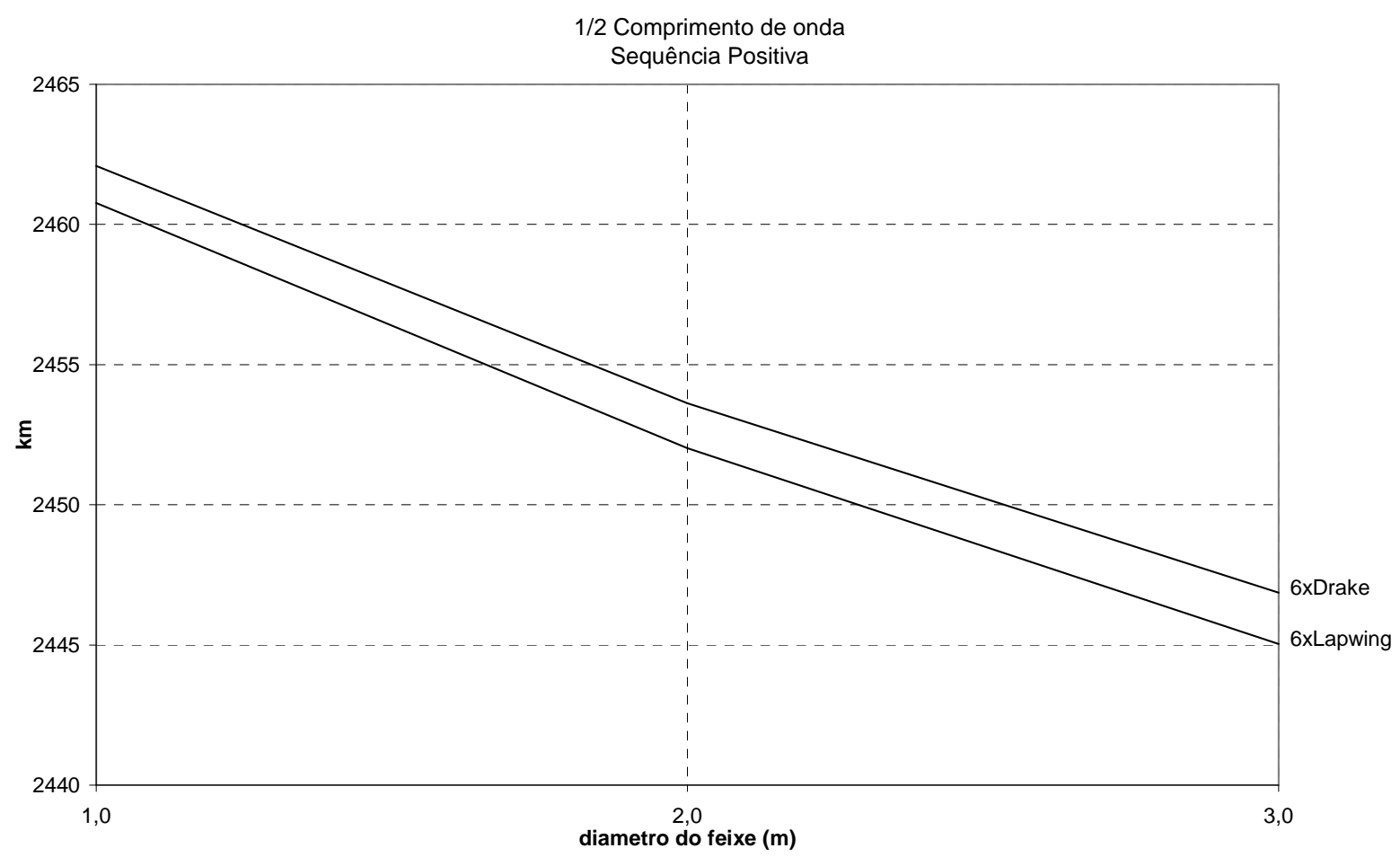

Figura 5 - Metade dos valores calculados para os comprimentos de onda, seqüência positiva, geometria $\mathrm{A}$.

Observa-se, pelos gráficos, que, com essa configuração, pode-se atingir o objetivo da linha ter potência característica em torno de 6000 MW (projetos I e II), mas não 
$3000 \mathrm{MW}$ (projeto III). Portanto, para o projeto III foi considerada a geometria B, descrita na seção a seguir.

\subsubsection{Geometria B considerada}

A geometria proposta para cada linha do projeto III é apresentada na Figura 6.
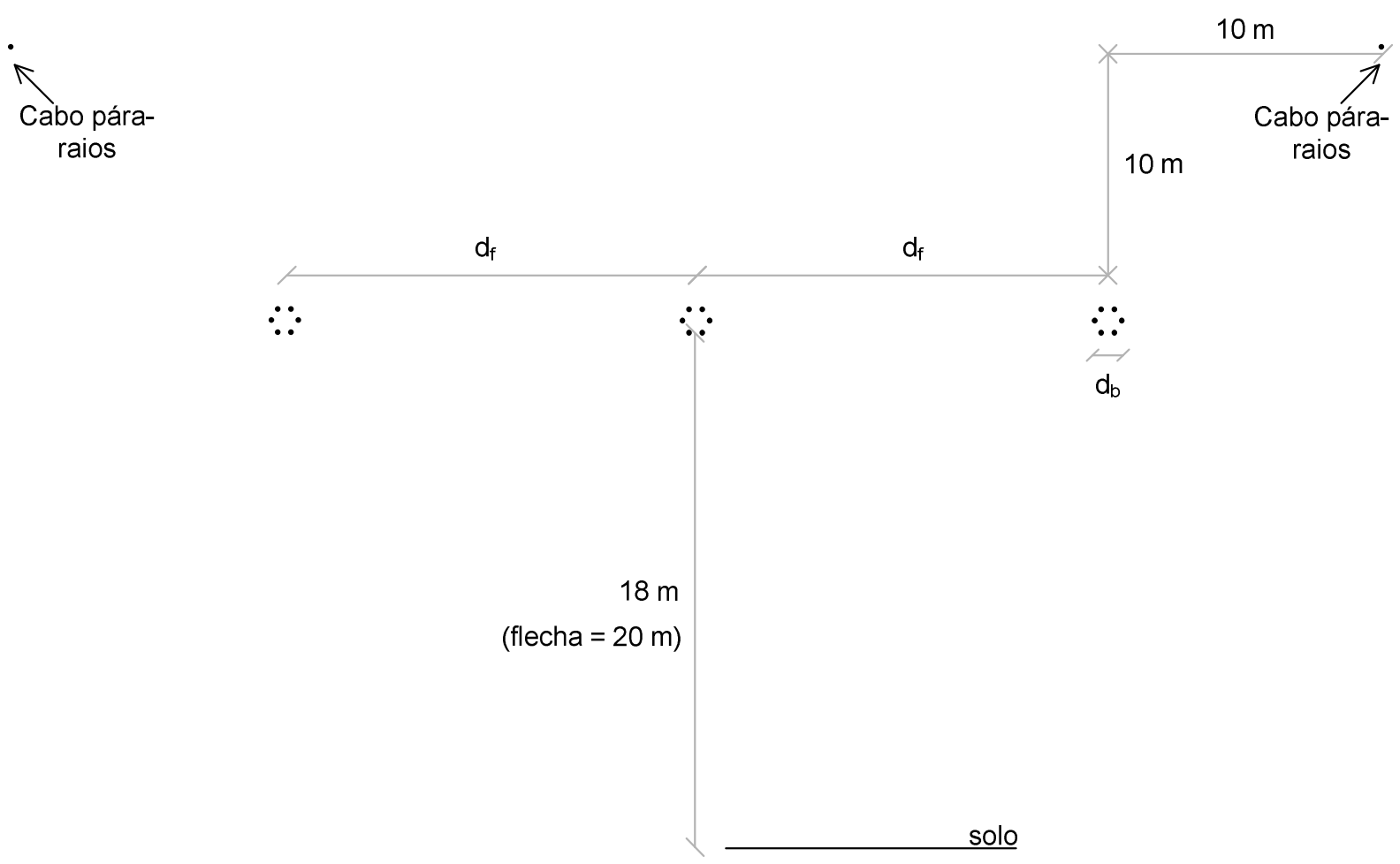

Figura 6 - Geometria B proposta

\subsubsection{Premissas para a geometria B}

\subsubsection{Isoladores e ferragens}

Adotou-se o mesmo nível de poluição e o mesmo tipo de isolador utilizado para a geometria $\mathrm{A}$.

\subsubsection{Flecha e altura mínima do condutor}

Consideraram-se os mesmos valores da geometria A: altura mínima condutor-solo, no meio do vão, igual a 18 metros, e flecha do condutor igual a 20 metros. 


\subsubsection{Cabos para-raios}

Da mesma forma que a geometria A, adotou-se o cabo de aço 3/8" EHS como cabo pára-raios, localizados a uma altura de 10 metros acima das fases mais altas e a uma distância horizontal de 10 metros da fase mais próxima.

\subsubsection{Geometria do feixe}

Os subcondutores do feixe se distribuem em forma de hexágono, conforme Figura 2, mesma disposição da geometria $A$.

\subsubsection{Alternativas a serem simuladas para a geometria B}

Serão consideradas, apenas para o projeto III (cabo 6xDrake), duas opções de espaçamento horizontal $\left(d_{f}\right): 12$ ou 15 metros e duas opções de diâmetro do feixe $\left(d_{b}\right)$ : 1 ou 2 metros, conforme Figura 6.

\subsubsection{Resultados para a geometria B}

Os resultados estão apresentados na Figura 7 à Figura 9. Os valores numéricos, bem como os gráficos dos demais parâmetros, estão no Anexo B. 
Impedância Característica

Sequência Positiva

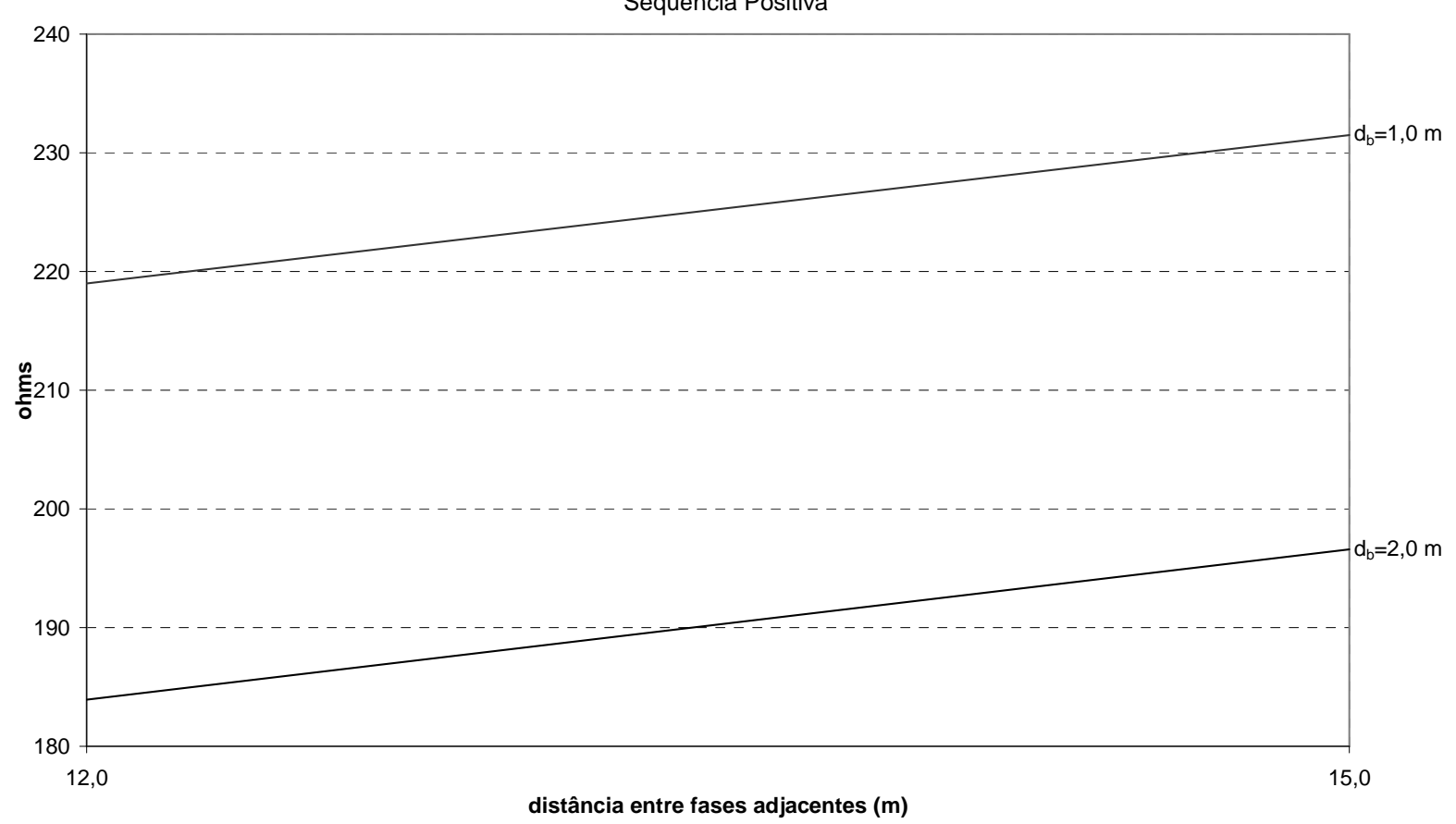

Figura 7 - Valores do módulo da impedância característica $\left(Z_{c}\right)$, seqüência positiva, geometria B.

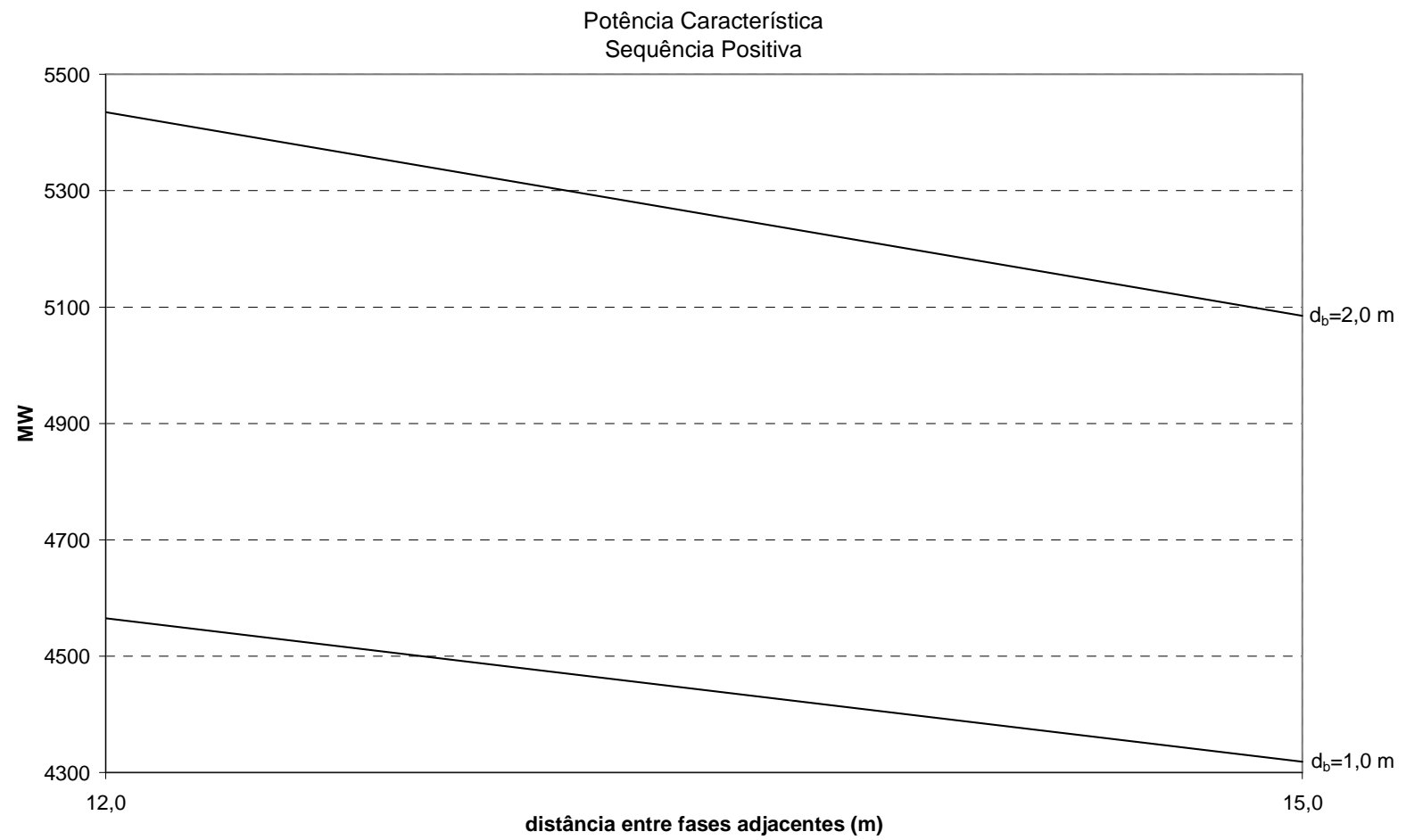

Figura 8 - Valores de potência característica, seqüência positiva, geometria B. 


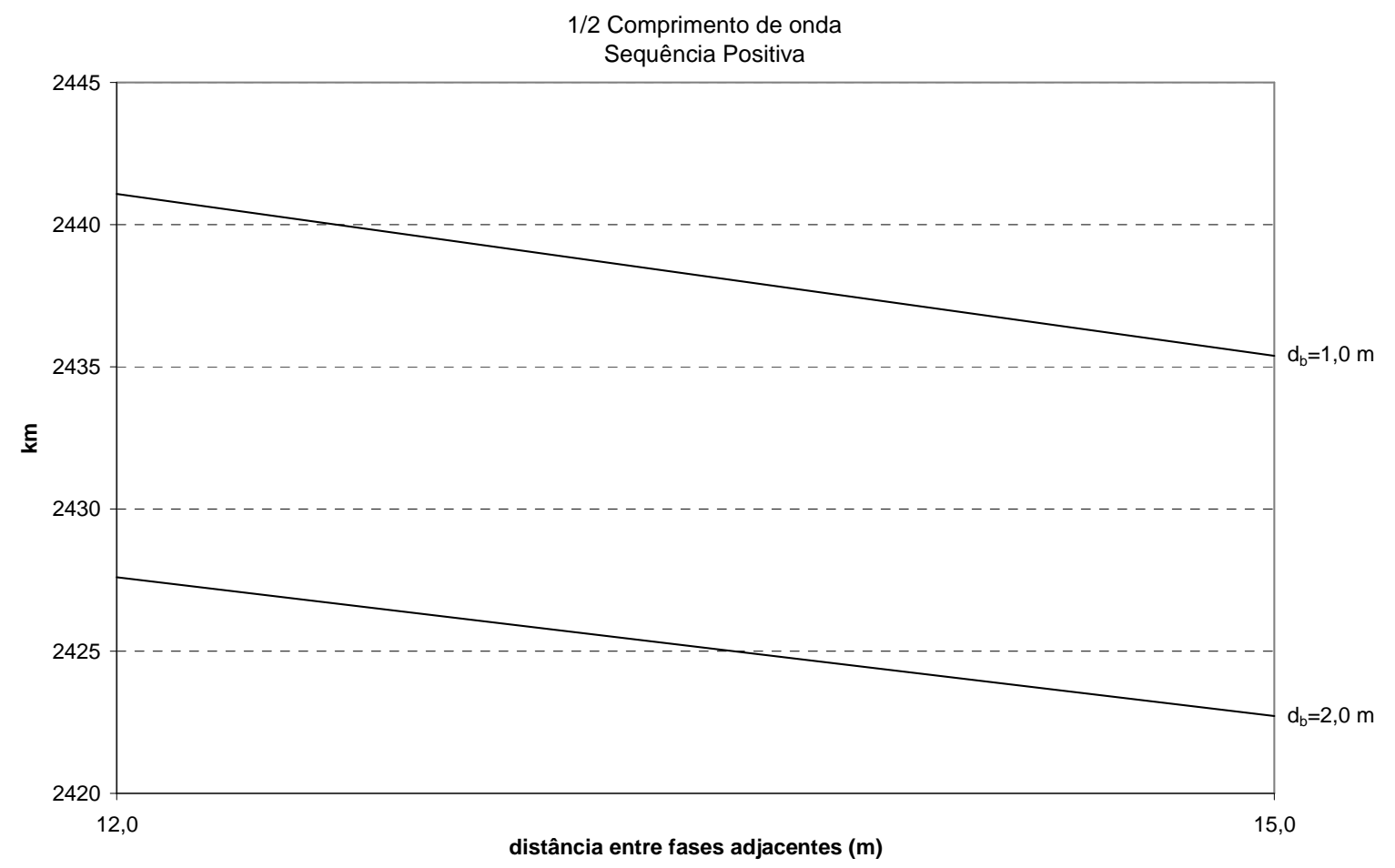

Figura 9 - Metade dos valores calculados para os comprimentos de onda, seqüência positiva, geometria B.

Observa-se que, mesmo com essa nova geometria, não se atinge o objetivo de se obter uma potência característica de 3000 MW. Porém, com o valor obtido (4318 $\mathrm{MW}$ ), ainda é possível observar o comportamento da linha ao transmitir uma potência maior que a potência característica.

\subsubsection{Seleção da geometria dos projetos I, II e III}

Foram então selecionadas as seguintes alternativas para os projetos I, II e III, conforme Tabela 4.

Notar que não há necessidade de se atingir exatamente os objetivos de potência característica (6000MW e $3000 \mathrm{MW})$.

Tabela 4 - Alternativas selecionadas para projetos I, II e III

\begin{tabular}{|c|c|c|c|c|c|c|}
\hline & $\begin{array}{c}\text { 1 ou 2 } \\
\text { linhas? }\end{array}$ & $\begin{array}{c}\text { Geometria } \\
\text { A ou B? }\end{array}$ & Cabo & Alternativa & $\begin{array}{c}\text { Impedância } \\
\text { característica } \\
\text { (módulo) }\end{array}$ & $\begin{array}{c}\text { Potência } \\
\text { característica } \\
\text { de cada linha }\end{array}$ \\
\hline $\begin{array}{c}\text { Projeto } \\
\text { I }\end{array}$ & 1 & A & $\begin{array}{c}6 \times 1590 \mathrm{MCM} \\
(6 \times \text { Lapwing) }\end{array}$ & $\mathrm{d}_{\mathrm{b}}=3 \mathrm{~m}$ & $162 \Omega$ & $6159 \mathrm{MW}$ \\
\hline $\begin{array}{c}\text { Projeto } \\
\text { II }\end{array}$ & 2 & $\mathrm{~A}$ & $\begin{array}{c}6 \times 795 \mathrm{MCM} \\
(6 \times \mathrm{Drake})\end{array}$ & $\mathrm{d}_{\mathrm{b}}=3 \mathrm{~m}$ & $165 \Omega$ & $6042 \mathrm{MW}$ \\
\hline $\begin{array}{c}\text { Projeto } \\
\text { III }\end{array}$ & 2 & $\mathrm{~B}$ & $\begin{array}{c}6 \times 795 \mathrm{MCM} \\
(6 \times D r a k e)\end{array}$ & $\begin{array}{c}\mathrm{d}_{\mathrm{f}}=15 \mathrm{~m} \\
\mathrm{~d}_{\mathrm{b}}=1 \mathrm{~m}\end{array}$ & $231 \Omega$ & $4318 \mathrm{MW}$ \\
\hline
\end{tabular}


Para o projeto III, escolheu-se a alternativa que resultou numa maior impedância característica (menor potência característica).

Seriam obtidos valores mais próximos da impedância desejada (333 $\Omega$ ) se fossem admitidos menores valores de diâmetro $d_{b}$ do feixe. Da mesma forma, maiores valores da distância horizontal $d_{f}$ também contribuiriam para o aumento da potência característica, porém a faixa de servidão necessária seria maior, o que não seria adequado. 


\section{AVALIAÇÃO TÉCNICA DO SISTEMA}

Nesta seção, avalia-se o comportamento das três opções de projeto (I, II e III). São apresentados os resultados de simulação para operação em regime com atenção às perdas resistivas (para diferentes níveis de carga), curtos-circuitos e energizações.

\subsection{Operação em regime}

\subsubsection{Premissas}

O circuito utilizado para estudo é da Figura 10. Es+Xgs representam o equivalente da geração; Ts1, Ts2 e Tr representam transformadores (ou banco de transformadores) de $6000 \mathrm{MVA}$, com relações 20/500 kV, 500/1000/138 kV e 1000/500/138 kV, respectivamente. Er+Xr representam o equivalente do sistema receptor. Considerou-se $X g s=0,25 \mathrm{pu}, X r=0,34 \mathrm{pu}$, e cada um dos transformadores com uma reatância de 0,10 pu. Utilizaram-se como base 1000 kV e 6000 MVA.

As simulações foram realizadas no software ATP. As linhas foram simuladas através de 48 trechos com 52,083 km, o que totaliza um comprimento de $2500 \mathrm{~km}$. Os trechos são identificados por A01,..,A47 em uma das linhas e por B01,..,B47 na outra linha. Dessa forma, foi possível obter os valores de tensão e corrente em cada trecho. Foi utilizado o modelo Bergeron, considerando a linha como transposta. Supõe-se que as linhas são suficientemente separadas, e, portanto, não foram consideradas indutâncias ou capacitâncias mútuas entre elas.

Quando a simulação envolvia apenas uma linha (caso do projeto I, e também do projeto II e III, em caso de indisponibilidade de uma das linhas), era necessário apenas desconectar a segunda linha das barras $V s$ e $V r$.

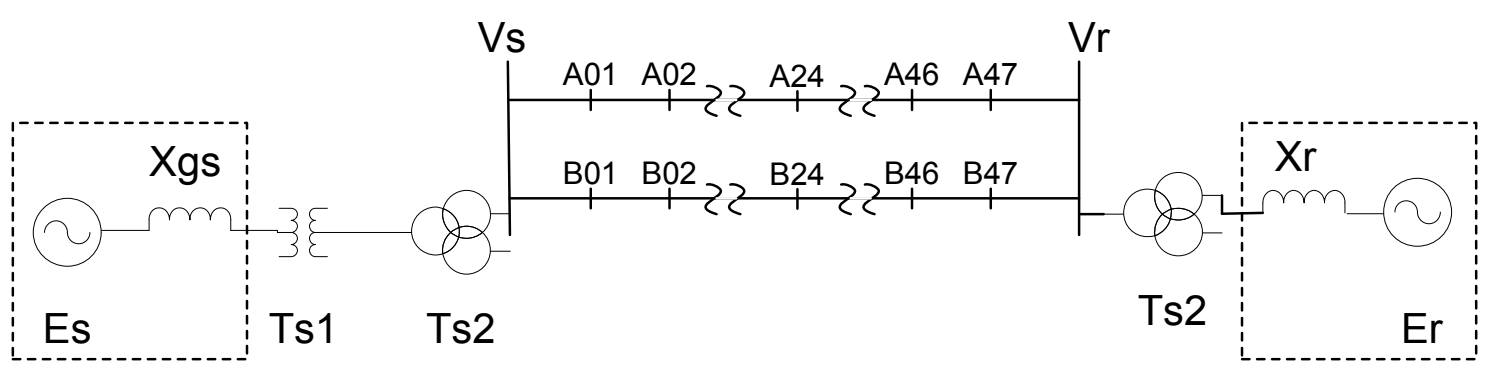

Figura 10 - Circuito utilizado para simulação em regime. 
Salvo quando especificado em contrário, considera-se que o fator de potência na barra Vr é unitário.

Foram simulados os carregamentos propostos na Tabela 1, além do carregamento nulo (linha sem carga). Salvo quando especificado em contrário, a tensão no início da linha foi fixada em 1,05 pu, para carregamento não-nulo, e 1,00 pu para carregamento nulo.

Adotou-se, em todo este trabalho, tensão base de $1000 \mathrm{kV}$ e potência base de 6000 MVA.

\subsubsection{Operação em regime - Projeto I}

Para o projeto I, só há uma linha, com potência característica de 6159 MW. Observa-se na Figura 11 que, conforme esperado, as tensões no meio da linha são reduzidas em caso de carga menor que 1 pu, sendo mínima em caso de carregamento nulo. Na Figura 12, observa-se que as correntes no meio da linha praticamente não variam com a carga. As menores perdas, em percentual da carga, são observadas para carga de 1 pu, próxima à potência característica, conforme Tabela 5.

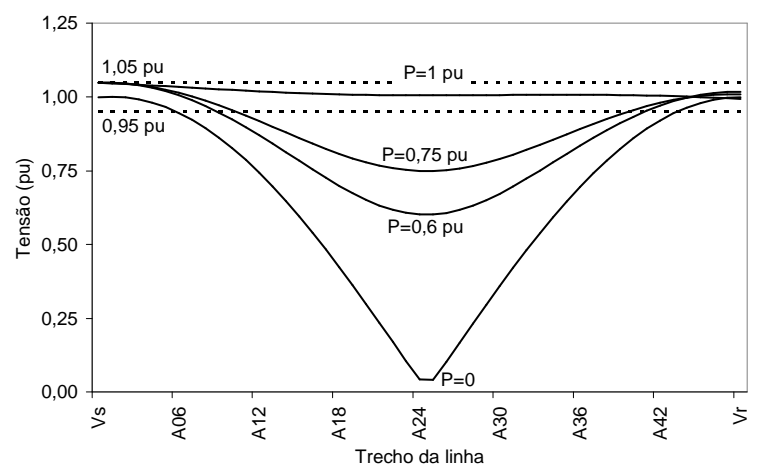

Figura 11 - Tensões ao longo da linhas, projeto I.

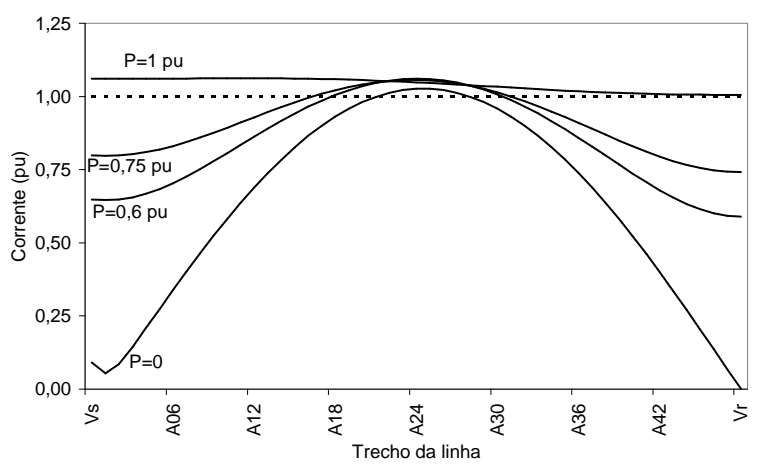

Figura 12 - Correntes ao longo da linha, projeto I. 
Tabela 5 - Perdas na linha, projeto I.

\begin{tabular}{|c|c|c|}
\hline Carga (pu) & Perdas (MW) & Perda (\%) \\
\hline 0,60 & 468 & 13,0 \\
\hline 0,75 & 532 & 11,8 \\
\hline 1,00 & 679 & 11,3 \\
\hline 0,00 & 324 & - \\
\hline
\end{tabular}

\subsubsection{Operação em regime - Projeto II}

Como as duas linhas do Projeto II (potência característica de 6042 MW) são idênticas, apresentam valores iguais de tensão e corrente em todos os trechos. Nas simulações de duas linhas em operação, são apresentadas as tensões e correntes de apenas uma delas.

Observa-se, na Figura 13, que a tensão no meio da linha fica ligeiramente acima de 1 pu para carregamento de 1 pu através de uma única linha. Isso acontece porque a tensão em Vr, nesse caso, é menor que 1 pu, o que reduz a potência característica para menos de $6000 \mathrm{MW}$. Então, ao transmitir $1 \mathrm{pu}=6000 \mathrm{MW}$, a linha está transmitindo um valor ligeiramente maior que a potência característica, o que causa a pequena elevação de tensão no meio da linha. Ao transmitir 1 pu $=6000 \mathrm{MW}$ por duas linhas, a tensão no meio da linha fica próxima a 0,5 pu.

Observa-se que as perdas para o projeto II são maiores que para o projeto I, devido ao cabo utilizado (795 MCM para o projeto II e 1590 MCM para o projeto I).

Também é verificado que as perdas percentuais são maiores em caso de utilização de duas linhas. Isso é explicado pelo fato de que, mesmo que as correntes nas extremidades das linhas sejam bastante reduzidas, as correntes no meio da linha praticamente não variam em módulo. 

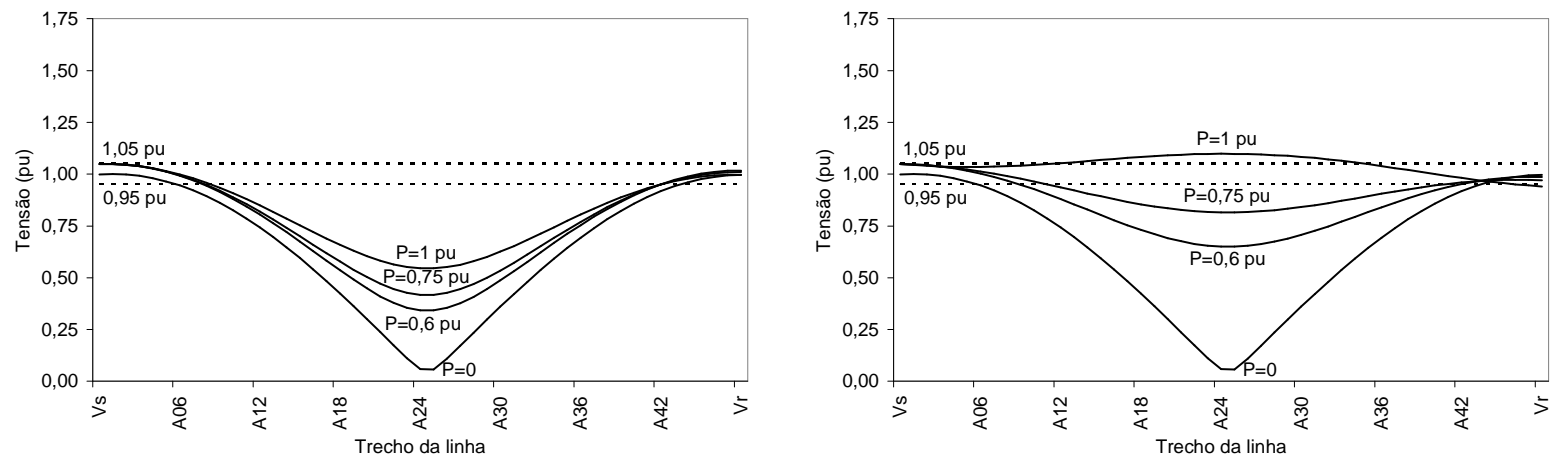

Figura 13 - Tensões ao longo da linha, 2 e 1 linha em operação, respectivamente, projeto II.
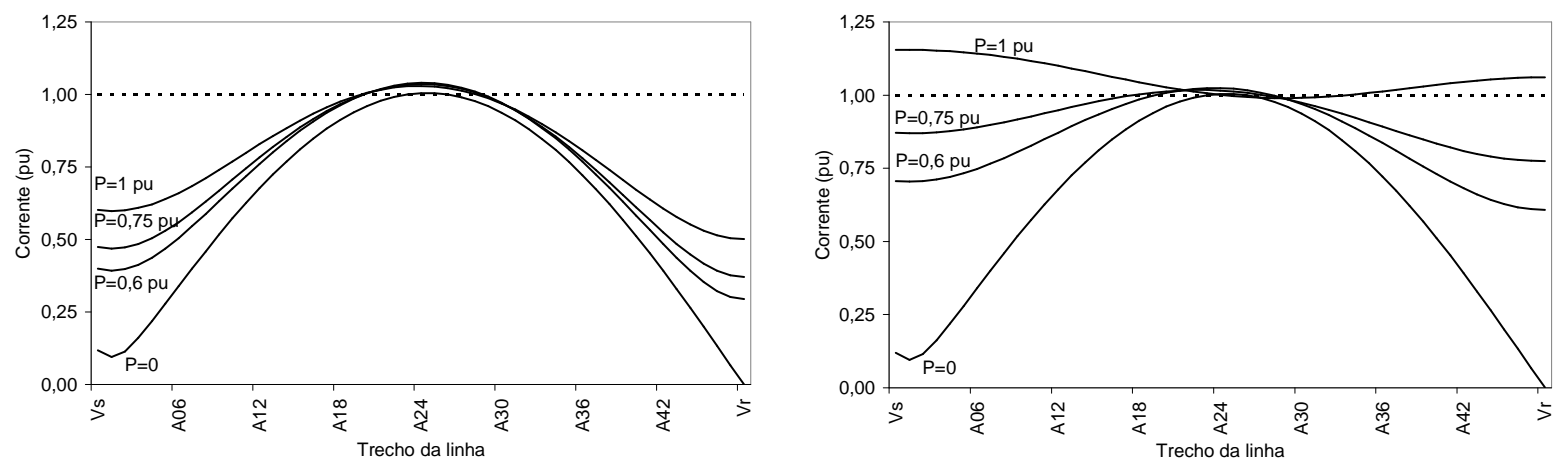

Figura 14 - Correntes ao longo da linha, 2 e 1 linha em operação, respectivamente, projeto II.

Tabela 6 - Perdas totais nas duas linhas, projeto II.

\begin{tabular}{|c|c|c|}
\hline Carga (pu) & $\begin{array}{c}\text { Perdas (MW) } \\
2 \text { linhas } \\
\text { em operação }\end{array}$ & $\begin{array}{c}\text { Perdas (MW) } \\
1 \text { linha } \\
\text { em operação }\end{array}$ \\
\hline 0,60 & 1358 & 843 \\
\hline 0,75 & 1418 & 977 \\
\hline 1,00 & 1549 & 1283 \\
\hline 0,00 & 1140 & 570 \\
\hline
\end{tabular}

\subsubsection{Operação em regime - Projeto III}

Em caso de indisponibilidade de uma das linhas (cada uma com potência característica de $4318 \mathrm{MW})$, a linha remanescente apresenta tensão consideravelmente elevada, no meio da linha, durante todo o período de carga pesada. Por outro lado, as perdas são menores que as simuladas para o projeto II. 

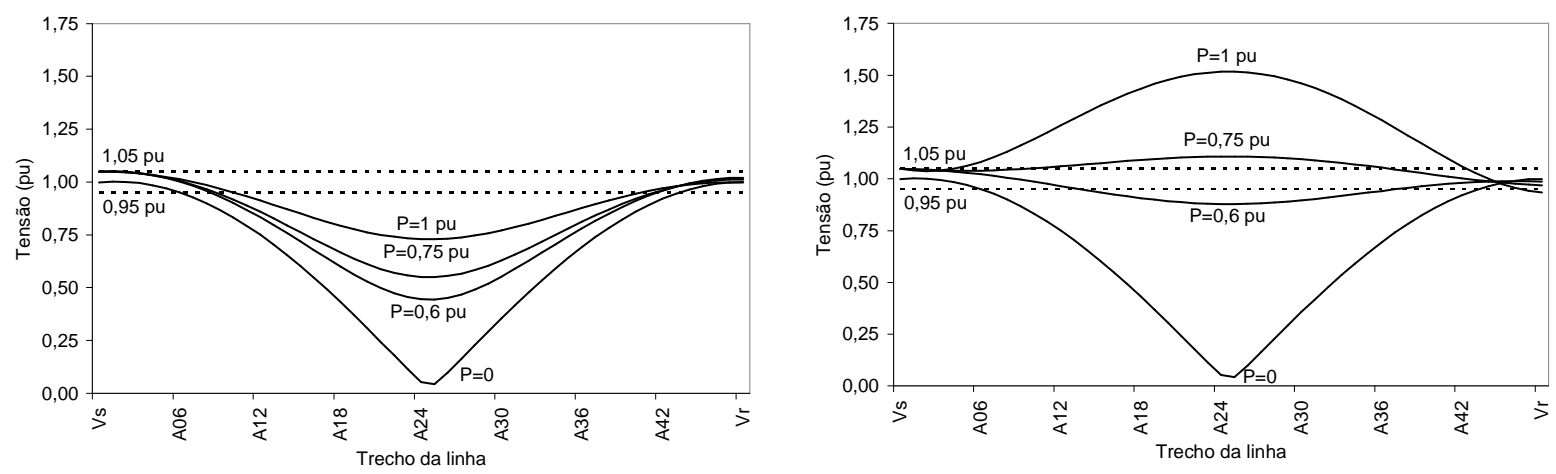

Figura 15 - Tensões ao longo da linha, 2 e 1 linha em operação, respectivamente, projeto III.
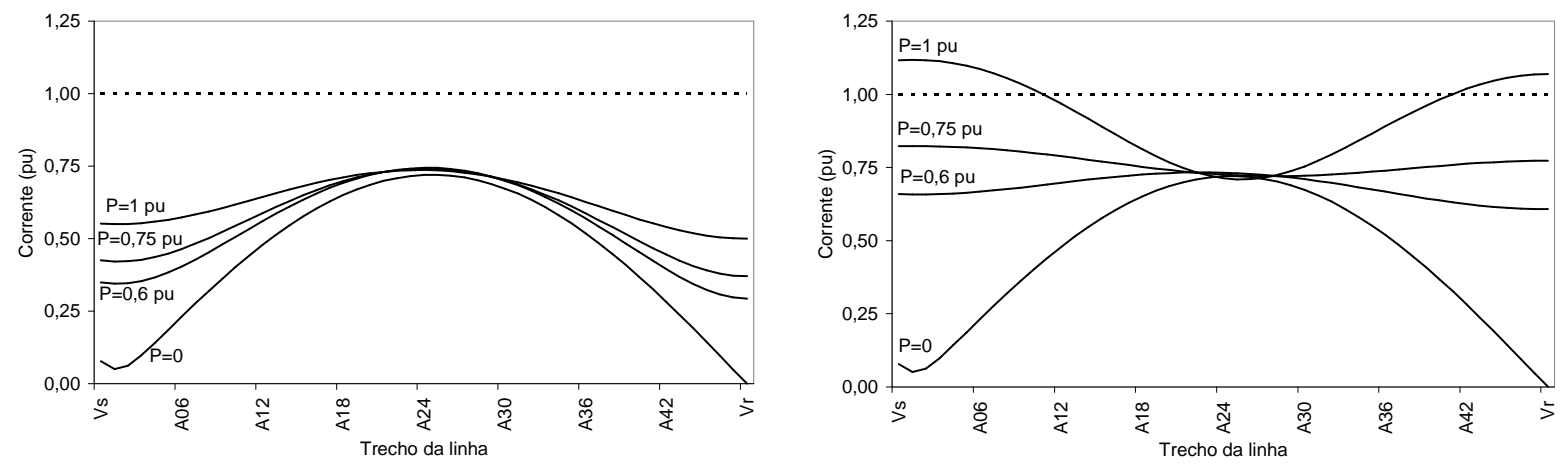

Figura 16 - Correntes ao longo da linha, 2 e 1 linha em operação, respectivamente, projeto III.

Tabela 7 - Perdas totais nas duas linhas, projeto III

\begin{tabular}{|c|c|c|}
\hline Carga (pu) & $\begin{array}{c}\text { Perdas (MW) } \\
2 \text { linhas } \\
\text { em operação }\end{array}$ & $\begin{array}{c}\text { Perdas (MW) } \\
1 \text { linha } \\
\text { em operação }\end{array}$ \\
\hline 0,60 & 759 & 548 \\
\hline 0,75 & 820 & 685 \\
\hline 1,00 & 955 & 1011 \\
\hline 0,00 & 595 & 298 \\
\hline
\end{tabular}

\subsubsection{Operação em regime com fator de potência não-unitário}

Apenas para fins ilustrativos, foram realizadas simulações considerando que o fator de potência na barra Vr seja 0,92. Utilizando-se os dados do projeto II, uma linha em operação, foram comparados as tensões e correntes para:

- Potência ativa de 0,75 pu, fator de potência = 1;

- Potência ativa de 0,75 pu, fator de potência =0,92;

- Potência ativa de 0,69 pu, fator de potência = 0,92 (potência aparente de 0,75 $\mathrm{pu})$. 
Observa-se, na Figura 17, que um fator de potência menor que um na barra receptora ocasiona o aumento de tensões em alguns trechos da linha. Os pontos de máxima tensão não se localizam no meio da linha, como acontece no caso de fator de potência unitário. Os módulos da corrente variam ao longo da linha de forma inversa à tensão. No meio da linha, os módulos da corrente praticamente não se alteram com a redução do fator de potência
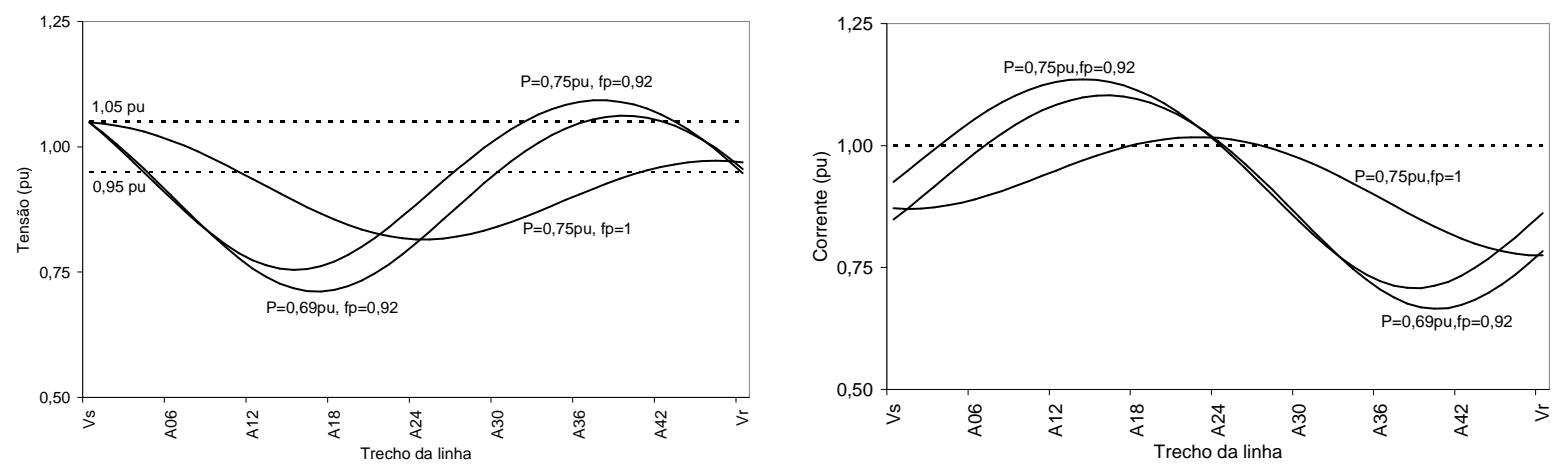

Figura 17 - Tensões e correntes ao longo da linha, para fator de potência 1 e 0,92, 1 linha em operação, projeto II

Este comportamento indica a necessidade de se alocar, no sistema, compensação reativa controlável para ajustar o fator de potência no lado da carga.

\subsubsection{Avaliação de perdas}

Como linhas de meia onda são uma opção para transmissão ponto-a-ponto, envolvendo grandes blocos de energia, faz-se necessário estimar e simular de forma mais precisa as perdas resistivas nas linhas de transmissão em meia onda, pois os grandes valores de corrente envolvidos, ao longo de milhares de quilômetros, fazem com que uma pequena redução percentual de perdas represente uma quantidade considerável de energia não desperdiçada.

\subsubsection{Estratégia para redução de perdas}

Serão utilizados os parâmetros de linha do projeto II, duas linhas em operação (potência característica de $6042 \mathrm{MW}$ ). Inicialmente, as tensões nos terminais são mantidas em valores próximos de 1 pu, chamando essa opção de alternativa (a). Apresentam-se, na Tabela 8, os valores de carga, tensões nos terminais e perdas 
observadas.

Como alternativa (b), foi utilizada a estratégia de ajustar as tensões nos terminais da linha, de forma que o perfil de tensões e de correntes resultante seja o mais plano possível ao longo da linha. Os valores de tensões nos terminais e as perdas observadas são apresentados na Tabela 9.

Tabela 8 - Valores de carga, tensão e perdas, projeto II, 2 linhas em operação, alternativa (a), tensão

\begin{tabular}{|c|c|c|c|}
\hline \multicolumn{4}{|c|}{ da IIIna $=1,05 \mathrm{pu}$} \\
\hline Carga & $|\mathrm{Vs}|$ & $|\mathrm{Vr}|$ & Perdas (MW) \\
\hline $0,6 \mathrm{pu}$ & 1,05 & 1,02 & 1358 \\
\hline $0,75 \mathrm{pu}$ & 1,05 & 1,01 & 1418 \\
\hline $1,00 \mathrm{pu}$ & 1,05 & 1,00 & 1549 \\
\hline \multicolumn{3}{|c|}{ Média ponderada no dia } & 1399 \\
\hline
\end{tabular}

Tabela 9 - Valores de carga, tensão e perdas, projeto II, 2 linhas em operação, alternativa (b)

\begin{tabular}{|c|c|c|c|}
\hline Carga & $|\mathrm{Vs}|$ & $|\mathrm{Vr}|$ & Perdas (MW) \\
\hline $0,6 \mathrm{pu}$ & 0,60 & 0,55 & 766 \\
\hline $0,75 \mathrm{pu}$ & 0,67 & 0,61 & 957 \\
\hline $1,00 \mathrm{pu}$ & 0,78 & 0,70 & 1277 \\
\hline \multicolumn{4}{|l|}{ Média ponderada no dia } \\
\hline
\end{tabular}

A estratégia de operação representada pela alternativa (b), ou seja, variar a tensão no início da linha de acordo com a carga, apresenta as menores perdas.

Os perfis de tensão e corrente para potência transmitida de 0,6 pu, 0,75 pu e $1 \mathrm{pu}$, para as três opções de tensão operativa simuladas, são apresentados na Figura 18 à Figura 20.

Os perfis de correntes observados, nos casos simulados, para $\left|\mathrm{V}_{\mathrm{s}}\right|=1,05 \mathrm{pu}$, resultam em maiores perdas, devido aos elevados valores de correntes no trecho central da linha. Observa-se, também, que as situações de carregamento leve, para $\left|V_{s}\right|=1,05 \mathrm{pu}$, apresentam perdas percentuais maiores. 

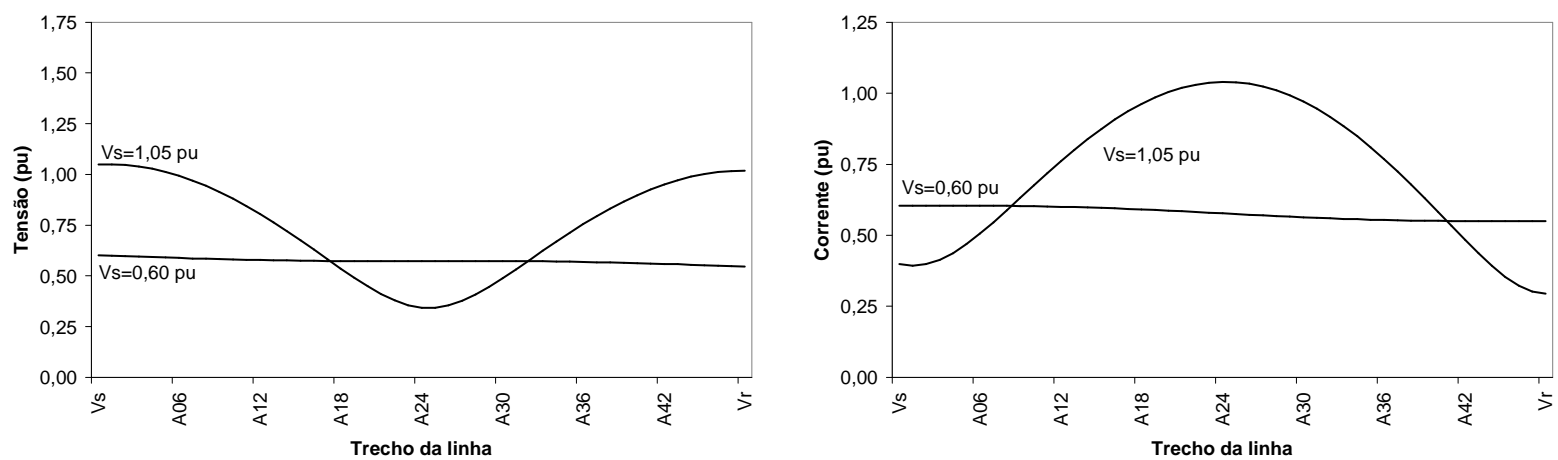

Figura 18 - Perfis de tensão e corrente, para potência transmitida de 0,6 pu, para diversos valores de tensão operativa
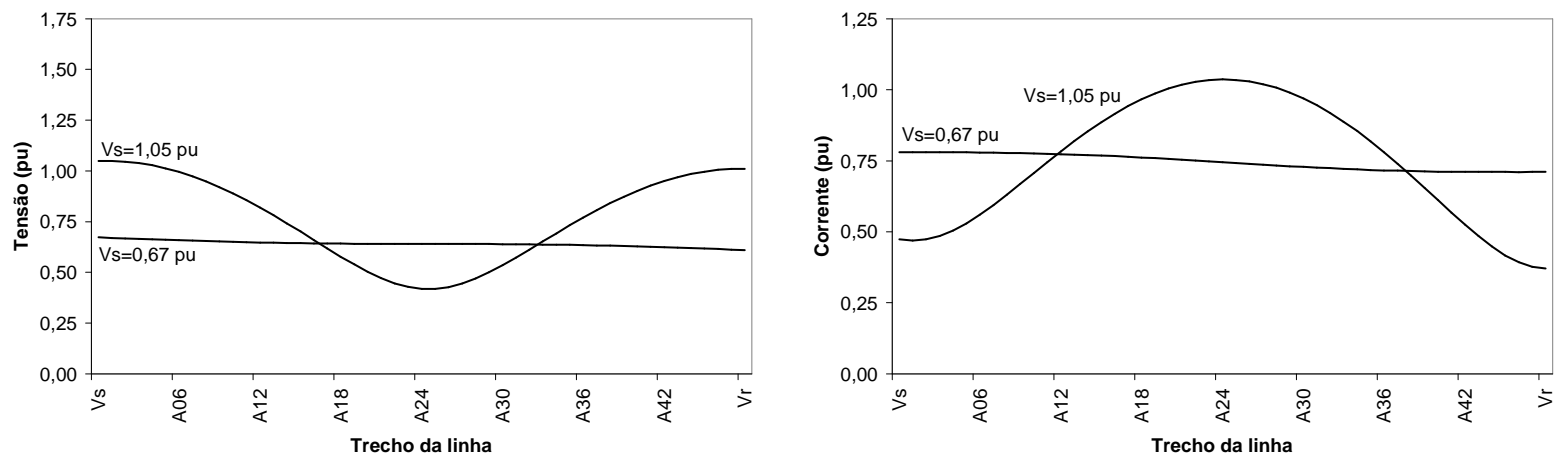

Figura 19 - Perfis de tensão e corrente, para potência transmitida de $0,75 \mathrm{pu}$, para diversos valores de tensão operativa
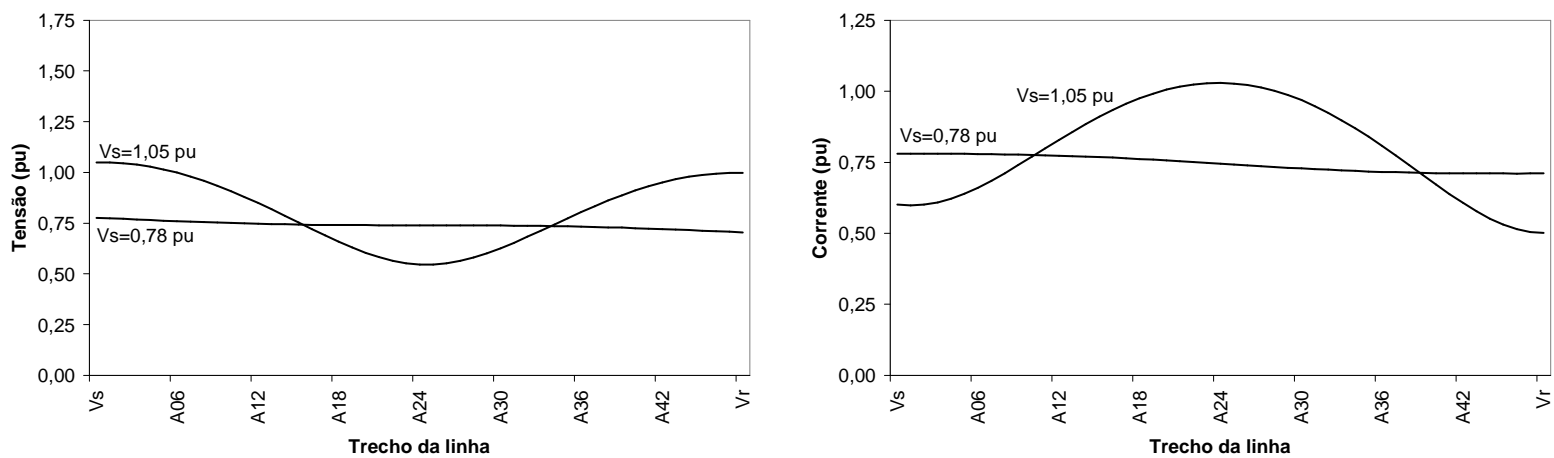

Figura 20 - Perfis de tensão e corrente, para potência transmitida de 1 pu, para diversos valores de tensão operativa

\subsection{Metodologia de estimativa de perdas}

A alternativa (a) abordada anteriormente (seção 5.1.6.1), além de resultar em maiores perdas, apresenta o inconveniente de tornar difícil a sua estimativa, pois as perdas não são proporcionais à potência transmitida. Para estimar as perdas para vários níveis de potência transmitida, é necessário realizar uma simulação, utilizando, por exemplo, o software ATP, para cada nível de potência transmitida. 
Caso a alternativa (b) seja utilizada, ou seja, as tensões sejam ajustadas de acordo com a potência transmitida, poderia-se apenas fazer uma simulação para carga pesada, e as perdas para cargas média e leve podem ser determinadas de forma proporcional à potência transmitida.

Ao se utilizar a alternativa (b), mais vantajosa em termos de redução de perdas, a utilização do ATP para estimativa de perdas ainda é recomendada (ainda que apenas a simulação em carga pesada seja necessária), pois é possível levar em consideração a queda de tensão na linha. Para os casos simulados para a alternativa (b), a queda entre o terminal emissor e o terminal receptor foi da ordem de $10 \%$, função do condutor, da geometria utilizada e do comprimento da linha. Para a alternativa (b), a queda de tensão percentual é a mesma para carga leve, média e pesada.

\subsubsection{Utilização de reator no meio da linha}

Foram realizadas investigações quanto à possibilidade de reduzir as sobretensões no meio da linha, em caso de potência transmitida superior à potência nominal, através da utilização de um reator em paralelo no meio da linha.

Utilizando-se os parâmetros de linha do projeto III (potência característica de 4318 MW), simulou-se o caso de um circuito em operação transmitindo $6000 \mathrm{MW}$, de acordo com a Figura 21.

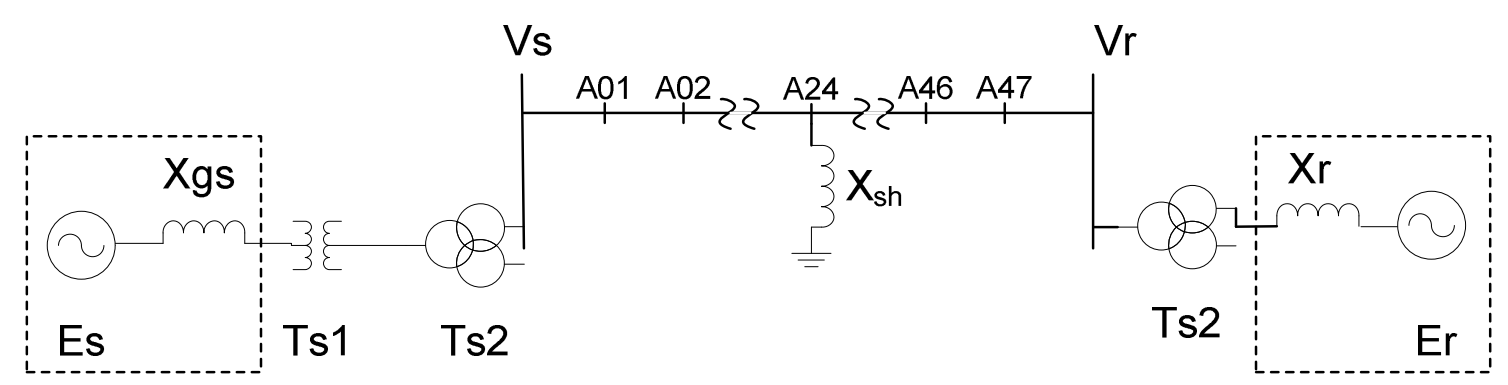

Figura 21 - Circuito utilizado para simulação da utilização de reator no meio da linha

Foram propostos reatores de potência reativa nominal de 1000 Mvar e 1500 Mvar. Observa-se que a tensão no final da linha é bastante reduzida com a utilização dos reatores, sem que haja nenhuma redução da tensão do meio da linha, e ocorrem sobretensões ainda maiores em outros pontos. 


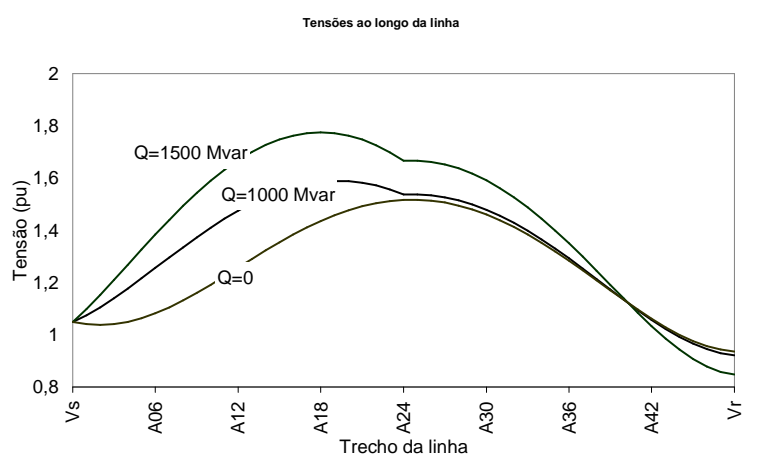

Figura 22 - Perfis de tensão, para o projeto II, transmitindo $6000 \mathrm{MW}$ com em um único circuito: com a utilização de reator de 1000 Mvar e de 1500 Mvar em paralelo no meio da linha, em comparação com nenhum reator no meio da linha $(Q=0)$

Conclui-se, então, que o reator em paralelo não é uma solução para as sobretensões de longa duração decorrentes de carregamento superior à potência característica.

\subsection{Curto-circuito}

Foram realizadas simulações de curtos-circuitos monofásicos, conforme Figura 23 e Figura 24. Os parâmetros de linha são correspondentes ao projeto II (cabo Drake, $\mathrm{Pc}=6041 \mathrm{MW})$.

Os curtos monofásicos foram simulados em alguns pontos ao longo da linha para verificar o comportamento das correntes nos terminais Vs e Vr. Utilizou-se uma resistência de curto na torre de 20 ohms. O curto monofásico foi aplicado na fase A, em vários pontos da linha, sendo escolhidos, para este relatório, os valores obtidos nos pontos F1, F2, F3, F4 e F5, no instante $t=50 \mathrm{~ms}$ ( 3 ciclos de $60 \mathrm{~Hz}$ ). Foram observadas as correntes das três fases, tanto para a linha em curto quanto para a linha sã. Os valores foram obtidos nas extremidades das linhas, para analisar o desempenho de eventual proteção que utilize sinais de corrente. Buscou-se também observar algum eventual valor notável de tensão ao longo da linha, conforme sugerido em [1]. 


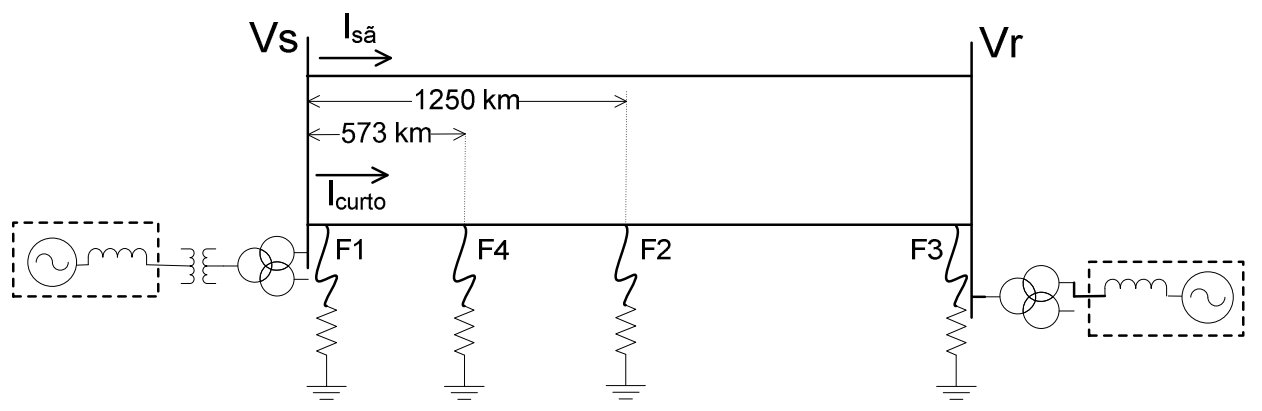

Figura 23 - Circuito utilizado para simulações de curtos-circuitos, 2 linhas em operação

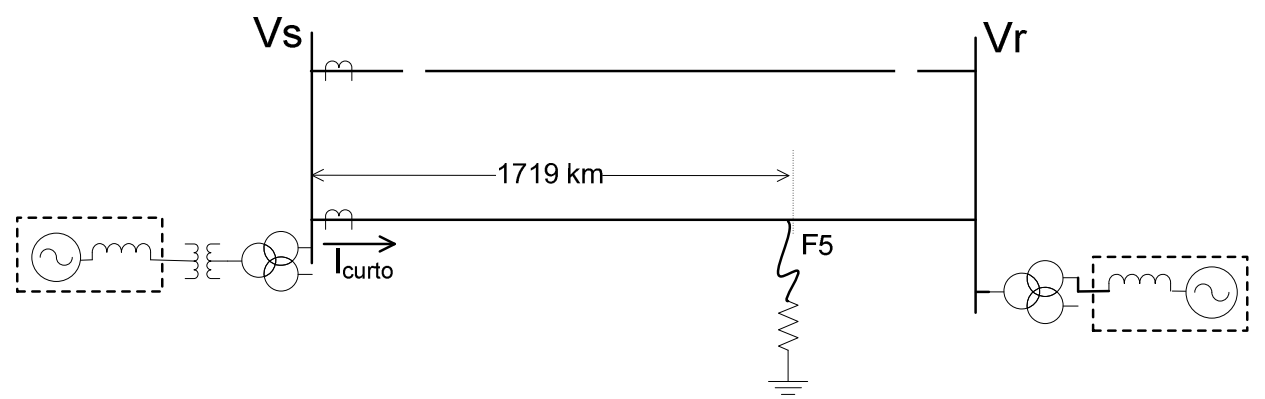

Figura 24 - Circuito utilizado para simulações de curtos-circuitos, 1 linha em operação

Para o curto em F1, ponto bastante próximo do início da linha, foram obtidas as curvas da Figura 25. Na linha em curto, observa-se um sensível aumento na corrente da fase A no início da linha. No início da linha em curto, bem como dos dois terminais da linha sã, é notado um ligeiro aumento da corrente na fase B. 

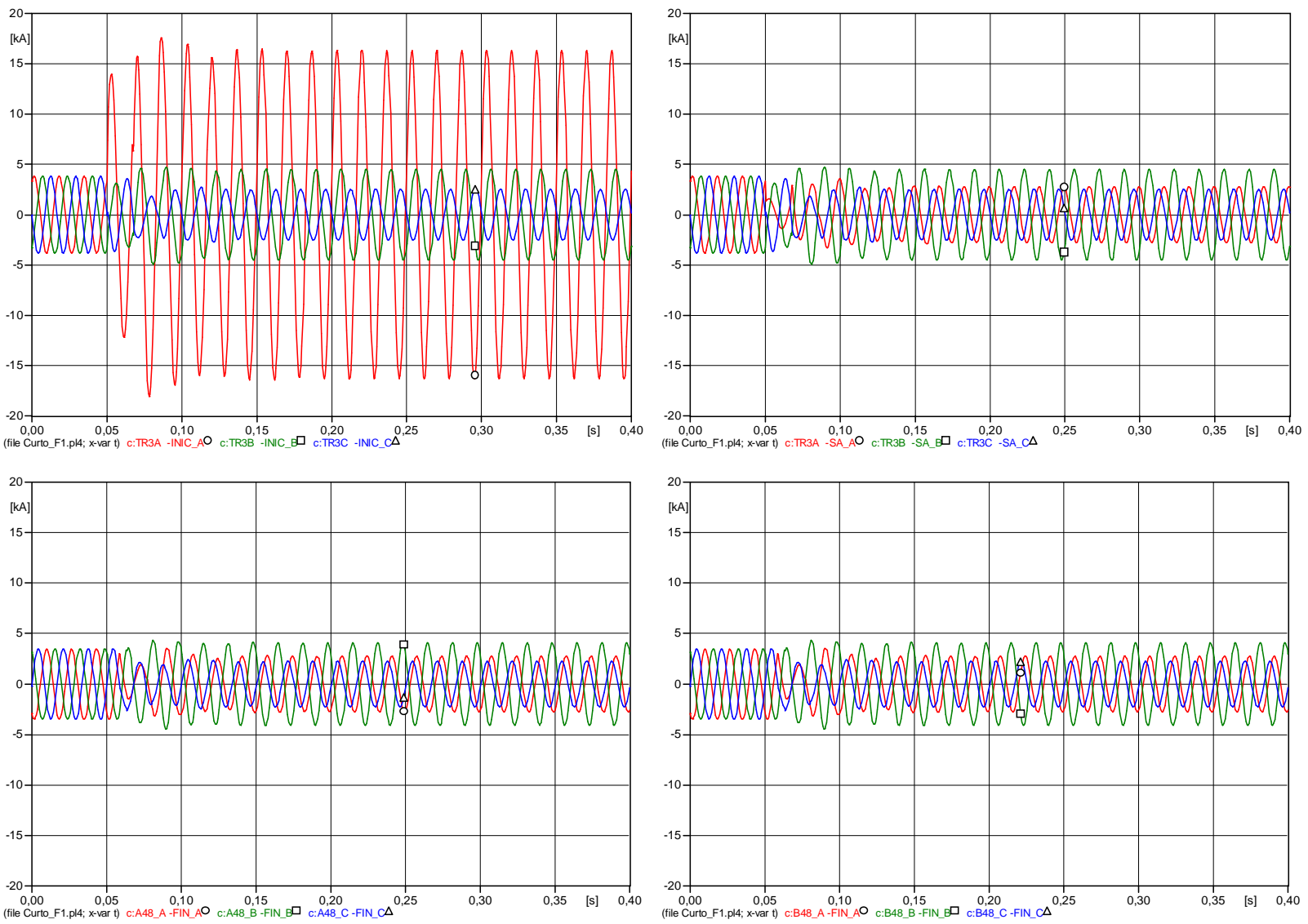

Figura 25 - Curto em F1 - Correntes no início da linha em curto, no início da linha sã, no final da linha em curto e no final da linha sã, respectivamente.

Para o curto em F2, localizado no meio da linha, as correntes no início e no final da linha em curto, na fase $A$, sofrem uma sensível redução, conforme Figura 26. As correntes da fase A, no final e no início da linha sã, fase A, aumentam de maneira perceptível. 

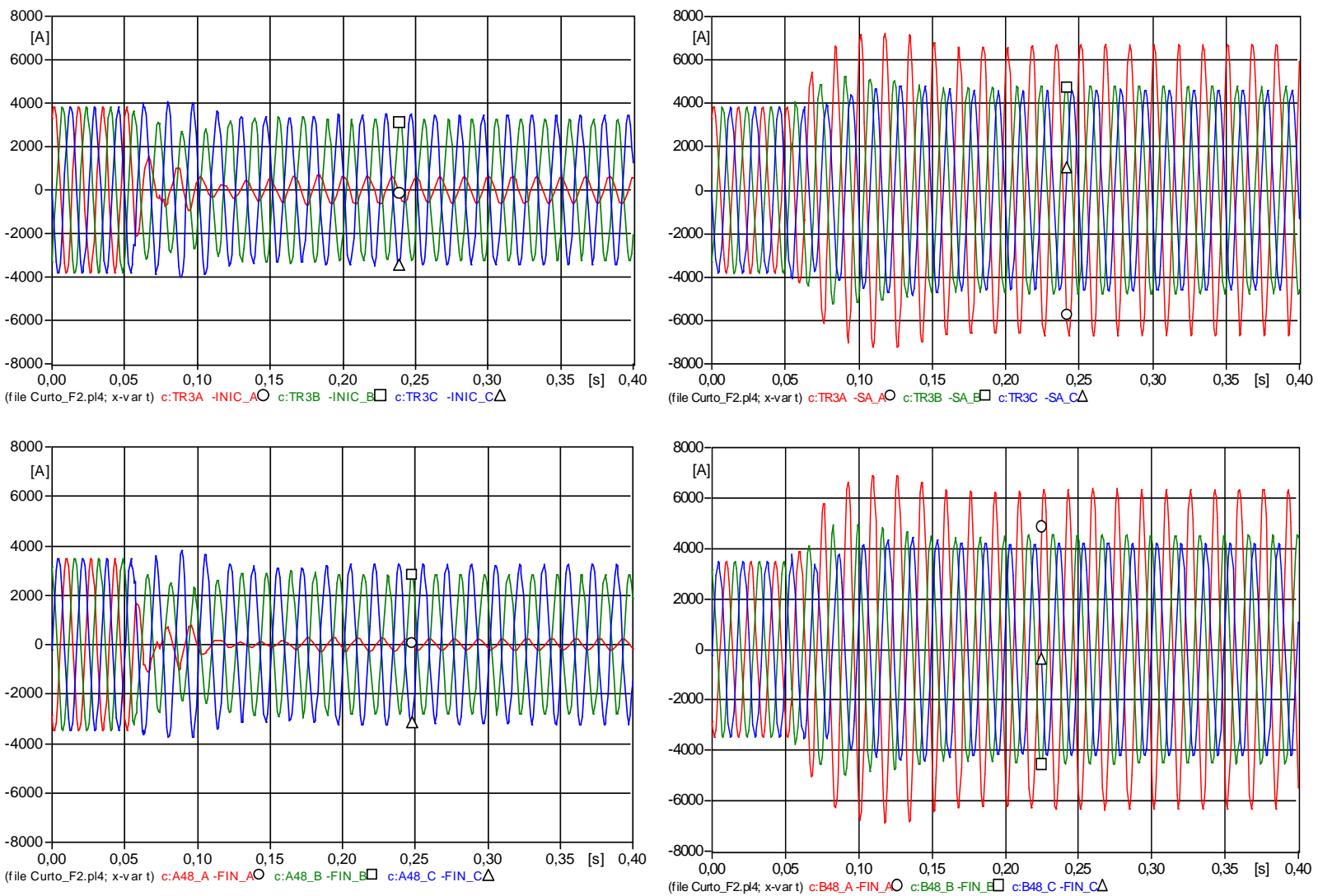

Figura 26 - Curto em F2 - Correntes no início da linha em curto, no início da linha sã, no final da linha em curto e no final da linha sã, respectivamente.

Para o curto em F3, localizado no final da linha, a corrente no início da linha em curto apresenta ligeiro aumento nas fases $\mathrm{A}$ e $\mathrm{C}$, e uma ligeira redução na fase $\mathrm{B}$. $\mathrm{O}$ mesmo comportamento ocorre nos dois terminais da linha sã. Já a corrente no final da linha em curto sofre um aumento pronunciado. 

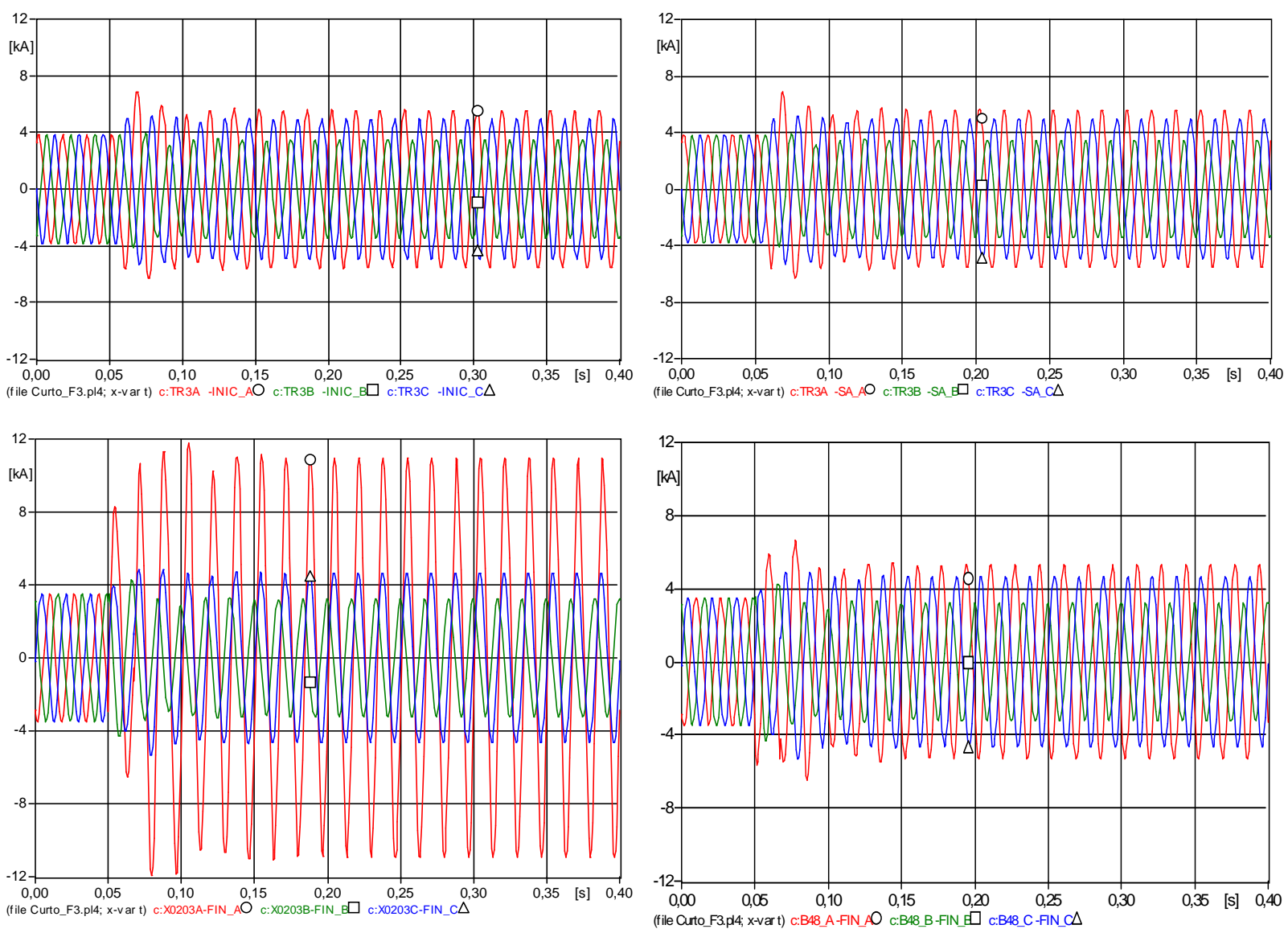

Figura 27 - Curto em F3 - Correntes no início da linha em curto, no início da linha sã, no final da linha em curto e no final da linha sã, respectivamente.

Os valores de pico das correntes das Figura 25 a Figura 27 estão apresentados na Tabela 10.

Tabela 10 - Valores de pico de correntes nos inícios das linhas para curtos fase A-terra em F1, F2 e F3.

\begin{tabular}{|c|c|c|c|c|c|c|}
\cline { 2 - 7 } \multicolumn{1}{c|}{} & \multicolumn{3}{c|}{$\begin{array}{c}\text { Correntes no início da linha } \\
\text { em curto }\end{array}$} & \multicolumn{3}{c|}{$\begin{array}{c}\text { Correntes no início da linha } \\
\text { sã }\end{array}$} \\
\cline { 2 - 7 } \multicolumn{1}{c|}{} & $\mathrm{I}(\mathrm{A})$ & $\mathrm{I}(\mathrm{B})$ & $\mathrm{I}(\mathrm{C})$ & $\mathrm{I}(\mathrm{A})$ & $\mathrm{I}(\mathrm{B})$ & $\mathrm{I})$ \\
\hline Pré-falta & 3824 & 3824 & 3824 & 3824 & 3824 & 3824 \\
\hline Curto em F1 & 16261 & 4483 & 2514 & 2793 & 4499 & 2522 \\
\hline Curto em F2 & 607 & 3250 & 3454 & 6695 & 4791 & 4619 \\
\hline Curto em F3 & 5578 & 3454 & 4929 & 5578 & 3454 & 4929 \\
\hline
\end{tabular}

Observa-se que o curto monofásico no meio da linha não seria facilmente detectado por funções de proteção baseadas em sobrecorrente. Dessa forma, são necessários estudos adicionais (fora do escopo deste documento) para definir funções de proteção adequadas a linhas de meia onda. 
Para a verificação de tensões ao longo da linha, foram realizadas simulações de curtos em diversas posições, sendo escolhidos os valores mais significativos para esse relatório, que são os obtidos em F4 e F5.

Para o curto em F4, buscaram-se, nos resultados, os maiores valores de tensão ao longo da linha em curto e da linha sã. Na linha em curto, o maior valor de tensão observado ocorreu na fase C, a $1771 \mathrm{~km}$ do início da linha, com um valor de 1,40 pu, conforme Figura 28. Na linha sã, o maior valor de tensão observado ocorreu na fase A, a 1146 km do início da linha, com um valor de 1,51 pu, conforme Figura 29.

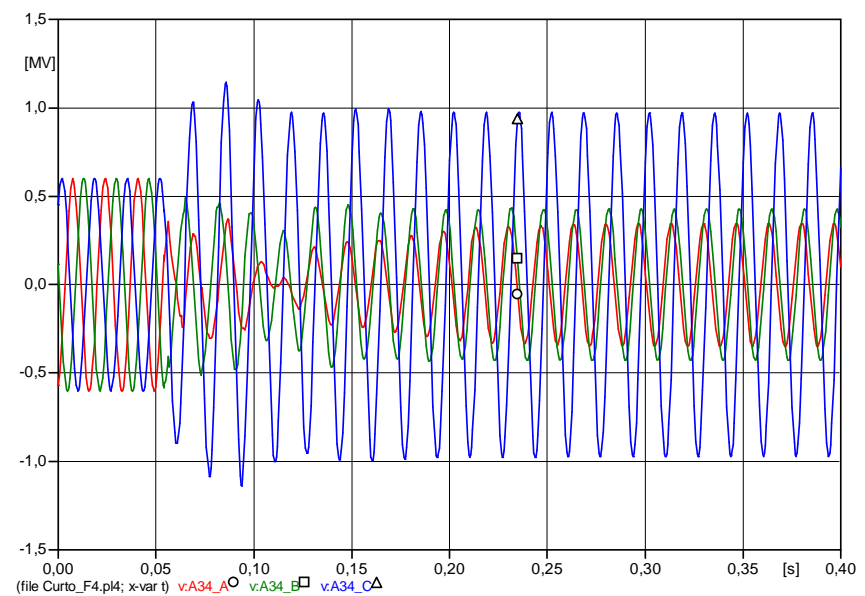

Figura 28 - Curto em F4 - Tensões em um ponto localizado a 1771 km do início da linha em curto.

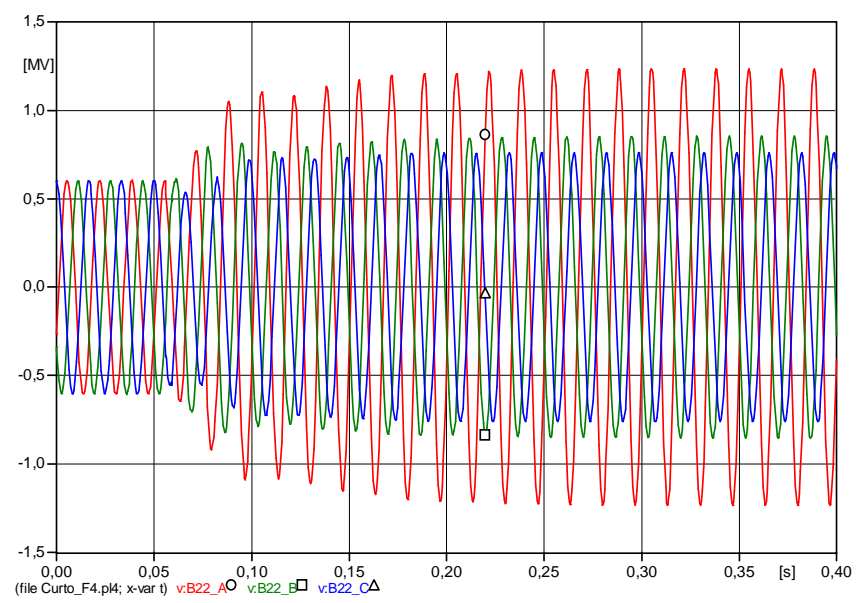

Figura 29 - Curto em F4 - Tensões em um ponto localizado a 1146 km do início da linha sã.

Para o caso de curto em F5 (uma única linha em operação), verificou-se o maior valor de tensão em um ponto localizado a $781 \mathrm{~km}$ do início da linha, com um valor de 3,5 pu na fase A, conforme Figura 30. 


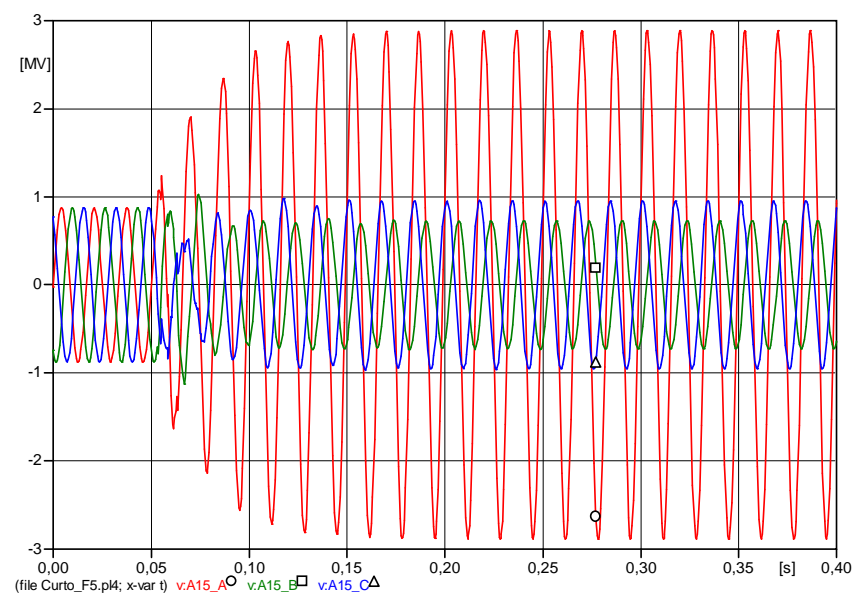

Figura 30 - Curto em F5 - Tensões em um ponto localizado a 781 km do início da linha em curto.

A partir das informações das Figura 28 a Figura 30, conclui-se que a coordenação de isolamento da linha deve levar em conta a ocorrência de sobretensões decorrentes de curtos na própria linha ou na linha adjacente.

\subsection{Energizações}

Foram realizadas simulações para observar os transitórios de energização de uma linha de meia onda, e comparar seu comportamento com 0 das linhas convencionais. Conforme recomendado em [1], a linha é energizada pelo terminal emissor (Vs), conforme Figura 31. Considera-se que a outra linha ainda está desligada.

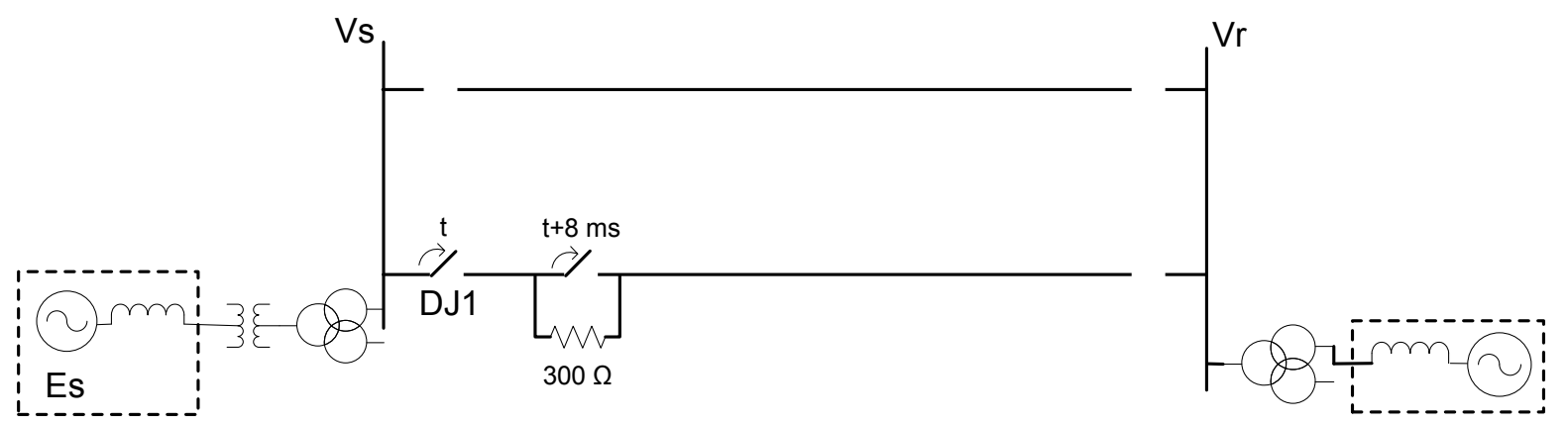

Figura 31 - Circuito utilizado para simulação de energização

Foram utilizados os parâmetros do projeto II. Nesta simulação, a tensão Es utilizada é de 1 pu. Considera-se a utilização de um resistor de pré-inserção de $300 \Omega$, com o objetivo de reduzir as sobretensões transitórias após a energização. Esse resistor 
fica em série com a linha assim que ela é energizada, e assim permanece por um intervalo de $8 \mathrm{~ms}$, após o qual ele é retirado através de um disjuntor de by-pass.

Como as máximas tensões observadas são influenciadas pelos instantes de fechamento das fases do disjuntor, a simulação foi realizada em duas etapas. Em primeiro lugar, foram simulados fechamentos simultâneos das três fases em diversos ângulos do ciclo de tensão, espaçados de 15 ․ Para essa simulação, foi utilizado o modelo de chave sistêmica do ATP para representar o disjuntor. Foi verificado qual instante de fechamento $t_{f}$ resultava em tensões mais severas.

$\mathrm{Na}$ segunda etapa, foi utilizado o modelo de chave estatística do ATP para simular 200 energizações, com instantes de fechamento do disjuntor dispersos em torno de $t_{f}$.

Os resultados de tensões ao longo da linha são apresentados na Figura 32 e na Tabela 11.

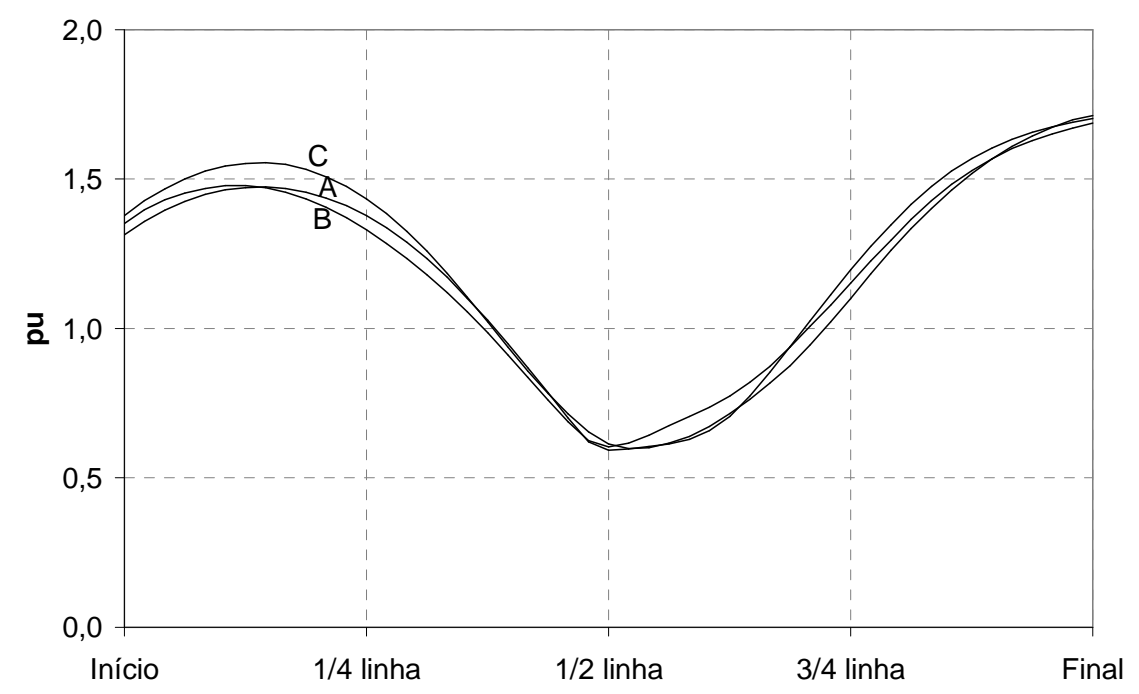

Figura 32 - Tensões médias durante energização 
Tabela 11 - Estatísticas das tensões máximas durante energização

\begin{tabular}{|c|c|c|c|c|c|}
\cline { 2 - 6 } \multicolumn{1}{c|}{} & Início & $1 / 4$ linha & $1 / 2$ linha & $3 / 4$ linha & Final \\
\hline média A $(\mathrm{pu})$ & 1,31 & 1,38 & 0,59 & 1,20 & 1,70 \\
\hline $\begin{array}{c}\text { desvio padrão A } \\
\text { (em relação à média) }\end{array}$ & $3,4 \%$ & $10,3 \%$ & $5,6 \%$ & $6,1 \%$ & $8,7 \%$ \\
\hline média B $(\mathrm{pu})$ & 1,35 & 1,33 & 0,60 & 1,15 & 1,69 \\
\hline $\begin{array}{c}\text { desvio padrão B } \\
\text { (em relação à média) }\end{array}$ & $6,1 \%$ & $5,4 \%$ & $5,6 \%$ & $8,0 \%$ & $11,0 \%$ \\
\hline média C (pu) & 1,38 & 1,43 & 0,61 & 1,10 & 1,71 \\
\hline $\begin{array}{c}\text { desvio padrão C } \\
\text { (em relação à média) }\end{array}$ & $4,4 \%$ & $7,3 \%$ & $8,6 \%$ & $8,9 \%$ & $8,8 \%$ \\
\hline
\end{tabular}

As máximas tensões são observadas no trecho final da linha, da mesma forma que para linhas mais curtas. Nos trechos intermediários, as tensões são bastante reduzidas.

Observa-se, então, que a linha de meia onda não apresenta maiores problemas de sobretensões durante o transitório eletromagnético de sua energização. 


\section{CONCLUSÕES}

Como resultado desse trabalho, apresentam-se as seguintes conclusões:

- A escolha do valor adequado da potência característica é particularmente importante para a linha de meia onda. Este parâmetro determina a maior ou menor ocorrência de sobretensões em regime, bem como a amplitude dessas sobretensões. Também influencia as perdas resistivas da linha. A definição da potência característica deve ser baseada em premissas tais como curva de carga, possibilidade de atendimento da carga por outras linhas, entre outras.

- Recomenda-se a utilização de técnicas que facilitem a definição de arranjos dos feixes de subcondutores, de forma que seja atingida a potência característica desejada.

- As perdas resistivas na linha podem ser minimizadas pela adoção de uma estratégia de operação que ajuste convenientemente a tensão operativa de acordo com a potência transmitida no momento. Esse ajuste de tensão pode ser feito através de tapes com comutadores sob carga nos transformadores nos terminais da linha, que devem ser incluídos nos custos do sistema.

- Para adequação operacional de linhas de meia onda, é necessário prover equipamentos para ajuste do fator de potência na carga, para evitar sobretensões decorrentes de baixo fator de potência.

- As simulações de curtos-circuitos monofásicos evidenciaram que funções de proteção baseadas em sinais de corrente convencionais não podem ser aplicadas em linhas de meia onda.

- A coordenação de isolamento da linha deve levar em conta a ocorrência de sobretensões decorrentes de curtos na própria linha ou na linha adjacente.

A linha de meia onda representa uma alternativa interesssante para transmissão ponto-a-ponto de grandes blocos de energia. Porém, para que ela possa se tornar competitiva em relação à transmissão em corrente contínua, fazem-se necessários estudos adicionais, dentre eles:

- Estudos de estabilidade;

- Simulações de religamentos e rejeições de carga;

- Modelamento da linha levando em conta o efeito corona;

- Estudo de funções de proteção aplicáveis; 
- Estimativa de custos de construção da linha, para fins de comparação com linhas de transmissão em corrente contínua. 


\section{ANEXO A - EXPRESSÕES MATEMÁTICAS PARA LINHAS DE MEIA ONDA}

Nesta seção, são deduzidas algumas expressões matemáticas que explicam 0 comportamento de linhas de meia onda em regime permanente. As expressões aqui apresentadas podem ser verificadas de forma gráfica na seção 5.1 .

Dada uma linha de transmissão com resistência por quilômetro $r$, reatância indutiva por quilômetro $x$ e susceptância capacitiva por quilômetro $b$, definem-se a impedância série por quilômetro $z$ e a admitância paralelo $y$ desta linha pelas expressões [6]:

$z=r+j \cdot x$

$y=j \cdot b$

A partir dessas últimas, a constante de propagação $\gamma$ é determinada pela expressão [6]:

$\gamma=\sqrt{z \cdot y}=\alpha+j \cdot \beta$

$\alpha$ (parte real de $\gamma$ ) é chamada de constante de atenuação. É nula para linhas consideradas sem perdas.

$\beta$ (parte imaginária de $\gamma$ ) é chamada de constante de fase.

O comprimento de onda das tensões e correntes para uma dada linha de transmissão é determinado por

$\lambda=\frac{2 \pi}{\beta}=\frac{2 \sqrt{2} * \pi}{\sqrt{b} \sqrt{\sqrt{\mathrm{r}^{2}+x^{2}}+x}}$

Para linhas consideradas sem perdas,

$\lambda \approx \frac{1}{f \sqrt{L C}} \approx \frac{c}{f}$

$f$ é a frequência das tensões e correntes senoidais (50 ou $60 \mathrm{~Hz}$ ), L é a indutância por quilômetro, $\mathrm{C}$ é a capacitância por quilômetro $c$ é a velocidade de propagação da 
luz no vácuo. A velocidade de propagação da linha sem perdas, $1 / \sqrt{L C}$, é próxima à velocidade da luz.

Para os exemplos de linhas utilizados neste trabalho, a expressão (A4) fornece valores cerca de $50 \mathrm{~km}$ menores que o da expressão aproximada.

A impedância característica $Z_{c}$ é dada pela expressão

$$
Z_{c}=\sqrt{\frac{z}{y}}
$$

A potência característica da linha, para uma dada tensão $V_{r}$ no terminal receptor, é dada por

$S_{c}=\frac{\left|V_{r}\right|^{2}}{Z_{c}^{*}}$

onde $Z_{c}^{*}$ é o complexo conjugado de $Z_{c}$,

Dado o comprimento $l$ da linha, as tensões e correntes no início da linha, ou seja, no terminal emissor, $V_{s}$ e $I_{s}$, são dadas pelas expressões [6]

$V_{s}=\cosh (\gamma \cdot l) \cdot V_{r}+Z_{c} \cdot \operatorname{senh}(\gamma \cdot l) \cdot I_{r}$

$I_{s}=\frac{\operatorname{senh}(\gamma \cdot l)}{Z_{c}} \cdot V_{r}+\cosh (\gamma \cdot l) \cdot I_{r}$

Essas expressões são aplicadas para linhas longas, ou seja, acima de $340 \mathrm{~km}$. Para linhas mais curtas, essas expressões, apesar de ainda válidas, podem ser bastante simplificadas.

Se a razão entre a tensão e a corrente no terminal receptor, ou seja, no final da linha, é $\frac{V_{r}}{I_{r}}=Z_{r}$, onde $Z_{r}$ é uma impedância fictícia e variável com o carregamento da linha, de forma que a potência $S_{r}$ no final da linha é inversamente proporcional a $Z_{r}$, pela expressão $S_{r}=\frac{\left|V_{r}\right|^{2}}{Z_{r}{ }^{*}}$, então:

$V_{s}=\cosh (\gamma \cdot l) \cdot V_{r}+Z_{c} \cdot \operatorname{senh}(\gamma \cdot l) \cdot \frac{V_{r}}{Z_{r}}$

$V_{s}=V_{r} \cdot\left(\cosh (\gamma \cdot l)+\frac{Z_{c}}{Z_{r}} \cdot \operatorname{senh}(\gamma \cdot l)\right)$ 


$$
\begin{aligned}
& I_{s}=\frac{\operatorname{senh}(\gamma \cdot l)}{Z_{c}} \cdot Z_{r} \cdot I_{r}+\cosh (\gamma \cdot l) \cdot I_{r} \\
& I_{s}=I_{r} \cdot\left(\cosh (\gamma \cdot l)+\frac{Z_{r}}{Z_{c}} \cdot \operatorname{senh}(\gamma \cdot l)\right)
\end{aligned}
$$

Podem-se utilizar estas expressões para determinar tensões e correntes em pontos intermediários da linha. Para o ponto intermediário que dista $\Delta l$ do terminal receptor, ou seja, que fica a uma distância $l-\Delta l$ do terminal emissor, onde $l$ é o comprimento da linha, a tensão e a corrente são calculadas pelas expressões

$V(l-\Delta l)=V(l) \cdot\left(\cosh (\gamma \cdot \Delta l)+\frac{Z_{c}}{Z_{r}} \cdot \operatorname{senh}(\gamma \cdot \Delta l)\right)$

$I(l-\Delta l)=I(l) \cdot\left(\cosh (\gamma \cdot \Delta l)+\frac{Z_{r}}{Z_{c}} \cdot \operatorname{senh}(\gamma \cdot \Delta l)\right)$

onde $V(l)=V_{r}$ e $I(l)=I_{r}$

A partir das equações (A11) e (A12), podemos verificar algumas propriedades interessantes das linhas de meia onda

\section{A.1 Tensões e correntes para $\mathrm{Zr}=\mathrm{Zc}$}

Nesse caso, a linha transmite exatamente a potência característica.

Por (A11),

$V(l-\Delta l)=V(l) \cdot(\cosh (\gamma \cdot \Delta l)+\operatorname{senh}(\gamma \cdot \Delta l))=V_{r} \cdot e^{\gamma \cdot \Delta l}=V_{r} \cdot e^{\alpha \cdot \Delta l} e^{\beta \cdot \Delta l}$

A expressão para a corrente é similar:

$I(l-\Delta l)=I(l) \cdot(\cosh (\gamma \cdot \Delta l)+\operatorname{senh}(\gamma \cdot \Delta l))=I_{r} \cdot e^{\gamma \cdot \Delta l}=I_{r} \cdot e^{\alpha \cdot \Delta l} e^{\beta \cdot \Delta l}$

Se $\Delta l=l$, então $l-\Delta l=0$.

Então,

$|V(0)|=\left|V_{s}\right|=\left|V_{r}\right| e^{\alpha \cdot l} \quad$ e $\quad|I(0)|=\left|I_{s}\right|=\left|I_{s}\right| e^{\alpha \cdot l}$

As expressões acima são válidas para qualquer comprimento $l$ da linha. 
Para uma linha sem perdas, $\alpha \approx 0$ e, portanto,

$\left|V_{s}\right| \approx\left|V_{r}\right| \quad$ e $\quad\left|I_{s}\right| \approx\left|I_{r}\right|$

\section{A.2 Tensões e correntes no início da linha para uma linha de meia onda}

Nesse caso, $l=\lambda / 2$, ou seja, o comprimento da linha é exatamente metade do comprimento de onda, e deseja-se determinar $V_{s}=V(0)$ e $I_{s}=I(0)$ em função de $V_{r}=V(l)=V(\lambda / 2)$ e de $I_{r}=I(l)=I(\lambda / 2)$.

$l=\frac{\lambda}{2}=\frac{2 \pi / \beta}{2}=\frac{\pi}{\beta}$, e $l=\Delta l$.

$\gamma \cdot \Delta l=\gamma \frac{\pi}{\beta}=(\alpha+j \beta) \frac{\pi}{\beta}=\frac{\alpha \cdot \pi}{\beta}+j \pi$

$V(0)=V(\lambda / 2) \cdot\left(\cosh \left(\frac{\alpha \pi}{\beta}+j \pi\right)+\frac{Z_{c}}{Z_{r}} \operatorname{senh}\left(\frac{\alpha \pi}{\beta}+j \pi\right)\right)$

$V_{s}=V_{r} \cdot(\cosh \left(\frac{\alpha \pi}{\beta}\right) \underbrace{\cos \pi}_{=-1}+j \operatorname{senh}\left(\frac{\alpha \pi}{\beta}\right) \underbrace{\operatorname{sen} \pi}_{=0}+\frac{Z_{c}}{Z_{r}} \operatorname{senh}\left(\frac{\alpha \pi}{\beta}\right) \underbrace{\cos \pi}_{=-1}+j \frac{Z_{c}}{Z_{r}} \cosh \left(\frac{\alpha \pi}{\beta}\right) \underbrace{\operatorname{sen} \pi}_{=0})$

$V_{s}=V_{r} \cdot\left(-\cosh \left(\frac{\alpha \pi}{\beta}\right)-\frac{Z_{c}}{Z_{r}} \operatorname{senh}\left(\frac{\alpha \pi}{\beta}\right)\right)$

Para uma linha sem perdas, $\alpha \approx 0$ e, portanto,

$$
\left\{\begin{array}{l}
\cosh \left(\frac{\alpha \pi}{\beta}\right) \approx 1 \\
\operatorname{senh}\left(\frac{\alpha \pi}{\beta}\right) \approx 0
\end{array}\right.
$$

Então,

$$
\left\{\begin{array}{l}
V_{s} \approx-V_{r} \\
I_{s} \approx-I_{r}
\end{array}\right.
$$


As tensões e as correntes do início da linha são praticamente as mesmas do final da linha, com o sinal invertido.

\section{A.3 Tensões e correntes no meio da linha para uma linha de meia onda}

Nesse caso, $l=\frac{\lambda}{2}$ e $\Delta l=\frac{\lambda}{4}$. Deseja-se determinar $\mathrm{V}_{\text {meio }}=\mathrm{V}(\lambda / 4)$ e $\mathrm{I}_{\text {meio }}=\mathrm{I}(\lambda / 4)$ em função de $V_{r}=V(l)=V(\lambda / 2)$ e de $I_{r}=I(l)=I(\lambda / 2)$.

$\gamma \cdot \Delta l=\gamma \frac{\lambda}{4}=\gamma \frac{\pi}{2 \beta}=(\alpha+j \beta) \frac{\pi}{2 \beta}=\frac{\alpha \cdot \pi}{2 \beta}+j \frac{\pi}{2}$

Considerando que a razão $Z_{r} / Z_{c}$ é um número real, ou seja, que o fator de potência da carga é igual ao fator de potência da potência característica (praticamente unitário),

$$
\begin{aligned}
& V\left(\frac{\lambda}{2}-\frac{\lambda}{4}\right)=V\left(\frac{\lambda}{4}\right)=V_{\text {meio }}=V\left(\frac{\lambda}{2}\right) \cdot\left(\cosh \left(\frac{\alpha \cdot \pi}{2 \beta}+j \frac{\pi}{2}\right)+\frac{Z_{c}}{Z_{r}} \operatorname{senh}\left(\frac{\alpha \cdot \pi}{2 \beta}+j \frac{\pi}{2}\right)\right) \\
& V_{\text {meio }}=V_{r} \cdot(\cosh \left(\frac{\alpha \cdot \pi}{2 \beta}\right) \underbrace{\cos \frac{\pi}{2}}_{=0}+j \operatorname{senh}\left(\frac{\alpha \cdot \pi}{2 \beta}\right) \underbrace{\operatorname{sen} \frac{\pi}{2}}_{=1}+\frac{Z_{c}}{Z_{r}} \operatorname{senh}\left(\frac{\alpha \cdot \pi}{2 \beta}\right) \underbrace{\cos \frac{\pi}{2}}_{=0}+j \frac{Z_{c}}{Z_{r}} \cosh \left(\frac{\alpha \cdot \pi}{2 \beta}\right) \underbrace{\operatorname{sen} \frac{\pi}{2}}_{=1}) \\
& V_{\text {meio }}=V_{r} \cdot\left(j \operatorname{senh}\left(\frac{\alpha \cdot \pi}{2 \beta}\right)+j \frac{Z_{c}}{Z_{r}} \cosh \left(\frac{\alpha \cdot \pi}{2 \beta}\right)\right)
\end{aligned}
$$

Fazendo as mesmas considerações de (A14),

$$
V_{\text {meio }} \approx j \frac{Z_{c}}{Z_{r}} V_{r}
$$

Ou seja, a tensão no meio da linha é maior quanto menor o valor de $Z_{r}$, ou seja, quanto maior for a potência $S_{r}=\frac{\left|V_{r}\right|^{2}}{Z_{r}}$

Para a corrente,

$$
I\left(\frac{\lambda}{2}-\frac{\lambda}{4}\right)=I\left(\frac{\lambda}{4}\right)=I_{\text {meio }}=I\left(\frac{\lambda}{2}\right) \cdot\left(\cosh \left(\frac{\alpha \cdot \pi}{2 \beta}+j \frac{\pi}{2}\right)+\frac{Z_{r}}{Z_{c}} \operatorname{senh}\left(\frac{\alpha \cdot \pi}{2 \beta}+j \frac{\pi}{2}\right)\right)
$$




$$
\begin{aligned}
& I_{\text {meio }}=I_{r} \cdot(\cosh \left(\frac{\alpha \cdot \pi}{2 \beta}\right) \underbrace{\cos \frac{\pi}{2}}_{=0}+j \operatorname{senh}\left(\frac{\alpha \cdot \pi}{2 \beta}\right) \underbrace{\operatorname{sen} \frac{\pi}{2}}_{=1}+\frac{Z_{r}}{Z_{c}} \operatorname{senh}\left(\frac{\alpha \cdot \pi}{2 \beta}\right) \underbrace{\cos \frac{\pi}{2}}_{=0}+j \frac{Z_{r}}{Z_{c}} \cosh \left(\frac{\alpha \cdot \pi}{2 \beta}\right) \underbrace{\operatorname{sen} \frac{\pi}{2}}_{=1}) \\
& I_{\text {meio }}=I_{r} \cdot\left(j \cdot \operatorname{senh}\left(\frac{\alpha \cdot \pi}{2 \beta}\right)+j \frac{Z_{r}}{Z_{c}} \cosh \left(\frac{\alpha \cdot \pi}{2 \beta}\right)\right)=j \cdot I_{r} \cdot \operatorname{senh}\left(\frac{\alpha \cdot \pi}{2 \beta}\right)+j \frac{V_{r}}{Z_{c}} \cosh \left(\frac{\alpha \cdot \pi}{2 \beta}\right)
\end{aligned}
$$

Fazendo as mesmas considerações de (A14),

$$
I_{\text {meio }} \approx j \frac{V_{r}}{Z_{c}}
$$

Como $\mathrm{Vr}$ é praticamente constante e Zc é um parâmetro da linha, o módulo da corrente no meio da linha também é constante para quaisquer valores de carga que tenham o mesmo fator de potência da potência característica.

\section{A.4 Tensões e correntes ao longo de uma linha de meia onda para fatores de potência quaisquer}

Nesse caso, a razão $Z_{\delta} / Z_{r}$ é um número complexo:

$$
\frac{Z_{c}}{Z_{r}}=k \angle \theta=k \cdot \cos \theta+j \cdot k \cdot \operatorname{sen} \theta \leftrightarrow \frac{Z_{r}}{Z_{c}}=\frac{1}{k} \angle-\theta=\frac{1}{k} \cdot \cos \theta-j \cdot \frac{1}{k} \cdot \operatorname{sen} \theta
$$

Deseja-se determinar $V(m)$ e $I(m)$, em um ponto da linha a uma distância $m$ do terminal receptor, ou seja, a uma distância $\lambda / 2-m$ do terminal receptor, em função de $V_{r}=V(l)=V(\lambda / 2)$ e de $I_{r}=I(l)=I(\lambda / 2)$.

$$
\begin{aligned}
& V\left(\frac{\lambda}{2}-m\right)=V\left(\frac{\lambda}{2}\right) \cdot\left(\cosh (\gamma \cdot m)+\frac{Z_{c}}{Z_{r}} \operatorname{senh}(\gamma \cdot m)\right) \\
& V\left(\frac{\lambda}{2}-m\right)=V_{r} \cdot\left(\cosh (\alpha \cdot m+j \beta \cdot m)+\frac{Z_{c}}{Z_{r}} \operatorname{senh}(\alpha \cdot m+j \beta \cdot m)\right) \\
& V\left(\frac{\lambda}{2}-m\right)=V_{r}\left(\cosh (\alpha \cdot m) \cos (\beta \cdot m)+j \operatorname{senh}(\alpha \cdot m) \operatorname{sen}(\beta \cdot m)+\frac{Z_{c}}{Z_{r}}(\operatorname{senh}(\alpha \cdot m) \cos (\beta \cdot m)+j \cosh (\alpha \cdot m) \operatorname{sen}(\beta \cdot m))\right)
\end{aligned}
$$


Fazendo as mesmas considerações de (A14),

$V\left(\frac{\lambda}{2}-m\right)=V_{r}\left(\cos (\beta \cdot m)+\frac{Z_{c}}{Z_{r}} \cdot j \operatorname{sen}(\beta \cdot m)\right)=V_{r}(\cos (\beta \cdot m)+(k \cos \theta+j \cdot k \cdot \operatorname{sen} \theta) \cdot(j \operatorname{sen}(\beta \cdot m)))$

\section{Calculando o módulo,}

$\left|V\left(\frac{\lambda}{2}-m\right)\right|=\left|V_{r}\right| \cdot|\cos (\beta \cdot m)+(k \cos \theta+j k \operatorname{sen} \theta)(j \operatorname{sen}(\beta \cdot m))|=\left|V_{r}\right| \cdot|\cos (\beta \cdot m)-k \operatorname{sen} \theta \cdot \operatorname{sen}(\beta \cdot m)+j k \cos \theta \cdot \operatorname{sen}(\beta \cdot m)|$

$\left|V\left(\frac{\lambda}{2}-m\right)\right|=\left|V_{r}\right| \cdot \sqrt{(\cos (\beta \cdot m)-k \operatorname{sen} \theta \cdot \operatorname{sen}(\beta \cdot m))^{2}+(k \cos \theta \cdot \operatorname{sen}(\beta \cdot m))^{2}}$

$\left|V\left(\frac{\lambda}{2}-m\right)\right|=\left|V_{r}\right| \cdot \sqrt{\cos ^{2}(\beta \cdot m)-2 k \operatorname{sen} \theta \cdot \operatorname{sen}(\beta \cdot m) \cos (\beta \cdot m)+k^{2} \operatorname{sen}^{2} \theta \cdot \operatorname{sen}^{2}(\beta \cdot m)+k^{2} \cos ^{2} \theta \cdot \operatorname{sen}^{2}(\beta \cdot m)}$

$\left|V\left(\frac{\lambda}{2}-m\right)\right|=\left|V_{r}\right| \cdot \sqrt{\cos ^{2}(\beta \cdot m)-k \operatorname{sen} \theta \cdot \operatorname{sen}(2 \beta \cdot m)+k^{2} \operatorname{sen}^{2}(\beta \cdot m)}$

Para a corrente,

$I\left(\frac{\lambda}{2}-m\right)=I\left(\frac{\lambda}{2}\right) \cdot\left(\cosh (\gamma \cdot m)+\frac{Z_{r}}{Z_{c}} \operatorname{senh}(\gamma \cdot m)\right)$

$I\left(\frac{\lambda}{2}-m\right)=I_{r} \cdot\left(\cosh (\alpha \cdot m+j \beta \cdot m)+\frac{Z_{r}}{Z_{c}} \operatorname{senh}(\alpha \cdot m+j \beta \cdot m)\right)$

$I\left(\frac{\lambda}{2}-m\right)=I_{r}\left(\cosh (\alpha \cdot m) \cos (\beta \cdot m)+j \operatorname{senh}(\alpha \cdot m) \operatorname{sen}(\beta \cdot m)+\frac{Z_{r}}{Z_{c}}(\operatorname{senh}(\alpha \cdot m) \cos (\beta \cdot m)+j \cosh (\alpha \cdot m) \operatorname{sen}(\beta \cdot m))\right)$

Fazendo as mesmas considerações de (A14),

$I\left(\frac{\lambda}{2}-m\right)=I_{r}\left(\cos (\beta \cdot m)+\left(\frac{1}{k} \cdot \cos \theta-j \cdot \frac{1}{k} \cdot \operatorname{sen} \theta\right) \cdot(j \operatorname{sen}(\beta \cdot m))\right)$ 
Calculando o módulo,

$\left|I\left(\frac{\lambda}{2}-m\right)\right|=\left|I_{r}\right| \cdot\left|\cos (\beta \cdot m)+\left(\frac{1}{k} \cdot \cos \theta-j \cdot \frac{1}{k} \cdot \operatorname{sen} \theta\right)(j \operatorname{sen}(\beta \cdot m))\right|=\left|I_{r}\right| \cdot\left|\cos (\beta \cdot m)+\frac{1}{k} \operatorname{sen} \theta \cdot \operatorname{sen}(\beta \cdot m)+j \frac{1}{k} \cos \theta \cdot \operatorname{sen}(\beta \cdot m)\right|$

$\left|I\left(\frac{\lambda}{2}-m\right)\right|=\left|I_{r}\right| \cdot \sqrt{\left(\cos (\beta \cdot m)+\frac{1}{k} \operatorname{sen} \theta \cdot \operatorname{sen}(\beta \cdot m)\right)^{2}+\left(\frac{1}{k} \cos \theta \cdot \operatorname{sen}(\beta \cdot m)\right)^{2}}$

$\left|I\left(\frac{\lambda}{2}-m\right)\right|=\left|I_{r}\right| \cdot \sqrt{\cos ^{2}(\beta \cdot m)+\frac{2}{k} \operatorname{sen} \theta \cdot \operatorname{sen}(\beta \cdot m) \cos (\beta \cdot m)+\frac{1}{k^{2}} \operatorname{sen}^{2} \theta \cdot \operatorname{sen}^{2}(\beta \cdot m)+\frac{1}{k^{2}} \cos ^{2} \theta \cdot \operatorname{sen}^{2}(\beta \cdot m)}$

||$\left(\frac{\lambda}{2}-m\right)|=| I_{r} \mid \cdot \sqrt{\cos ^{2}(\beta \cdot m)+\frac{1}{k} \operatorname{sen} \theta \cdot \operatorname{sen}(2 \beta \cdot m)+\frac{1}{k^{2}} \operatorname{sen}^{2}(\beta \cdot m)}$

Para $\theta=0$, ou seja, fator de potência igual ao fator de potência da potência característica, $\left|V\left(\frac{\lambda}{2}-m\right)\right|$ e $\left|I\left(\frac{\lambda}{2}-m\right)\right|$ apresentam derivadas iguais a zero (pontos de máximo ou mínimo) na metade na linha, ou seja, no ponto que $\beta \cdot m=\pi / 2$.

Para $\theta \neq 0$, ou seja, fator de potência igual ao fator de potência da potência característica, $\left|V\left(\frac{\lambda}{2}-m\right)\right|$ e $\left|I\left(\frac{\lambda}{2}-m\right)\right|$ variam em função de $2 \cdot \beta \cdot m$, apresentando dois pontos de derivada igual a zero (um ponto de máximo e um de mínimo), e que não estão localizados no meio da linha. 


\section{ANEXO B - DETALHES DO CÁLCULO DE PARÂMETROS DAS}

\section{LINHAS}

\section{B.1 Geometria A}

\section{B.1.1 Dados de entrada para o ATP}

Tabela 12 - Dados de entrada das diversas alternativas, geometria A

\begin{tabular}{|c|c|c|c|c|c|c|c|c|c|}
\hline Caso & $\begin{array}{l}\text { Rin } \\
(\mathrm{cm})\end{array}$ & $\begin{array}{l}\text { Rout } \\
(\mathrm{cm})\end{array}$ & $\begin{array}{c}\text { Resis } \\
\text { (ohm/km) }\end{array}$ & $\begin{array}{l}\text { Horiz } \\
(\mathrm{m})\end{array}$ & $\begin{array}{l}\text { Vtower } \\
(\mathrm{m})\end{array}$ & $\begin{array}{c}\text { Vmid } \\
(\mathrm{m})\end{array}$ & $\begin{array}{l}\text { Separ } \\
(\mathrm{cm})\end{array}$ & $\begin{array}{c}\text { Alpha } \\
\text { (graus) }\end{array}$ & NB \\
\hline \multirow{5}{*}{$\begin{array}{l}\text { 6xDrake } \\
d_{b}=1 \mathrm{~m}\end{array}$} & 0,5175 & 1,4055 & 0,071918 & $-8,660$ & 47,160 & 27,160 & 50 & 60 & 6 \\
\hline & 0,5175 & 1,4055 & 0,071918 & 0,000 & 38,500 & 18,500 & 50 & 60 & 6 \\
\hline & 0,5175 & 1,4055 & 0,071918 & 8,660 & 47,160 & 27,160 & 50 & 60 & 6 \\
\hline & 0 & 0,476 & 3,5 & $-18,660$ & 57,160 & 37,160 & 0 & 0 & 0 \\
\hline & 0 & 0,476 & 3,5 & 18,660 & 57,160 & 37,160 & 0 & 0 & 0 \\
\hline \multirow{5}{*}{$\begin{array}{l}\text { 6xDrake } \\
d_{b}=2 m\end{array}$} & 0,5175 & 1,4055 & 0,071918 & $-9,093$ & 48,093 & 28,093 & 100 & 60 & 6 \\
\hline & 0,5175 & 1,4055 & 0,071918 & 0,000 & 39,000 & 19,000 & 100 & 60 & 6 \\
\hline & 0,5175 & 1,4055 & 0,071918 & 9,093 & 48,093 & 28,093 & 100 & 60 & 6 \\
\hline & 0 & 0,476 & 3,5 & $-19,093$ & 58,093 & 38,093 & 0 & 0 & 0 \\
\hline & 0 & 0,476 & 3,5 & 19,093 & 58,093 & 38,093 & 0 & 0 & 0 \\
\hline \multirow{5}{*}{$\begin{array}{l}\text { 6xDrake } \\
d_{b}=3 \mathrm{~m}\end{array}$} & 0,5175 & 1,4055 & 0,071918 & $-9,526$ & 49,026 & 29,026 & 150 & 60 & 6 \\
\hline & 0,5175 & 1,4055 & 0,071918 & 0,000 & 39,500 & 19,500 & 150 & 60 & 6 \\
\hline & 0,5175 & 1,4055 & 0,071918 & 9,526 & 49,026 & 29,026 & 150 & 60 & 6 \\
\hline & 0 & 0,476 & 3,5 & $-19,526$ & 59,026 & 39,026 & 0 & 0 & 0 \\
\hline & 0 & 0,476 & 3,5 & 19,526 & 59,026 & 39,026 & 0 & 0 & 0 \\
\hline \multirow{5}{*}{$\begin{array}{c}\text { 6xLapwing } \\
d_{b}=1 \mathrm{~m}\end{array}$} & 0,477 & 1,911 & 0,035959 & $-8,660$ & 47,160 & 27,160 & 50 & 60 & 6 \\
\hline & 0,477 & 1,911 & 0,035959 & 0,000 & 38,500 & 18,500 & 50 & 60 & 6 \\
\hline & 0,477 & 1,911 & 0,035959 & 8,660 & 47,160 & 27,160 & 50 & 60 & 6 \\
\hline & 0 & 0,476 & 3,5 & $-18,660$ & 57,160 & 37,160 & 0 & 0 & 0 \\
\hline & 0 & 0,476 & 3,5 & 18,660 & 57,160 & 37,160 & 0 & 0 & 0 \\
\hline \multirow{5}{*}{$\begin{array}{c}\text { 6xLapwing } \\
d_{b}=2 \mathrm{~m}\end{array}$} & 0,477 & 1,911 & 0,035959 & $-9,093$ & 48,093 & 28,093 & 100 & 60 & 6 \\
\hline & 0,477 & 1,911 & 0,035959 & 0,000 & 39,000 & 19,000 & 100 & 60 & 6 \\
\hline & 0,477 & 1,911 & 0,035959 & 9,093 & 48,093 & 28,093 & 100 & 60 & 6 \\
\hline & 0 & 0,476 & 3,5 & $-19,093$ & 58,093 & 38,093 & 0 & 0 & 0 \\
\hline & 0 & 0,476 & 3,5 & 19,093 & 58,093 & 38,093 & 0 & 0 & 0 \\
\hline \multirow{5}{*}{$\begin{array}{c}\text { 6xLapwing } \\
d_{b}=3 \mathrm{~m}\end{array}$} & 0,477 & 1,911 & 0,035959 & $-9,526$ & 49,026 & 29,026 & 150 & 60 & 6 \\
\hline & 0,477 & 1,911 & 0,035959 & 0,000 & 39,500 & 19,500 & 150 & 60 & 6 \\
\hline & 0,477 & 1,911 & 0,035959 & 9,526 & 49,026 & 29,026 & 150 & 60 & 6 \\
\hline & 0 & 0,476 & 3,5 & $-19,526$ & 59,026 & 39,026 & 0 & 0 & 0 \\
\hline & 0 & 0,476 & 3,5 & 19,526 & 59,026 & 39,026 & 0 & 0 & 0 \\
\hline
\end{tabular}

Obs.: Rin/Rout=raios internos e externos de um condutor tubular;

Horiz=distância horizontal entre o centro do condutor ou feixe e o centro do feixe central;

Vtower=altura do centro do condutor ou feixe em relação ao solo, medida na torre;

Vmid= altura do centro do condutor ou feixe em relação ao solo, medida no meio do vão;

Separ=distância entre dois condutores adjacentes do feixe;

Alpha=ângulo medido, no centro do feixe, entre um dos condutores e o eixo horizontal;

$\mathrm{NB}=$ número de subcondutores do feixe. 


\section{B.1.2 Resultados seqüência positiva}

Tabela 13 - Resultados de parâmetros da linha, seqüência positiva, geometria A

\begin{tabular}{|c|c|c|c|c|c|c|}
\hline \multirow{2}{*}{ Cabo } & \multirow{2}{*}{$\begin{array}{l}\text { Diâm. } \\
\text { Feixe, } d_{b} \\
(m)\end{array}$} & \multicolumn{2}{|c|}{$\begin{array}{l}\text { Impedância } \\
\text { característica }\end{array}$} & \multirow{2}{*}{$\begin{array}{c}\text { Resistência } \\
\text { (ohm/km) }\end{array}$} & \multirow{2}{*}{$\begin{array}{l}\text { Reatância } \\
\text { (ohm/km) }\end{array}$} & \multirow{2}{*}{$\begin{array}{c}\text { Capacitância } \\
\text { (farad/km) }\end{array}$} \\
\hline & & $\begin{array}{l}\text { módulo, } \\
\text { (ohm) }\end{array}$ & $\begin{array}{l}\text { fase, } \\
\text { (graus) }\end{array}$ & & & \\
\hline 6xDrake & 1 & 215,29 & $-1,32$ & 0,012625 & 0,274486 & $1,573 \mathrm{E}-8$ \\
\hline 6xDrake & 2 & 183,26 & $-1,55$ & 0,012692 & 0,234390 & 1,854E-8 \\
\hline 6xDrake & 3 & 165,44 & $-1,72$ & 0,012765 & 0,212124 & $2,060 \mathrm{E}-8$ \\
\hline 6xLapwing & 1 & 212,23 & $-0,73$ & 0,006863 & 0,270884 & $1,596 \mathrm{E}-8$ \\
\hline 6xLapwing & 2 & 180,18 & $-0,86$ & 0,006915 & 0,230774 & $1,886 \mathrm{E}-8$ \\
\hline 6xLapwing & 3 & 162,33 & $-0,96$ & 0,006971 & 0,208491 & $2,100 \mathrm{E}-8$ \\
\hline
\end{tabular}

Tabela 14 - Meio comprimento de onda e potência característica para 1000 Kv, seqüência positiva, geometria A

\begin{tabular}{|c|c|c|c|}
\hline Cabo & $\begin{array}{c}\text { Diâm. } \\
\text { feixe, } \mathrm{d}_{\mathrm{b}} \\
(\mathrm{m})\end{array}$ & $\begin{array}{c}1 / 2 \text { onda } \\
(\mathrm{km})\end{array}$ & $\begin{array}{c}\text { Potência } \\
\text { característica, } \\
\mathrm{V}=1000 \mathrm{kV} \\
(\mathrm{MW})\end{array}$ \\
\hline 6xDrake & 1 & 2462 & 4643 \\
\hline 6xDrake & 2 & 2453 & 5454 \\
\hline 6xDrake & 3 & 2446 & 6041 \\
\hline 6xLapwing & 1 & 2460 & 4711 \\
\hline 6xLapwing & 2 & 2452 & 5549 \\
\hline 6xLapwing & 3 & 2445 & 6159 \\
\hline
\end{tabular}




\section{B.1.3 Resultados seqüência zero}

Tabela 15 - Resultados de parâmetros da linha, seqüência zero, geometria A

\begin{tabular}{|c|c|c|c|c|c|c|}
\hline \multirow{2}{*}{ Cabo } & \multirow{2}{*}{$\begin{array}{l}\text { Diâm. } \\
\text { feixe, } d_{b} \\
\quad(m)\end{array}$} & \multicolumn{2}{|c|}{$\begin{array}{l}\text { Impedância } \\
\text { característica }\end{array}$} & \multirow{2}{*}{$\begin{array}{c}\text { Resistência } \\
\text { (ohm/km) }\end{array}$} & \multirow{2}{*}{$\begin{array}{l}\text { Reatância } \\
\text { (ohm } / \mathrm{km} \text { ) }\end{array}$} & \multirow{2}{*}{$\begin{array}{c}\text { Capacitância } \\
\text { (farad/km) }\end{array}$} \\
\hline & & $\begin{array}{c}\text { módulo, } \\
\text { (ohm) }\end{array}$ & $\begin{array}{c}\text { fase, } \\
\text { (graus) }\end{array}$ & & & \\
\hline 6xDrake & 1 & 676,96 & $-7,17$ & 0,327284 & 1,280750 & 7,651E-09 \\
\hline 6xDrake & 2 & 635,73 & $\begin{array}{l}-7,42 \\
\end{array}$ & 0,326188 & 1,230340 & $8,354 \mathrm{E}-09$ \\
\hline 6xDrake & 3 & 610,13 & $\begin{array}{l}-7,59 \\
\end{array}$ & 0,325147 & 1,198210 & $8,847 \mathrm{E}-09$ \\
\hline 6xLapwing & 1 & 673,31 & $-7,07$ & 0,321517 & 1,277140 & 7,706E-09 \\
\hline 6xLapwing & 2 & 632,01 & $-7,32$ & 0,320398 & 1,226710 & $8,419 \mathrm{E}-09$ \\
\hline 6xLapwing & 3 & 606,36 & $\begin{array}{l}-7,48 \\
\end{array}$ & 0,319329 & 1,194540 & $8,921 \mathrm{E}-09$ \\
\hline
\end{tabular}

Tabela 16 - Meio comprimento de onda, seqüência zero, geometria $A$

\begin{tabular}{|c|c|c|}
\hline Cabo & $\begin{array}{c}\text { Diâm. } \\
\text { feixe, } \mathrm{d}_{\mathrm{b}} \\
(\mathrm{m})\end{array}$ & $\begin{array}{c}1 / 2 \\
\text { comprimento } \\
\text { de onda } \\
(\mathrm{km})\end{array}$ \\
\hline 6xDrake & 1 & 1621 \\
\hline 6xDrake & 2 & 1582 \\
\hline 6xDrake & 3 & 1557 \\
\hline 6xLapwing & 1 & 1618 \\
\hline 6xLapwing & 2 & 1578 \\
\hline 6xLapwing & 3 & 1553 \\
\hline
\end{tabular}

\section{B.1.4 Gráficos}

Seguem (Figura B1 a Figura B7) gráficos dos parâmetros das linhas, para as diversas simulações da Geometria A (ver Seção 4.3.2). Os gráficos de impedância característica de seqüência positiva, potência característica de seqüência positiva e 1/2 comprimento de onda de seqüência positiva são apresentados na seção 4.3.4. 


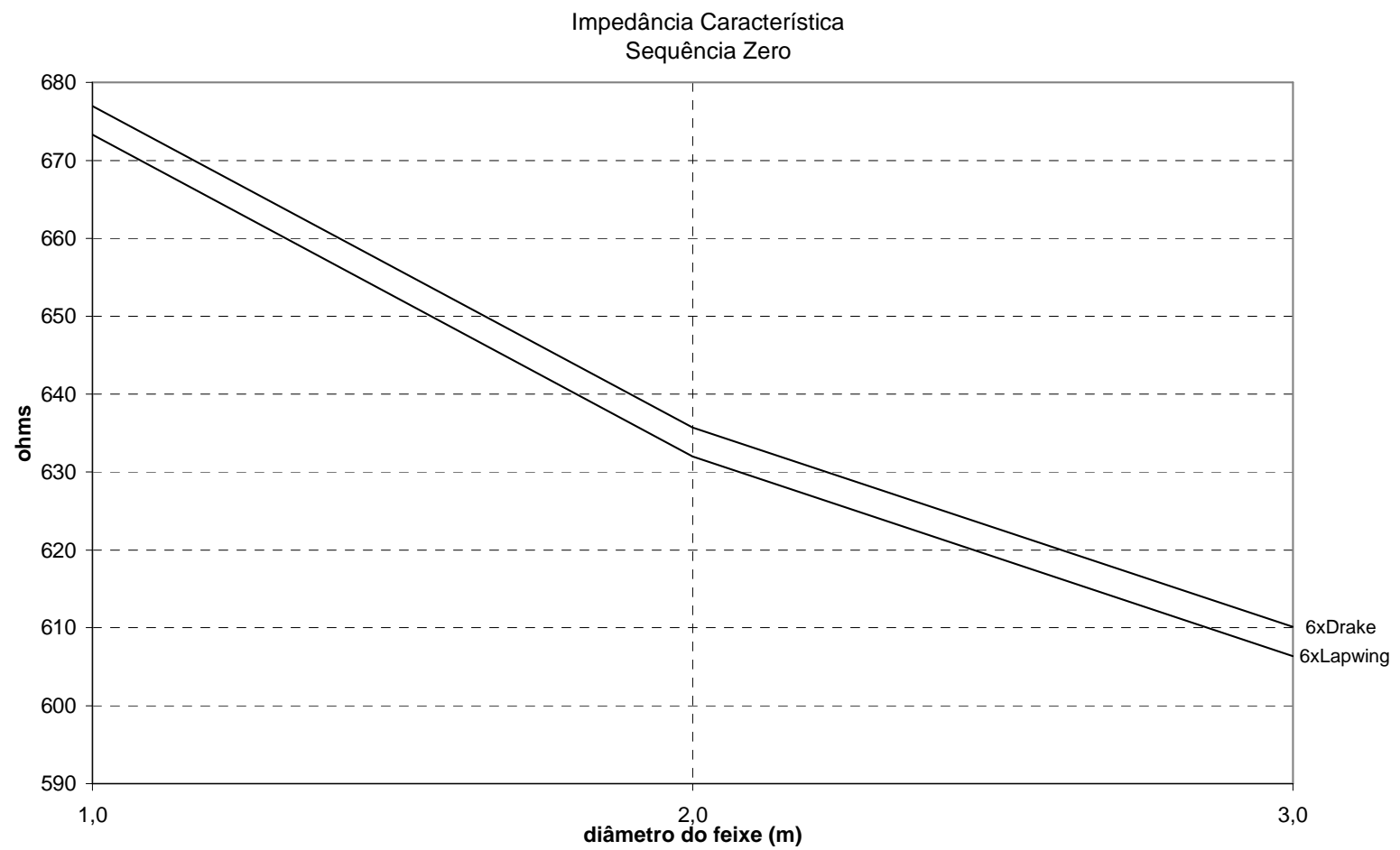

Figura B1 - Valores do módulo da impedância característica $\left(Z_{c}\right)$, seqüência zero, geometria A.

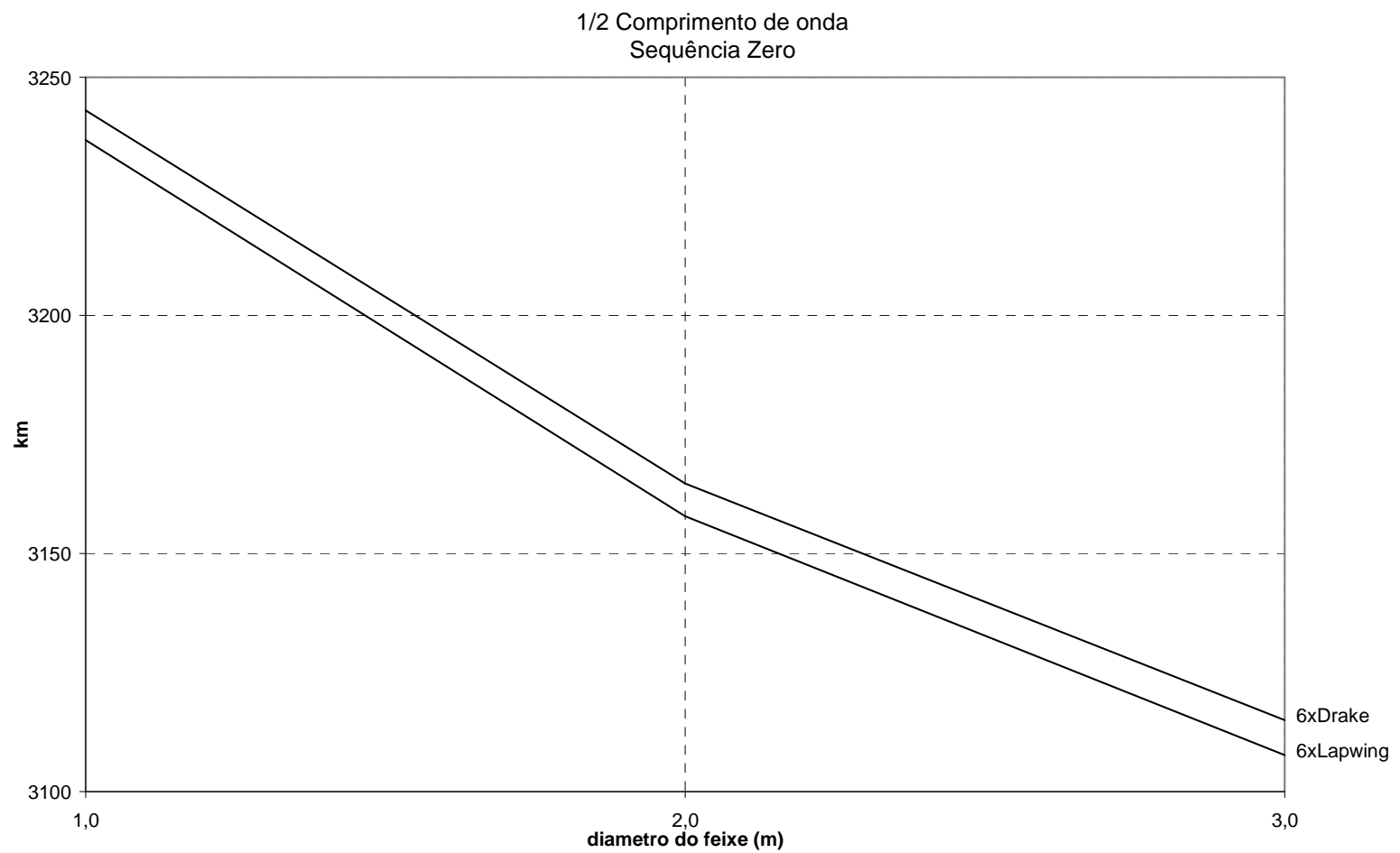

Figura B2 - Metade dos valores calculados para os comprimentos de onda, seqüência zero, geometria A. 
Reatância

Sequência Positiva

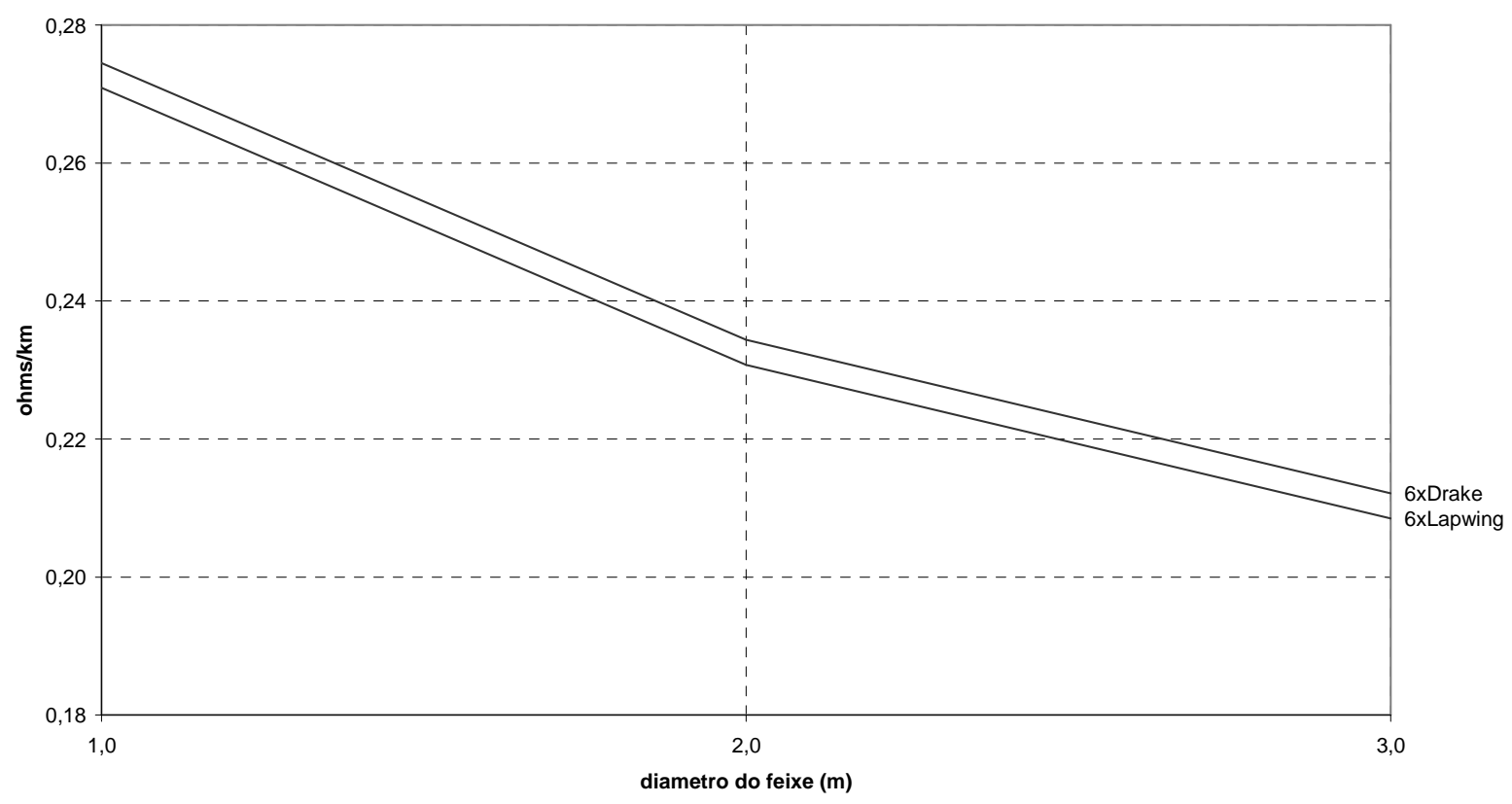

Figura B3 - Valores de reatância indutiva por km, seqüência positiva, geometria A.

Reatância

Sequência Zero

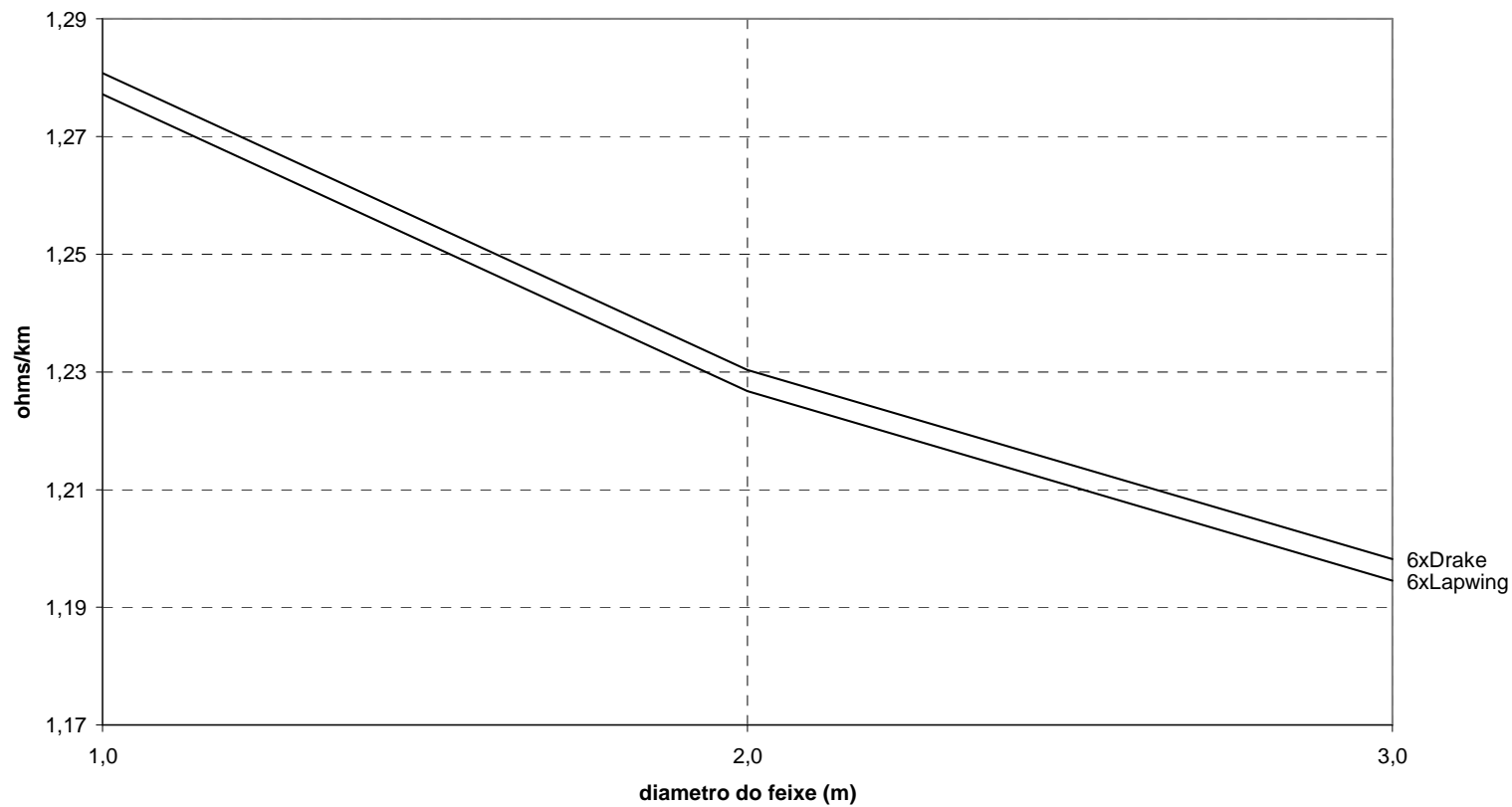

Figura B4 - Valores de reatância indutiva por km, seqüência zero, geometria A. 


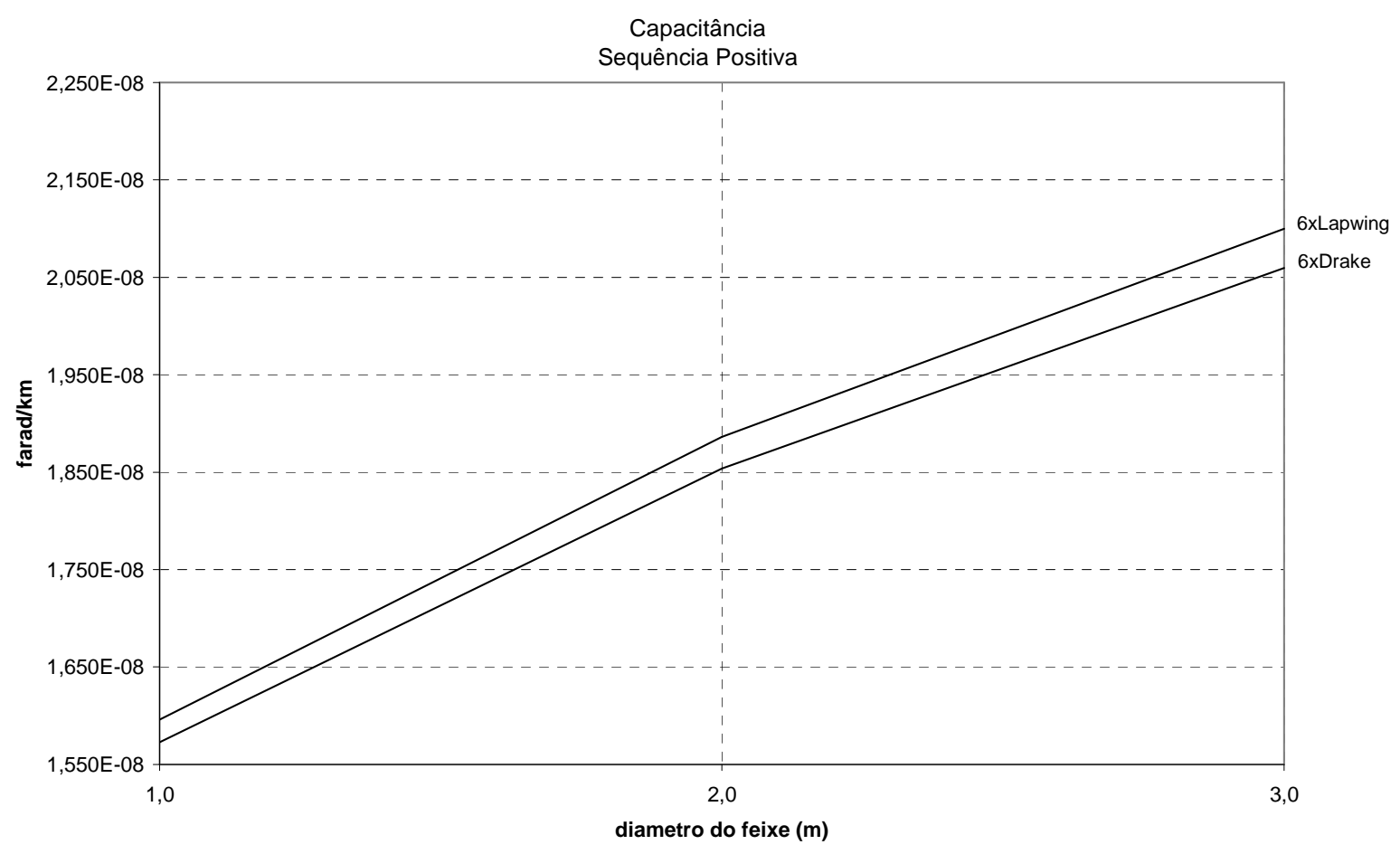

Figura B5 - Valores de capacitância por km, seqüência positiva, geometria A.

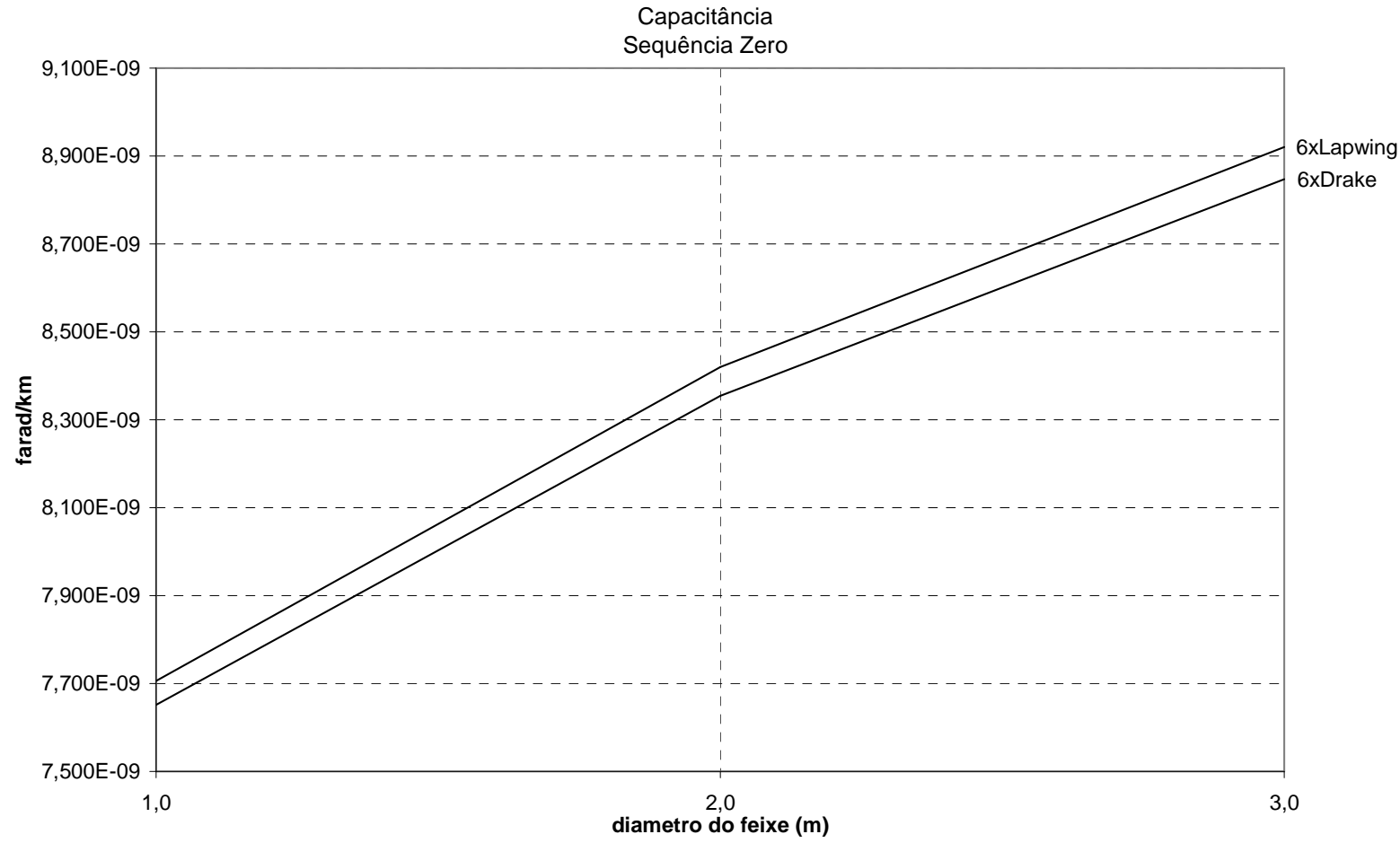

Figura B6 - Valores de capacitância por km, seqüência zero, geometria A. 


\section{B.2 Geometria B}

\section{B.2.1 Dados de entrada para o ATP}

Tabela 17 - Dados de entrada das diversas alternativas, geometria B

\begin{tabular}{|c|c|c|c|c|c|c|c|c|c|}
\hline Caso & $\begin{array}{l}\text { Rin } \\
(\mathrm{cm})\end{array}$ & $\begin{array}{l}\text { Rout } \\
(\mathrm{cm})\end{array}$ & $\begin{array}{c}\text { Resis } \\
\text { (ohm/km) }\end{array}$ & $\begin{array}{c}\text { Horiz } \\
\text { (m) }\end{array}$ & $\begin{array}{c}\text { Vtower } \\
\text { (m) }\end{array}$ & $\begin{array}{c}\text { Vmid } \\
(\mathrm{m})\end{array}$ & $\begin{array}{l}\text { Separ } \\
(\mathrm{cm})\end{array}$ & $\begin{array}{l}\text { Alpha } \\
\text { (graus) }\end{array}$ & NB \\
\hline \multirow{5}{*}{$\begin{array}{l}d_{f}=12 m \\
d_{b}=1 m\end{array}$} & 0,5175 & 1,4055 & 0,071918 & -12 & 38,5 & 18,5 & 50 & 60 & 6 \\
\hline & 0,5175 & 1,4055 & 0,071918 & 0 & 38,5 & 18,5 & 50 & 60 & 6 \\
\hline & 0,5175 & 1,4055 & 0,071918 & 12 & 38,5 & 18,5 & 50 & 60 & 6 \\
\hline & 0 & 0,476 & 3,5 & -22 & 48,5 & 28,5 & 0 & 0 & 0 \\
\hline & 0 & 0,476 & 3,5 & 22 & 48,5 & 28,5 & 0 & 0 & 0 \\
\hline \multirow{5}{*}{$\begin{array}{l}d_{f}=15 m \\
d_{b}=1 m\end{array}$} & 0,5175 & 1,4055 & 0,071918 & -15 & 38,5 & 18,5 & 50 & 60 & 6 \\
\hline & 0,5175 & 1,4055 & 0,071918 & 0 & 38,5 & 18,5 & 50 & 60 & 6 \\
\hline & 0,5175 & 1,4055 & 0,071918 & 15 & 38,5 & 18,5 & 50 & 60 & 6 \\
\hline & 0 & 0,476 & 3,5 & -25 & 48,5 & 28,5 & 0 & 0 & 0 \\
\hline & 0 & 0,476 & 3,5 & 25 & 48,5 & 28,5 & 0 & 0 & 0 \\
\hline \multirow{5}{*}{$\begin{array}{l}d_{f}=12 m \\
d_{b}=2 m\end{array}$} & 0,5175 & 1,4055 & 0,071918 & -12 & 39,0 & 19, & 100 & 60 & 6 \\
\hline & 0,5175 & 1,4055 & 0,071918 & 0 & 39,0 & 19 & 100 & 60 & 6 \\
\hline & 0,5175 & 1,4055 & 0,071918 & 12 & 39,0 & 19 & 100 & 60 & 6 \\
\hline & 0 & 0,476 & 3,5 & -22 & 49,0 & 29 & 0 & 0 & 0 \\
\hline & 0 & 0,476 & 3,5 & 22 & 49,0 & 29 & 0 & 0 & 0 \\
\hline \multirow{5}{*}{$\begin{array}{l}d_{f}=15 m \\
d_{b}=2 m\end{array}$} & 0,5175 & 1,4055 & 0,071918 & -15 & 39,0 & 19 & 100 & 60 & 6 \\
\hline & 0,5175 & 1,4055 & 0,071918 & 0 & 39,0 & 19 & 100 & 60 & 6 \\
\hline & 0,5175 & 1,4055 & 0,071918 & 15 & 39,0 & 19 & 100 & 60 & 6 \\
\hline & 0 & 0,476 & 3,5 & -25 & 49,0 & 29 & 0 & 0 & 0 \\
\hline & 0 & 0,476 & 3,5 & 25 & 49,0 & 29 & 0 & 0 & 0 \\
\hline
\end{tabular}




\section{B.2.2 Resultados sequência positiva}

Tabela 18 - Resultados de parâmetros da linha, seqüência positiva, geometria B

\begin{tabular}{|c|c|c|c|c|c|c|}
\hline \multirow{2}{*}{$\begin{array}{c}\text { Dist. } \\
\text { horizontal, } \\
d_{f} \\
(\mathrm{~m})\end{array}$} & \multirow{2}{*}{$\begin{array}{l}\text { Diâm. } \\
\text { feixe, } d_{b} \\
(m)\end{array}$} & \multicolumn{2}{|c|}{$\begin{array}{l}\text { Impedância } \\
\text { característica }\end{array}$} & \multirow{2}{*}{$\begin{array}{c}\text { Resistência } \\
\text { (ohm/km) }\end{array}$} & \multirow{2}{*}{$\begin{array}{l}\text { Reatância } \\
\text { (ohm/km) }\end{array}$} & \multirow{2}{*}{$\begin{array}{c}\text { Capacitância } \\
\text { (farad/km) }\end{array}$} \\
\hline & & $\begin{array}{c}\text { módulo, } \\
\text { (ohm) }\end{array}$ & $\begin{array}{l}\text { fase, } \\
\text { (graus) }\end{array}$ & & & \\
\hline 12,0 & 1,0 & 218,99 & $-1,30$ & 0,012821 & 0,281610 & 1,559E-08 \\
\hline 12,0 & 2,0 & 183,93 & $-1,55$ & 0,012862 & 0,237769 & 1,867E-08 \\
\hline 15,0 & 1,0 & 231,51 & $-1,25$ & 0,013057 & 0,298422 & 1,478E-08 \\
\hline 15,0 & 2,0 & 196,60 & $-1,47$ & 0,013082 & 0,254686 & 1,750E-08 \\
\hline
\end{tabular}

Tabela 19 - Meio comprimento de onda e potência característica para 1000 kV, seqüência positiva, geometria B

\begin{tabular}{|c|c|c|c|}
\hline $\begin{array}{c}\text { Dist. } \\
\text { horizontal, } \\
d_{f} \\
(\mathrm{~m})\end{array}$ & $\begin{array}{c}\text { Diâm. } \\
\text { feixe, } \mathrm{d}_{\mathrm{b}} \\
(\mathrm{m})\end{array}$ & $\begin{array}{c}1 / 2 \text { onda } \\
(\mathrm{km})\end{array}$ & $\begin{array}{c}\text { Potência } \\
\text { Caracteristica, } \\
\mathrm{V}=1000 \mathrm{kV} \\
(\mathrm{MW})\end{array}$ \\
\hline 12,0 & 1,0 & 2441,09 & 4565,30 \\
\hline 12,0 & 2,0 & 2427,61 & 5434,78 \\
\hline 15,0 & 1,0 & 2435,39 & 4318,51 \\
\hline 15,0 & 2,0 & 2422,72 & 5084,77 \\
\hline
\end{tabular}




\section{B.2.3 Resultados seqüência zero}

Tabela 20 - Resultados de parâmetros da linha, seqüência zero, geometria B

\begin{tabular}{|c|c|c|c|c|c|c|}
\hline \multirow{2}{*}{$\begin{array}{c}\text { Dist. } \\
\text { horizontal, } \\
d_{f} \\
(\mathrm{~m})\end{array}$} & \multirow{2}{*}{$\begin{array}{l}\text { Diâm. } \\
\text { feixe, } d_{b} \\
\quad(m)\end{array}$} & \multicolumn{2}{|c|}{$\begin{array}{l}\text { Impedância } \\
\text { característica }\end{array}$} & \multirow{2}{*}{$\begin{array}{c}\text { Resistência } \\
\text { (ohm } / \mathrm{km})\end{array}$} & \multirow{2}{*}{$\begin{array}{l}\text { Reatância } \\
\text { (ohm/km) }\end{array}$} & \multirow{2}{*}{$\begin{array}{c}\text { Capacitância } \\
\text { (farad/km) }\end{array}$} \\
\hline & & $\begin{array}{l}\text { módulo, } \\
\text { (ohm) }\end{array}$ & $\begin{array}{l}\text { fase, } \\
\text { (graus) }\end{array}$ & & & \\
\hline 12,0 & 1,0 & 649,13 & $-7,21$ & 0,325616 & 1,266950 & 8,2347E-09 \\
\hline 12,0 & 2,0 & 612,05 & $-7,45$ & 0,325645 & 1,223210 & $8,9632 \mathrm{E}-09$ \\
\hline 15,0 & 1,0 & 626,32 & $-7,25$ & 0,319982 & 1,236940 & 8,6395E-09 \\
\hline 15,0 & 2,0 & 589,15 & $-7,51$ & 0,319991 & 1,193310 & $9,4418 \mathrm{E}-09$ \\
\hline
\end{tabular}

Tabela 21 - Meio comprimento de onda, seqüência zero, geometria B

\begin{tabular}{|c|c|c|}
\hline $\begin{array}{c}\text { Dist. } \\
\text { horizontal, } \\
\mathrm{d}_{\mathrm{f}} \\
(\mathrm{m})\end{array}$ & $\begin{array}{c}\text { Diâm. } \\
\text { feixe, } \mathrm{d}_{\mathrm{b}} \\
(\mathrm{m})\end{array}$ & $\begin{array}{c}1 / 2 \\
\text { comprimento } \\
\text { de onda } \\
(\mathrm{km})\end{array}$ \\
\hline 12,0 & 1,0 & 1571,38 \\
\hline 12,0 & 2,0 & 1531,98 \\
\hline 15,0 & 1,0 & 1552,46 \\
\hline 15,0 & 2,0 & 1511,06 \\
\hline
\end{tabular}

\section{B.2.4 Gráficos}

Seguem (Figura B7 a Figura B12) gráficos dos parâmetros das linhas, para as diversas simulações da Geometria B (ver Seção 4.3.5). Os gráficos de impedância característica de seqüência positiva, potência característica de seqüência positiva e $1 / 2$ comprimento de onda de seqüência positiva são apresentados na seção 4.3.7. 


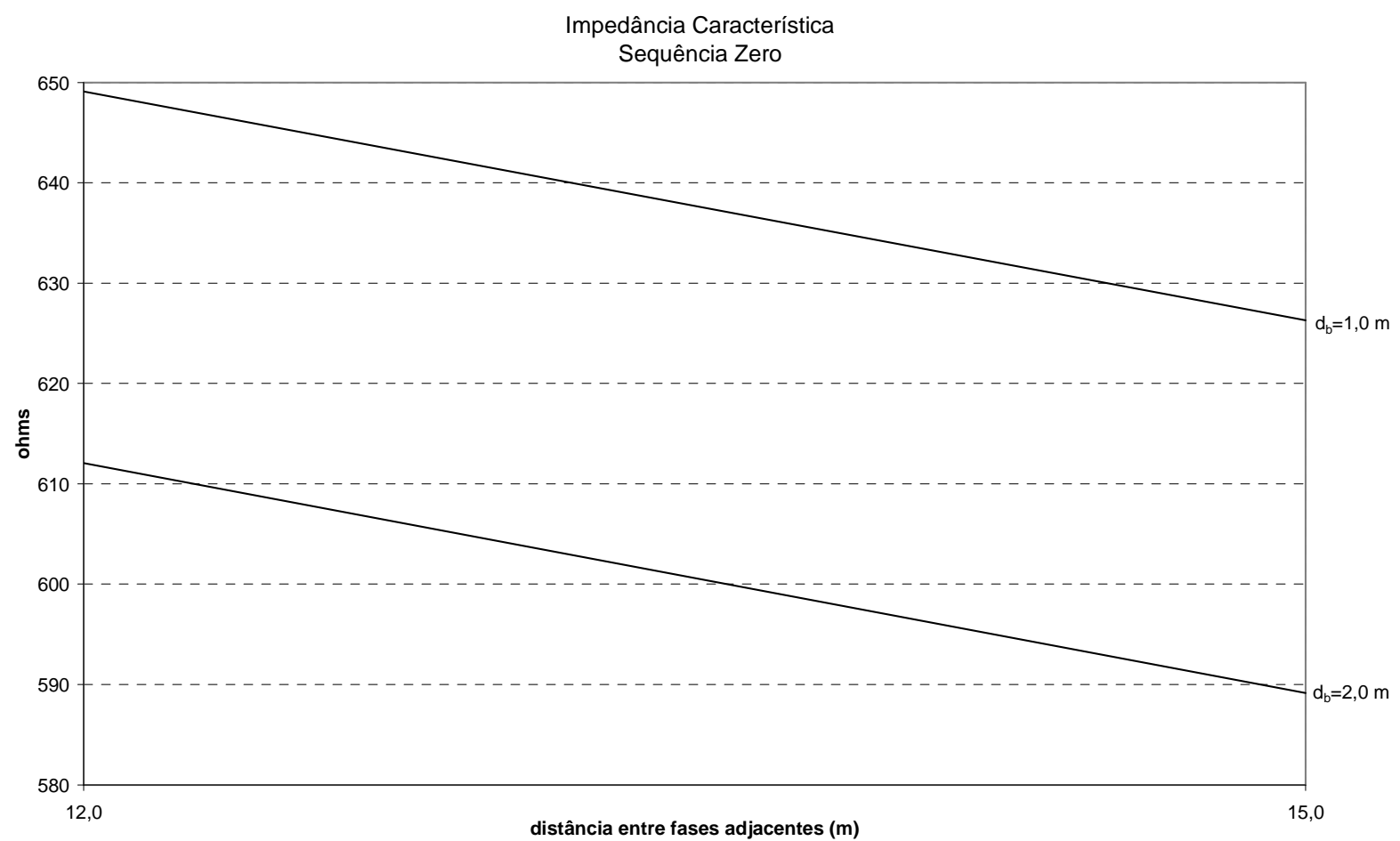

Figura B7 - Valores do módulo da impedância característica $\left(Z_{c}\right)$, seqüência zero, geometria B.

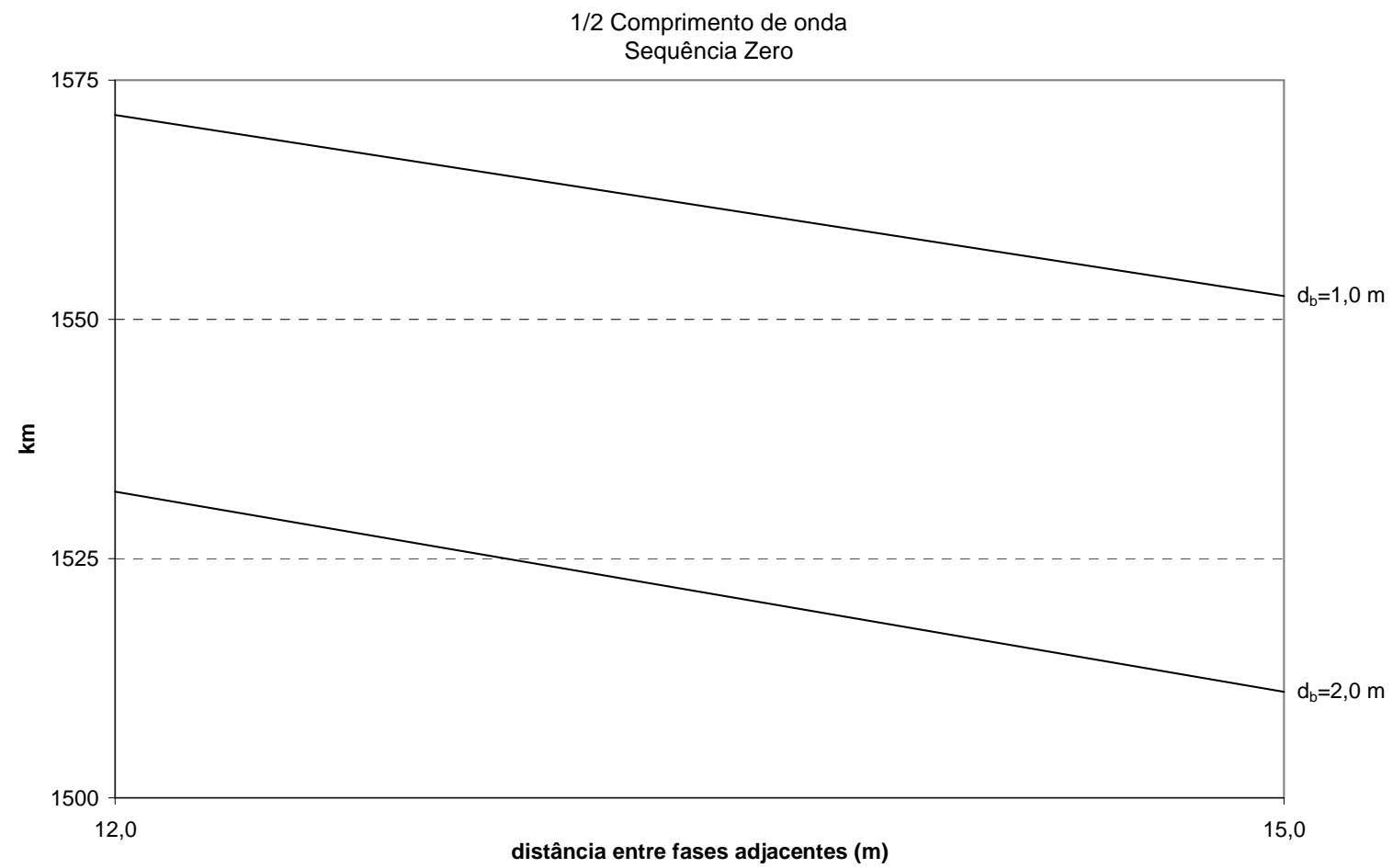

Figura B8 - Metade dos valores calculados para os comprimentos de onda, seqüência zero, geometria B. 
Reatância

Sequência Positiva

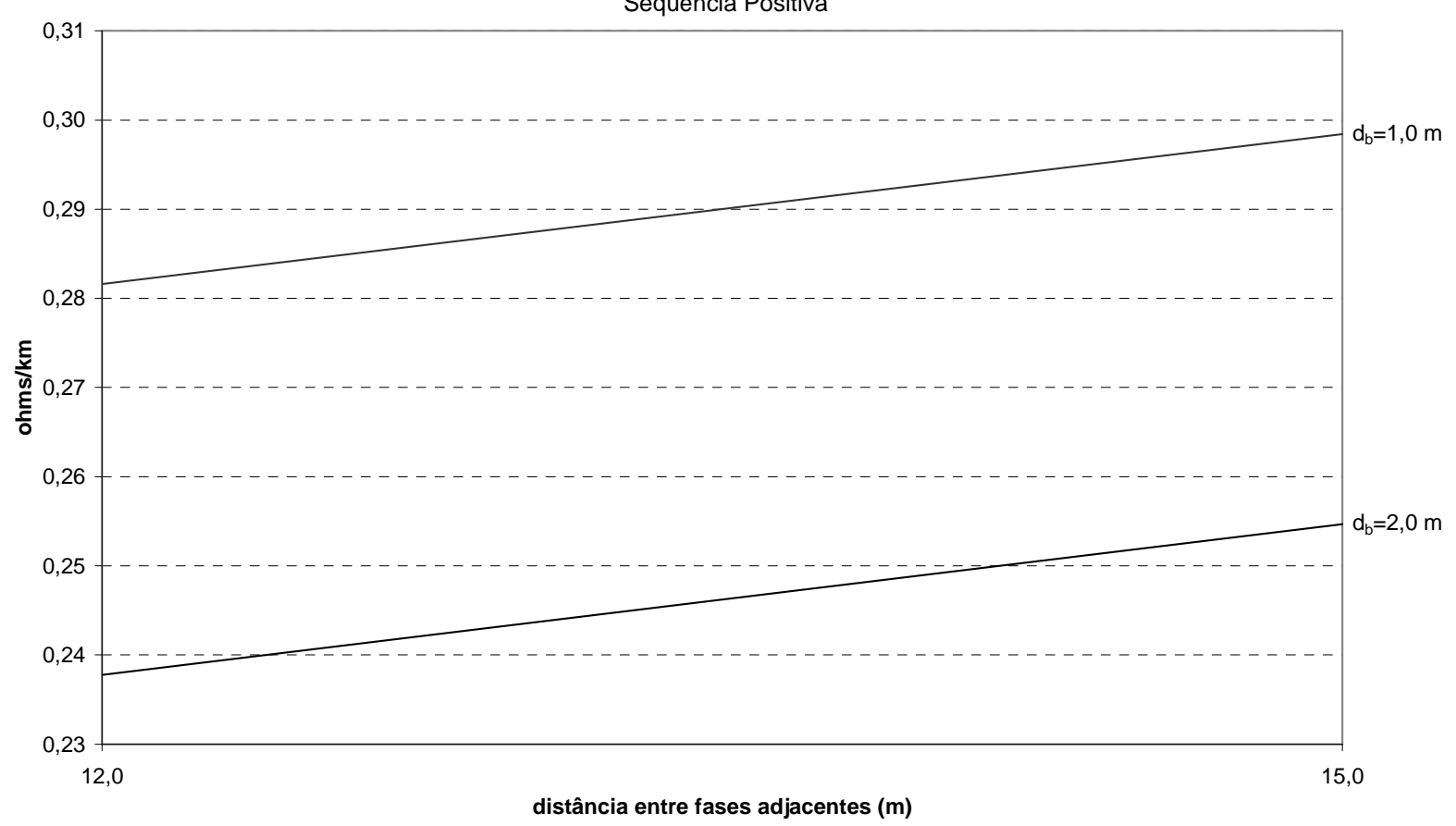

Figura B9 - Valores de reatância indutiva por km, seqüência positiva, geometria B.

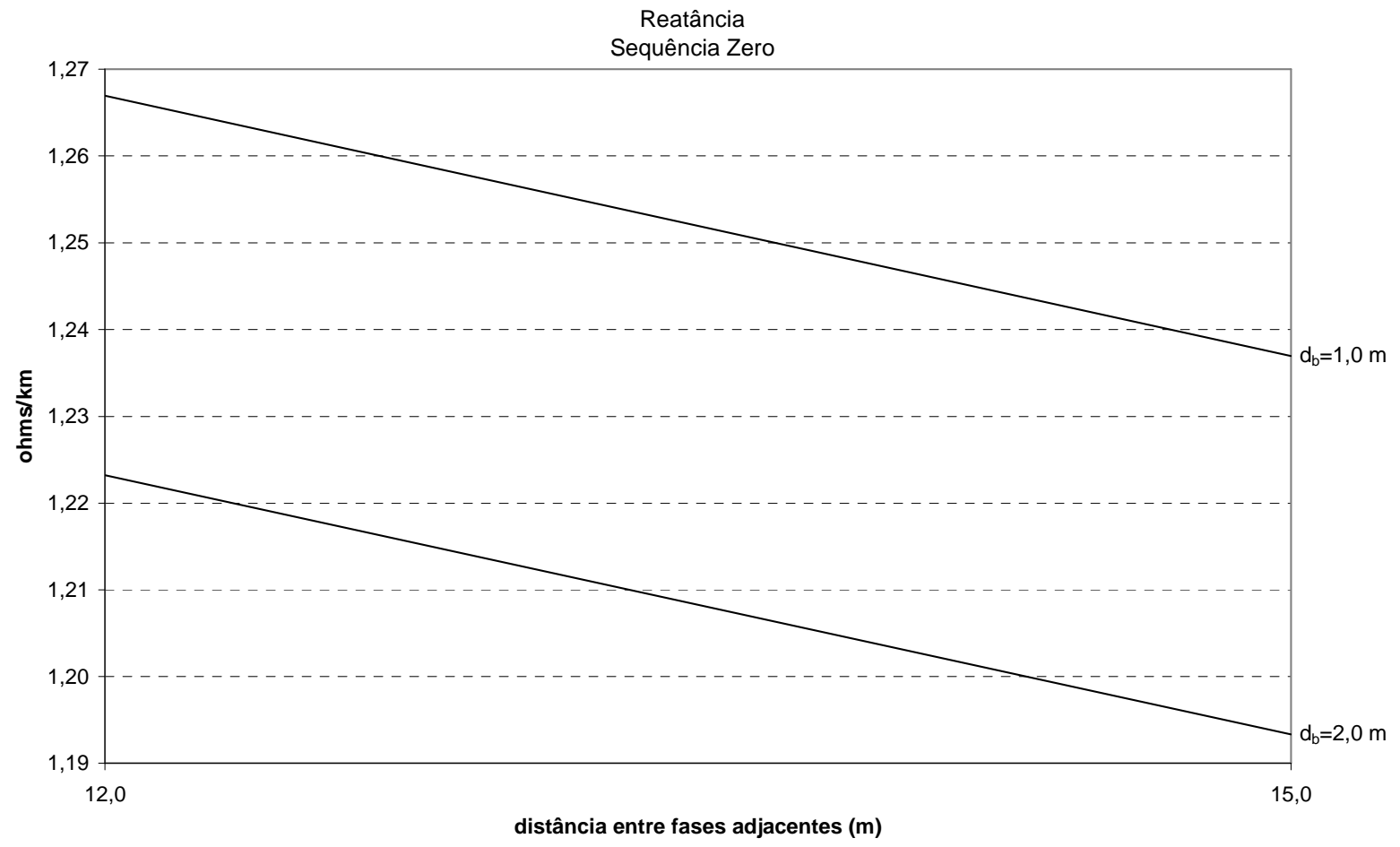

Figura B10 - Valores de reatância indutiva por km, seqüência zero, geometria B. 


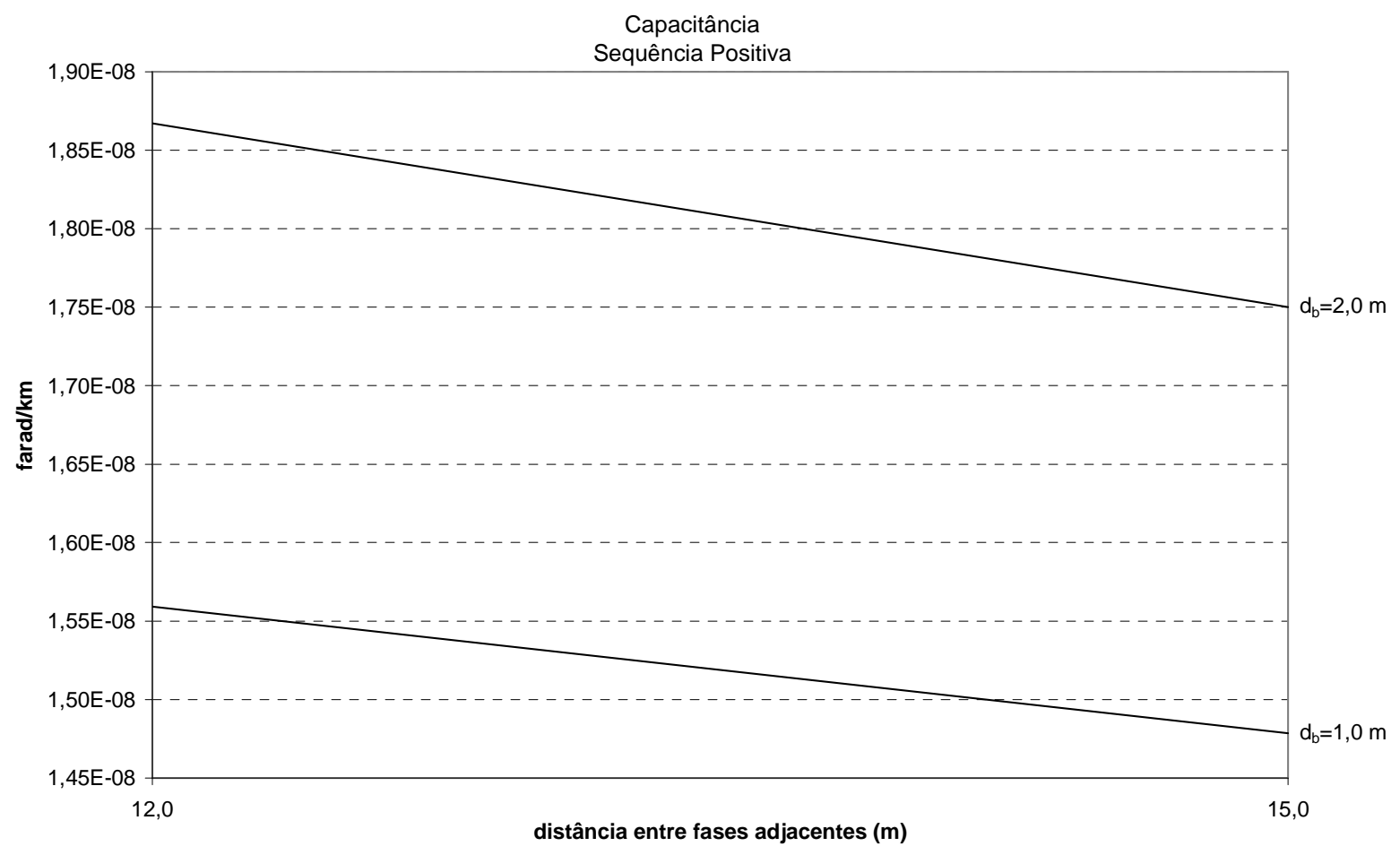

Figura B11 - Valores de capacitância por km, seqüência positiva, geometria B.

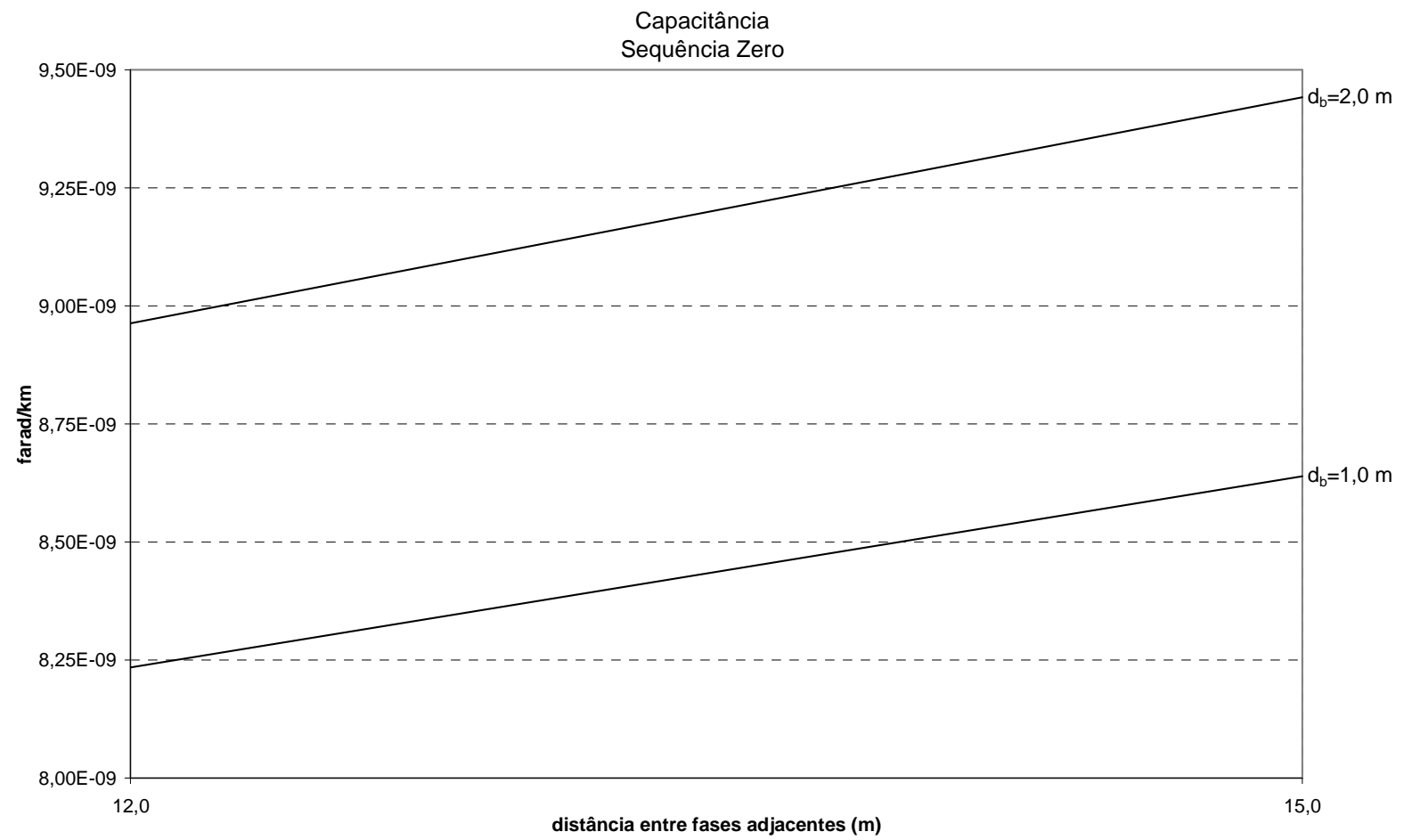

Figura B12 - Valores de capacitância por km, seqüência zero, geometria B. 


\section{REFERÊNCIAS BIBLIOGRÁFICAS}

[1] PRABHAKARA, F. S., PARTHASARATHY,K.,RAMACHANDRA RAO, H. N. Analysis of Natural Half-Wave-Length Power Transmission Lines. IEEE Transactions on Power Apparatus and Systems, Vol. PAS-88, No. 12, December 1969, p.1787-1794.

[2] HUBERT, F. J., GENT, M. R. Half-Wavelength Power Transmission Lines. Transactions on Power Apparatus and Systems, Vol. PAS-84, No. 10, October 1965, p. 965-973.

[3] ILICETO, F., CINIERI, E. Analysis of Half-Wave Length Transmission Lines with simulation of corona losses. IEEE Transactions on Power Delivery, Vol. 3, No. 4, October 1988, p. 2081-2091.

[4] GATTA, F. M., ILICETO, F. Analysis of some operation problems of half-wave length power transmission lines. AFRICON '92 Proceedings., 3rd AFRICON Conference, 1992, p. 59-64.

[5] NAYAK, R. N., SEHGAL, Y. K., SUBIR SEN. EHV Transmission Line Capacity Enhancement through Increase in Surge Impedance Loading Level. Power India Conference, IEEE, 2006.

[6] STEVENSON Jr., William D. Elementos de Análise de Sistemas de Potência. McGraw-Hill do Brasil, 2ª . Reimpressão, 1976.

[7] LNPE- LINHAS DE TRANSMISSÃO DE POTÊNCIA NATURAL ELEVADA [on-line] Web design Carlos Kleber. Baseado na apresentação original de Fernando C. Dart, CEPEL. Disponível em <http://www.cepel.br/ Ipne/> Acesso em 25 nov. 2009. 
[8] PEEK, Frank William Dieletric phenomena in high voltage engineering. McGraw-Hill Book Company, $2^{\text {nd }}$ edition, 1920.

[9] ELETROBRAS. Referências de Custos LTs e SEs de AT e EAT. Eletrobras, Junho de 2004, Rev.: Dezembro de 2004.

[10] AGÊNCIA NACIONAL DE ENERGIA ELÉTRICA. Chamada No 005/2008; Projeto Estratégico:alternativas não convencionais para transmissão de energia elétrica em longas distâncias. 2008. Disponível em < http://www.aneel.gov.br/arquivos/PDF/PeD_2008-ChamadaPE05-2008.pdf> 